\title{
WATER SCARCITY POLICY: EVALUATION WITH A FOCUS ON ALBERTA, BRITISH COLUMBIA AND ONTARIO
}

\author{
by \\ Heather Christine Adams \\ Bachelor of Science in Environmental Science (2002), University of Calgary \\ A thesis, \\ presented to Ryerson University \\ in partial fulfillment of the \\ requirements for the degree of Master of Applied Science \\ in the Program of \\ Environmental Applied Science and Management
}

Toronto, Ontario, Canada, 2015

(C) Heather Christine Adams 2015 


\section{Author's Declaration}

I hereby declare that I am the sole author of this thesis. This is a true copy of the thesis, including any required final revisions, as accepted by my examiners.

I authorize Ryerson University to reproduce this thesis to other institutions or individuals for the purpose of scholarly research.

I further authorize Ryerson University to reproduce this thesis by photocopying or by other means, in total or in part, at the request of other institutions or individuals for the purpose of scholarly research.

I understand that my thesis may be made electronically available to the public. 
Water Scarcity Policy: Evaluation with a Focus on Alberta, British Columbia and Ontario Heather Christine Adams, 2015

Master of Applied Science Environmental Applied Science and Management Ryerson University

\section{Abstract}

Water scarcity is inherently complex, yet it is a largely ignored and chronically understudied problem in Canada. The country has a relative abundance of freshwater, which has led to wasteful and inefficient use of water resources and high economic and environmental costs. Responsibility to govern this precious resource is predominantly in the power of the provinces in accordance with the 1982 Constitution Act. Alberta, British Columbia and Ontario were selected as jurisdictions of study. Alberta's Water for Life Strategy, British Columbia's Living Water Smart Strategy and Water Sustainability Act, as well as Ontario's Permit to Take Water Program are important policy instruments in the prevention of scarcity. To contribute to policy improvements for each of selected jurisdiction, policy recommendations and criteria for policy evaluation were developed and applied, drawing on examples of challenges and responses from selected international jurisdictions. 


\section{Acknowledgements}

I wish to thank Dr. Alex Wellington and Dr. Ronald Pushchak for their tireless guidance, support and leadership in the crafting of this thesis. This work would not have been possible without the substantial efforts of these two exemplary professors.

I also wish to recognize and thank the examination committee for this thesis, Dr. Andrew Laursen, Dr. Vadim Bostan and the Chair, Dr. Cory Searcy. 


\section{Dedication}

This thesis is dedicated to my family and my parents. To Jo, Ledger and Callahan:

thanks for all the love, support, encouragement, sushi and walkies. To my parents: you have supported me in everything I have ever done in this life and graduate school was no different. Thank you all for being there for me.

This would not have been possible without all of you. 


\section{Table of Contents}

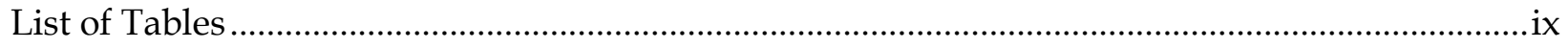

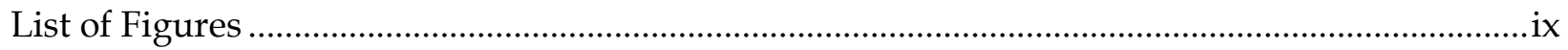

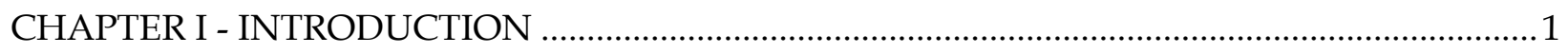

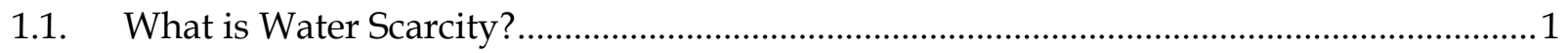

1.2 Water Scarcity and the Environment: The Canadian Context........................................2

1.3 Risk and Costs of Ignoring the Problem .....................................................................

1.4 Research Purpose, Objectives and Scope...................................................................... 6

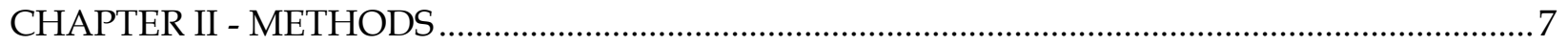

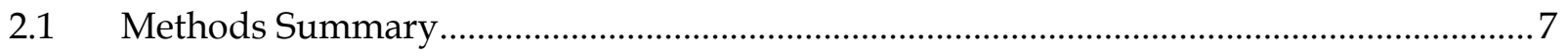

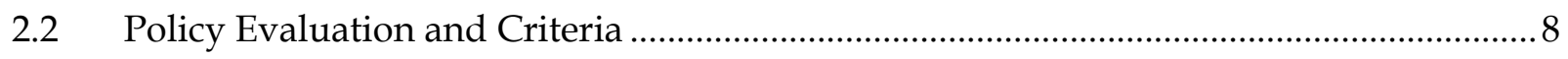

$2.3 \quad$ Experiences from Water Rich and Water Scarce Regions .............................................. 11

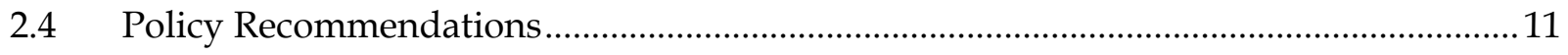

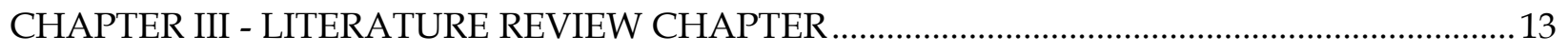

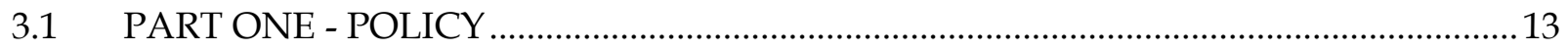

3.1.1 General Approach: Environmental Policy Evaluation …........................................13

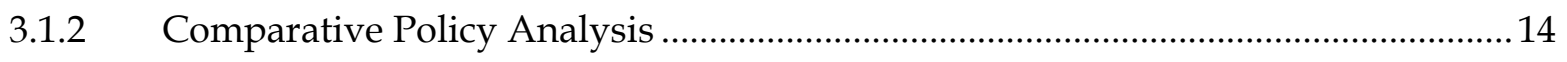

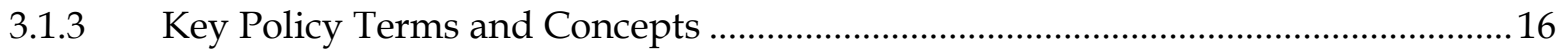

3.1.4 Selected Barriers to Effective Governance .............................................................. 21

3.1.5 Policy Instruments Currently Used in Water Quantity Management.....................23

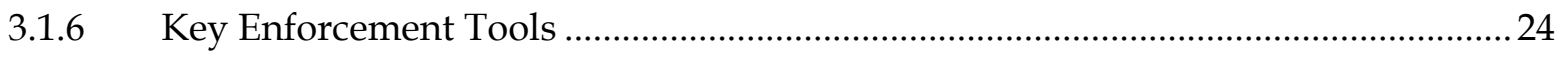

3.1.7 Management Strategies in Water Policy …............................................................... 25

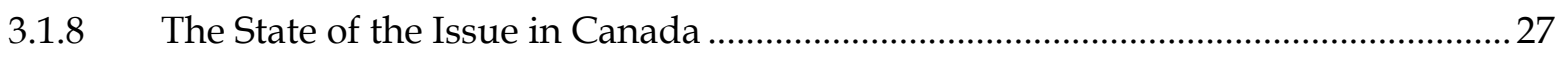

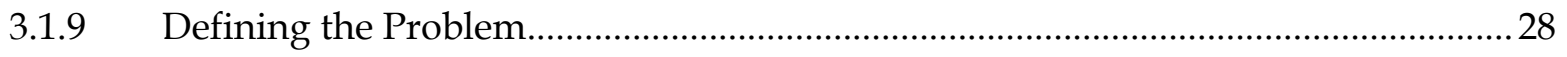

3.2 PART TWO - THE SCIENCE OF WATER SCARCITY …............................................. 32

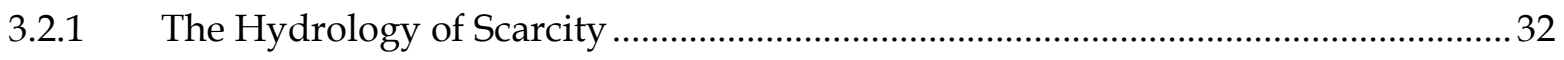

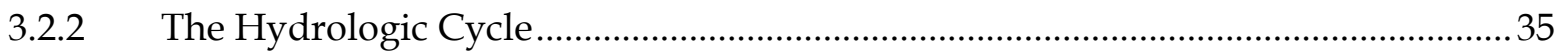

3.2.3 Predicted Impacts of Climate Change on Water Supplies .......................................36

3.2.4 Relevant Hydrology and Waterscape of Selected Provinces ................................... 37

3.2.5 Relevant Hydrology and Waterscape of Selected International Jurisdictions ........ 41 
4.1 Division of Powers in Canada - Water Governance ............................................................ 51

4.1.1. National Governance and The Federal Water Policy …..............................................52

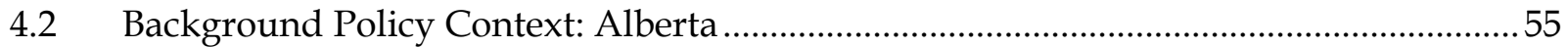

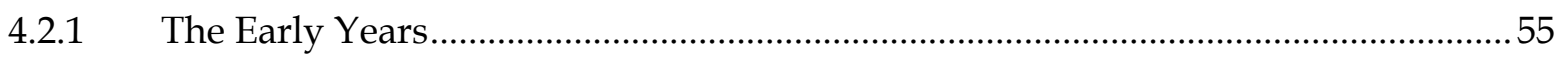

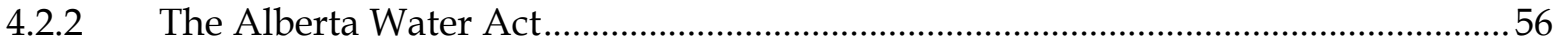

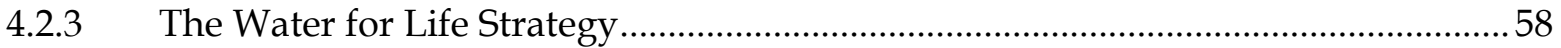

4.2.4 Strengths of Alberta's Water Governance ............................................................... 59

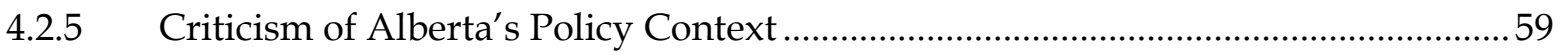

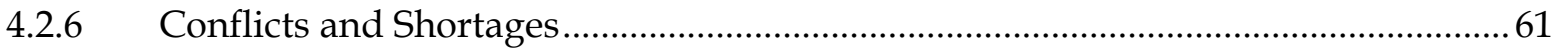

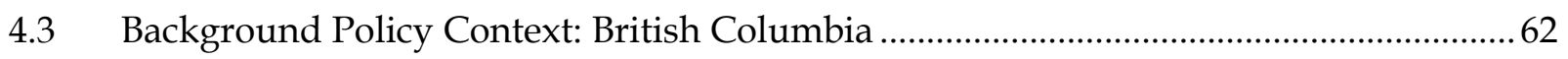

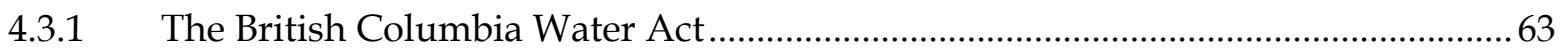

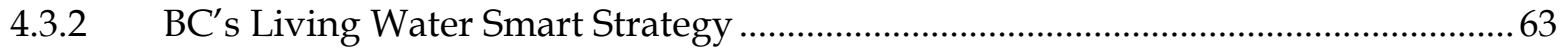

4.3.3 Proposed Changes: Modernizing BC's Water Act ................................................... 64

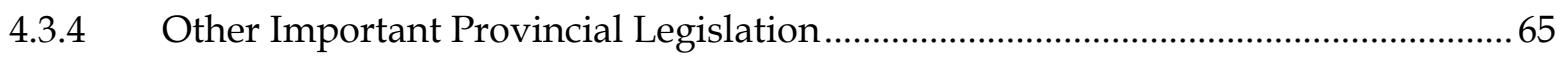

4.3.5 Issues and Criticism of the Current Policy Context ................................................... 66

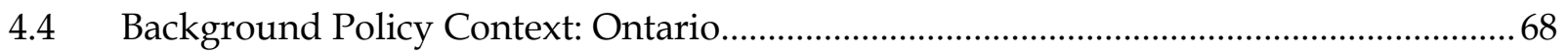

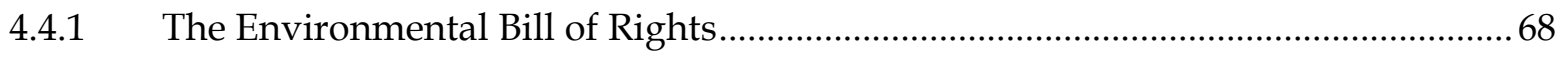

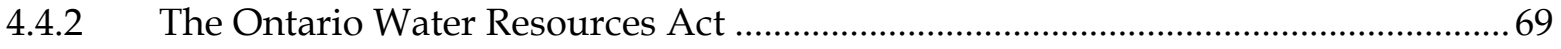

4.4.3 The Water Opportunities and Water Conservation Act........................................... 70

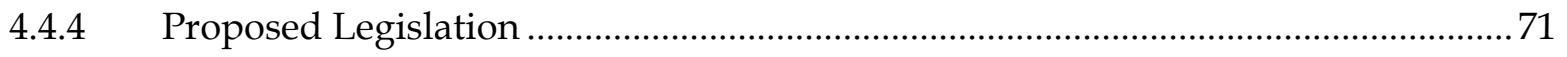

CHAPTER V - POLICY CONTEXT EVALUATION: ALBERTA, BRITISH COLUMBIA and

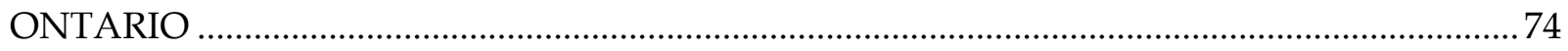

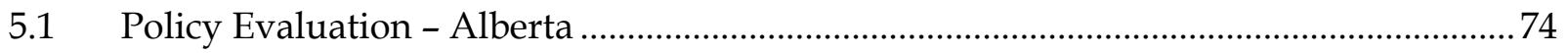

5.1.1 Context: The Alberta Water for Life Strategy …......................................................... 74

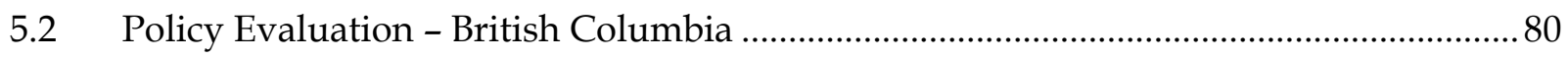

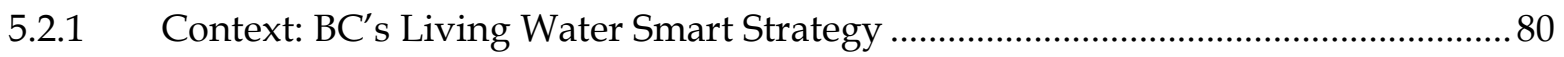

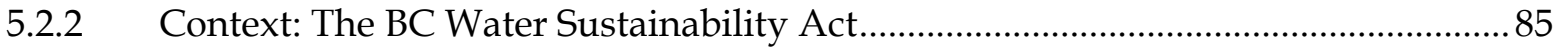

5.3 Context: Ontario's Permit to Take Water Program ......................................................... 91

CHAPTER VI - POLICY RECOMMENDATIONS and EXPERIENCES FROM OTHER JURISDICTIONS 
6.1. Best Practices or Principles for all Jurisdictions ............................................................ 96

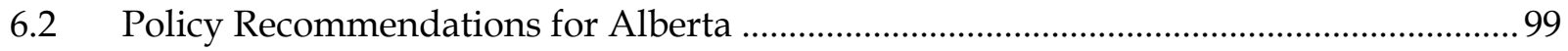

6.2.1 Reinforce and Strengthen the Priorities of the Water for Life Strategy …..............100

6.2.2 Add a Scarcity Prevention Priority to Water for Life............................................. 102

6.2.3 Take Measures to Safe-Guard Against/ Reverse the Over-Allocation of Water

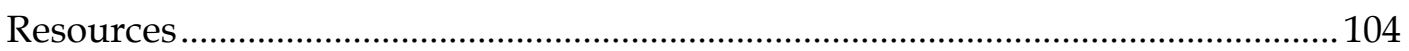

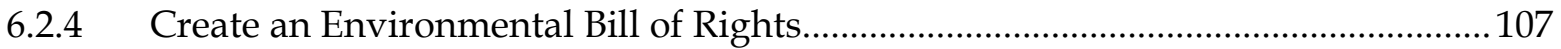

6.2.5 Experiences from Other Jurisdictions to Support AB Policy Recommendations .107

6.3 Policy Recommendations for British Columbia............................................................ 111

6.3.1 Implement and Enforce the Water Sustainability Act ...........................................111

6.3.2 Create an Environmental Bill of Rights.................................................................. 112

6.3.3 Experiences from Other Jurisdictions to Support BC Policy Recommendations.. 113

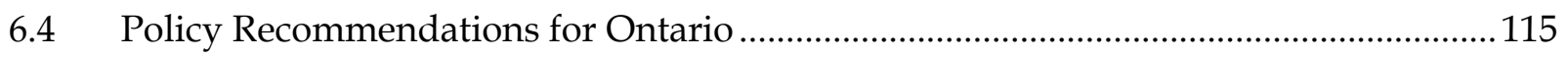

6.4.1 Overhaul the Permit to Take Water Program in Conjunction with the Water Opportunities and Water Conservation Act ............................................................. 116

6.4.2 Set and Commit to Province-Wide Conservation Goals ......................................... 120

6.4.3 Strengthen the Water Opportunities and Water Conservation Act........................ 120

6.4.4 Build on the Ontario Low Water Response Plan .................................................... 122

6.4.5 Continue to Strengthen Great Lakes Protection Measures .....................................123

6.4.6 Experiences from Other Jurisdictions to Support ON Policy Recommendations 124

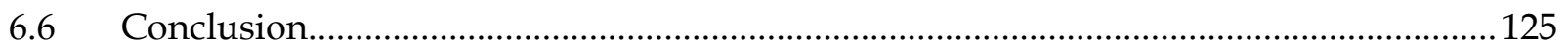

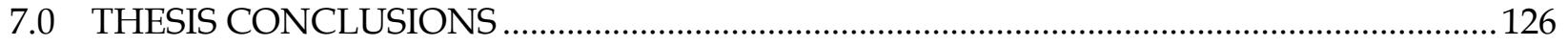

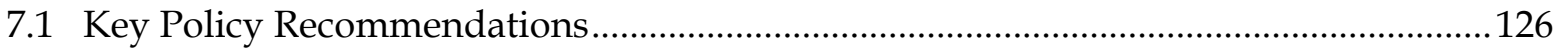

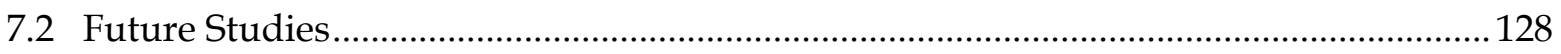

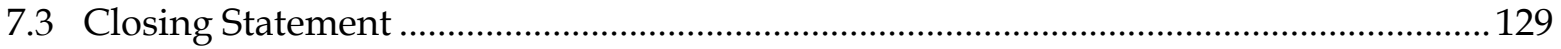

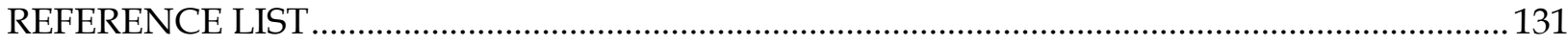




\section{List of Tables}

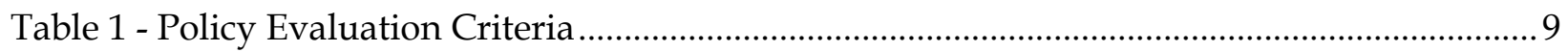

Table 2 - Definitions of the Principles of Good Governance (Doeveren, 2011) ............................. 20

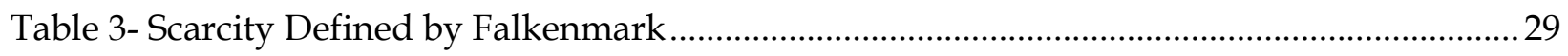

Table 4 - Important Federal Legislation Related to Water .............................................................. 52

Table 5 - Federal Guidelines and Policies Related to Water ..........................................................52

Table 6 - Relevant Alberta Water Governance Mechanisms......................................................... 62

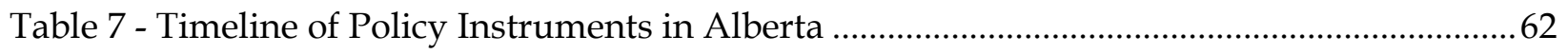

Table 8 - Relevant British Columbia Water Governance Mechanisms.......................................... 67

Table 9 - Timeline of Policy Instruments in British Columbia.........................................................6 68

Table 10 - Relevant Ontario Water Governance Mechanisms ...................................................... 72

Table 11 - Proposed Ontario Governance Mechanisms.............................................................. 72

Table 12 - Timeline of Policy Instruments in Ontario ................................................................... 72

Table 13 - Key BC Provincial Commitments Under Living Water Smart ...................................... 84

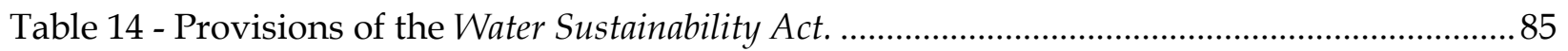

Table 15 - Key Sections of the Water Sustainability Act ............................................................. 86

Table 16 - Policy Recommendations for Alberta .............................................................................. 100

Table 17 - Policy Recommendations for British Columbia........................................................... 111

Table 18 - Policy Recommendations for Ontario ...................................................................... 116

\section{List of Figures}

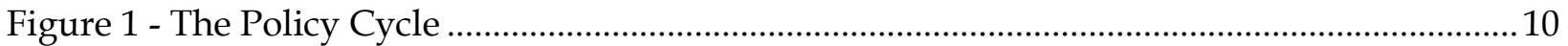

Figure 2 - Threats to Water Availability in Canada in 2009 (from Environment Canada, 2014)..30

Figure 3 - Saturated and Unsaturated Zones (Tauxe, 2015) ........................................................ 33

Figure 4 - Groundwater and Hydrologic Cycle (BC Gov, 2014d) .................................................. 36 


\section{CHAPTER I - INTRODUCTION}

Fresh water is essential for humans for drinking, cleaning, irrigation, recreation, energy creation and much more. Yet for years water resources have been overexploited, with little thought given to the concept that this precious resource in not unlimited. This lack of concern and precautionary forethought has significant economic and environmental costs. For example, overuse leads to stressed watersheds with decreased biodiversity (Thirlwell, Madramootoo and Heathcote, 2007; Vorosmarty et al, 2010).

Water scarcity has complex linkages with diverse and complicated issues such as food security, energy creation and the economy. Experts stress the importance of strengthening our understanding of the nexus between water, energy, land use and the environment (Falkenmark and Rockstrom, 2004: 5; Maas, McClenaghan and Pleasance, 2010; Dale, Efroymson and Kline, 2011; Cook and Bakker, 2012) in order to protect the environment and minimize costs.

An already precarious balance is predicted to be stressed in the near future. Population growth, climate change, pollution, poor water management and fragmented governance are all listed in the literature as significant factors in escalating water scarcity issues (Vorosmarty et al., 2000, Johansen, 2002; Wolfe and Brooks, 2003; Percy, 2004; Bakker, 2007; Boardley and Kinkhead, 2006; Cohen et al., 2006; Oki and Kanae, 2006; Castro, 2007; Grafton and Kompas, 2007; Johns and Raasmussen, 2007; Sandford, 2009; Martin-Downs, 2010; Vorosmarty et al., 2010; Bakker and Cook, 2011).

To begin, it is important to discuss what is meant by water scarcity as this is neither simple nor universal.

\subsection{What is Water Scarcity?}

The term 'water scarcity' is central to this work; however, there is not currently a widely accepted definition in the literature (Falkenmark, 1994; Falkenmark and Lundqvist, 1996; Wolfe and Brooks, 2003: Rijsberman, 2006; White, 2012). Scarcity occurs when 
water supply is not enough or demand places too much pressure on a supply (Nelitz, Douglas and Rutherford, 2009). For the purpose of this study, water scarcity is defined as a condition where the amount of water available does not meet the demand for human use and environmental needs. For an in depth discussion on the different definitions of water scarcity, refer to Chapter III. Water conservation is another term prevalent in this thesis, and therefore it is important to define it. Water conservation is an umbrella term that is used to describe measures taken to prevent scarcity and scarcity issues.

Scarcity, like all water issues, is inherently complex and multifaceted (Falkenmark, 1994; Gleick, 2002; Wolfe and Brooks, 2003; Bakker, 2007; Sandford, 2009). Water quantity issues tend to have multiple stakeholders, often with conflicted interests, values and objectives (Hipel et al, 2008).

Water management issues are so complex that they are referred to as a wicked problem. A wicked problem lacks consensus on the definition of the problem, let alone the best solution (Rittel and Webber, 1973). See Section 3.1.6 for more on water scarcity issues as a wicked problem.

\subsection{Water Scarcity and the Environment: The Canadian Context}

This study focused on water scarcity issues from an environmental perspective and in the Canadian context. As this problem is so vast and broad, it is important to select a scope of study that will allow a deep level of robustness and therefore create value. This problem is understudied and undervalued in the Canadian context.

\section{The Myth of Abundance}

Many Canadians believe that the country has more than enough freshwater and take for granted this "fact" will always be true. This is an attitude believed to lead to wasteful water habits, overconsumption of the resource and risk to the environment (Brooymans, 2011: 8; Boyd, 2011: 47). Canada has a relative abundance of freshwater, 
yet on a per capita basis, Canadians are second only to the United States in demand for water resources (McDonald and Brown, 2003). If climate change alters the available water supply, this heavy demand puts Canada at great risk for scarcity issues.

A commonly repeated overestimation states that Canada has twenty percent of the world's freshwater supply (Bakker, 2007: 20; Zubrycki et al., 2011). A more accurate estimation is that Canada has 6.5 percent of the world's renewable water supply (Christensen and Droitsch, 2008.) A key limitation in Canada is the amount of water available, which includes the geographic location of renewable fresh water ${ }^{1}$. It is estimated that $60 \%$ of Canada's freshwater is flowing north, away from the farmland and the most densely populated areas, in the south (Sprague, 2007: 24). Over 90 percent of Canada's population lives in a condensed area in close proximity to the US border (Woo, 2008: 86). This puts high demands on local water supplies, including shared demands with the Americans (Saunders and Wenig, 2007: 131).

Canada's approach to water management may contribute to this growing problem; perceived abundance encourages wasteful water use. Canada has been criticized for fragmented conservation best practices (Boardley and Kinkhead, 2006), federalprovincial jurisdictional struggles (Bakker, 2007: 1), lack of federal direction (de Loë, 2008) and delivering water at a fraction of the true cost to do so (Renzetti, 1999).

\section{Selection of Canadian Jurisdictions}

Responsibility to govern water issues in Canada is almost exclusively with the provinces, as per the powers bestowed on them by the 1982 Constitution Act (Kay, Hendricks and Rahman, 2007: 4; Greenbaum and Wellington, 2010: 71). Three provinces have been selected as jurisdictions for this study: Alberta, British Columbia (BC) and Ontario (ON).

\footnotetext{
${ }^{1}$ For a discussion on the hydrologic cycle, the definitions of important water-related terms and the meaning of scarcity, refer to Chapter III.
} 
Provinces usually govern these issues in the form of a provincial Ministry of the Environment (Brooymans, 2011: 125). Alberta Environment and Sustainable Resource Development, the British Columbia Ministry of the Environment and the Ontario Ministry of the Environment and Climate Change and Ministry of Natural Resources have the primary responsibility for freshwater management in the three selected jurisdictions.

\section{Alberta}

Alberta is a province with a drought-prone, semi-arid climate with an average annual precipitation of just 300 to 500 millimeters. The irrigation of crops has been important to the economy of the province for decades, especially in the southern part of the province. The region remains Canada's largest irrigation economy to date (Hienmiller, 2013). In Alberta, increasing population density and continuing economic development are expected to cause escalating water conflicts in the near future (Christensen and Droitsch, 2008).

\section{British Columbia}

Most importantly, BC was included as a province on the cusp of policy reform, discussed in Chapter IV. Other reasons for the provinces' inclusion of British Columbia as a jurisdiction are discussed next.

\section{Ontario}

The province of Ontario is a worthy jurisdiction for inclusion in this study of water conservation policy in Canada. Ontario is an important jurisdiction as it has Canada's largest population and most sizable economy (Kay, Hendricks and Rahman, 2007: 5). Ontario is a microcosm for Canada's economic water use sectors, including manufacturing, agriculture and resource extraction (Kay, Hendricks and Rahman, 2007: 5; Statistics Canada, 2015). Finally, Ontario's provincial water policy context was a strong choice as a comparator to that of British Columbia. Both provinces are geographically diverse with large populations and major cities. Each province has been 
a leader in Canada with respect to environmental legislation². Ontario is considered water-rich; however, the province is rapidly developing and there is concern about water supplies remaining adequate for the future in regions with high water demands (Environmental Commissioner of Ontario, 2010b).

The relevant policy contexts of Alberta, British Columbia and Ontario are discussed in detail in Chapter IV, as well as the federal context.

\subsection{Risk and Costs of Ignoring the Problem}

Ignoring this issue has both risks and costs that extend beyond the possibility of acute physical scarcity.

Wasteful water use has an associated high energy cost (Zhe, Boyle and Reynolds, 2010). Treating and delivering water for human use has very high economic and energy cost associated with it, and smart water management can help to minimize this. Water is also very important for the generation of electricity in many parts of Canada, for example the province of Ontario (Ponrajah, Witherspoon and Galiana, 1998). This process often involves large amounts of water for diversion and storage.

When there is not enough water capacity to meet demands, stakeholder conflicts often arise (Gleick, 1998). Economic costs for these stakeholders can be high, including individual businesses or even local economies. For example, a manufacturing business loses profits when outputs are limited by water use restrictions. Different sectors often compete for the same limited water resources. For example, the same limited water

2 For example, Ontario's framework of environmental legislation and regulations is some of the most robust in Canada (Phyper and Ibbotson, 2003). The province of British Columbia enacted progressive legislation in 1997 (the Fish Protection Act) that required consideration of water quantity when making decisions that affects sensitive fish habitat (Boyd, 2011: 47). 
sources can be used by farmers to irrigate their crops, cities for municipal use and by industry to create products. Smart water use can minimize both costs and conflicts.

If an area does become stressed to the point where human use threatens the watershed, there can be severe ecological repercussions such as decreased biodiversity (Vorosmarty and Sahagian, 2000; Xu et al., 2009) and extinction of aquatic species (Gleick, 1998).

River ecosystems are taxed and aquifers depleted.

There is a strong argument that our wasteful water use is not sustainable. Ignoring this problem may be risking the water security of future generations (Gleick, 1998; Bakker, 2007: 340).

\subsection{Research Purpose, Objectives and Scope}

This study focused on five objectives:

- Developing criteria to evaluate the effectiveness, strengths and weaknesses of the selected policy contexts.

- Analyzing the current policy contexts of the selected jurisdictions.

- Researching the policy contexts of international jurisdictions that have scarcity policies that could aid in the creation of policy recommendations for the selected jurisdictions.

- Evaluating the policy contexts of the Canadian jurisdictions using the developed criteria.

- Developing water conservation policy recommendations for Alberta, British Columbia and Ontario using conclusions from the evaluation.

The scope of this study includes the review of relevant academic literature, government publications, books, as well as laws and regulations for selected jurisdictions. 


\section{CHAPTER II - METHODS}

This chapter discusses the methods used in this study. This work utilized environmental policy evaluation as a general umbrella method. Environmental policy evaluation is an established and respected method that aims to ultimately improve policy. A summary of the methods used starts this chapter, followed by additional detail about each method component.

\subsection{Methods Summary}

The primary method for this study was an established and robust method called policy evaluation, which can be defined as the "systematic comparison and evaluation of alternatives in order to solve social problems" (Weimer and Vining, 2011). Policy evaluation can provide the basis to undertake comparative analysis. There are many specific subsets of comparative policy analysis that are widely accepted, including policy transfer, policy diffusion, policy convergence, policy learning (also known as lesson drawing), and indirect coercive policy transfer. This study focused on examining the experiences of water rich and water scare regions, to find examples that could be drawn upon in the Canadian context. This study focused on evidence of policy convergence in order to find water rich and water scarce regions with valuable experiences for Canada. Ultimately, the intent of this method is to improve policy, which will be done in the form of policy recommendations.

The following is a stepwise breakdown on the methods of this study:

1. Conduct a thorough two-part literature review with a focus on literature related to both the policy contexts and the science of these issues.

2. Research the policy contexts of water rich and water scarce international jurisdictions. Use examples of experiences from selected international jurisdictions to support the policy evaluation and the creation of policy recommendations for the selected Canadian jurisdictions. 
3. Select effective criteria for the purpose of aiding the evaluation of the three Canadian policy contexts. Evaluate and analyze the selected Canadian provincial policy contexts using the criteria.

4. Utilize the experiences and best practices from international jurisdictions and comparison of the provinces to create policy recommendations for the three selected jurisdictions relevant to the prevention of water scarcity. Best practices can be defined as an optimal way of performing work in order to achieve high performance (Dani et al., 2006).

\subsection{Policy Evaluation and Criteria}

Policy evaluation can be defined as 'a scientific analysis of a certain policy area, the policies of which are assessed for specific criteria on the basis of which recommendations are formulated' (Crabbe and Leroy, 2008; 21). The use of policy evaluation to help solve environmental problems is on the rise (OECD, 2015). This section discusses the selected evaluation criteria for policy contexts. Policy performance is beyond the scope of this study.

To make informed, sound decisions with respect to environmental policy choices, it is useful to use a structured decision making framework (Gregory and Keeney, 2002). Evaluating environmental policies is inherently difficult as these are complex problems, with vast uncertainties, and that include stakeholders with differing or even conflicting goals (Mickwitz, 2003). For this study, the evaluation framework selected is a carefully defined set of evaluation criteria, with which to analyze the water conservation policies of the selected regions.

The principles of good governance were carefully considered in the development of evaluation criteria for this study. The principles of good governance used in this study are accountability, efficiency and effectiveness, openness and transparency, and participation (Doeveren, 2011). The principles of good governance are discussed in detail in Section 3.1.3. 
The criteria in Table 1 below were used as benchmarks to measure the effectiveness of the policies utilized in the selected jurisdictions.

Table 1 - Policy Evaluation Criteria

\begin{tabular}{|c|c|c|}
\hline Category & Criterion & Description \\
\hline SCOPE & $\begin{array}{l}\text { Clearly defined } \\
\text { scope }\end{array}$ & $\begin{array}{l}\text { - The policy's goals and objectives are clearly stated. } \\
\text { - The roles and responsibilities of the policy are clearly stated. }\end{array}$ \\
\hline \multirow[t]{2}{*}{$\begin{array}{l}\text { EFFECTIVE AND } \\
\text { EFFICIENT }\end{array}$} & Impact & $\begin{array}{l}\text { - The policy has the potential to evoke highly significant }{ }^{3} \text { positive } \\
\text { change (Brandes and Curran, 2009; Guglyuvatyy, 2010; } \\
\text { Mickwitz, 2003) }\end{array}$ \\
\hline & $\begin{array}{l}\text { Feasibility/ } \\
\text { operational } \\
\text { practicality }\end{array}$ & $\begin{array}{l}\text { - Implementing the policy is expected to be practical from an } \\
\text { operational or administrative perspective. }\end{array}$ \\
\hline RESPONSIVENESS & Flexible toolkit & $\begin{array}{l}\text { - A policy instrument toolkit is available in order to adapt to } \\
\text { changing conditions (Mickwitz, 2003; Guglyuvatyy, 2010). }\end{array}$ \\
\hline $\begin{array}{l}\text { EQUITABILITY } \\
\text { and } \\
\text { INCLUSIVENESS } \\
\end{array}$ & $\begin{array}{l}\text { Public/stake- } \\
\text { holder } \\
\text { participation }\end{array}$ & $\begin{array}{l}\text { - The policy has a process for conflict resolution. } \\
\text { Hearings or other mechanisms of public participation and/or } \\
\text { stakeholder involvement are built in to the policy. }\end{array}$ \\
\hline $\begin{array}{l}\text { DATA } \\
\text { COLLECTION and } \\
\text { REPORTING }\end{array}$ & $\begin{array}{l}\text { Data collection } \\
\text { and reporting }\end{array}$ & $\begin{array}{l}\text { The policy includes mechanisms and instruments for data } \\
\text { collection and reporting. }\end{array}$ \\
\hline \multirow[t]{2}{*}{$\begin{array}{l}\text { PERFORMANCE } \\
\text { TARGETS and } \\
\text { MEASURES }\end{array}$} & $\begin{array}{l}\text { Presence of } \\
\text { performance } \\
\text { targets }\end{array}$ & $\begin{array}{l}\text { - The policy is meeting, or expected to meet performance } \\
\text { measures and targets. }\end{array}$ \\
\hline & $\begin{array}{l}\text { Performance } \\
\text { measures }\end{array}$ & $\begin{array}{l}\text { - Performance measures and targets have been developed and } \\
\text { clearly articulated. }\end{array}$ \\
\hline MONITORING & Monitoring & $\begin{array}{l}\text { - The policy includes mechanisms, instruments and resources that } \\
\text { are allocated for monitoring. }\end{array}$ \\
\hline ENFORCEMENT & Enforcement & $\begin{array}{l}\text { - The policy has mechanisms instruments, and resources that are } \\
\text { allocated for enforcement. }\end{array}$ \\
\hline EVALUATION & Evaluation & $\begin{array}{l}\text { - The policy has in built expectations, timelines, and reporting } \\
\text { mechanisms for evaluation. }\end{array}$ \\
\hline
\end{tabular}

In the selection of these criteria, each stage of the policy cycle (Figure 1) was considered. The policy cycle is a useful tool in policy work that can help to ensure the entire life cycle of the policy is being considered (Howlett, Ramesh and Perl, 2009: 2). It is essentially a breakdown of the "life cycle" of policies in order to understand the process. Linkages between the stages of the policy cycle and the selection criteria for this study are detailed here.

\footnotetext{
${ }^{3}$ See below for a discussion of the meaning of "significant'.
} 


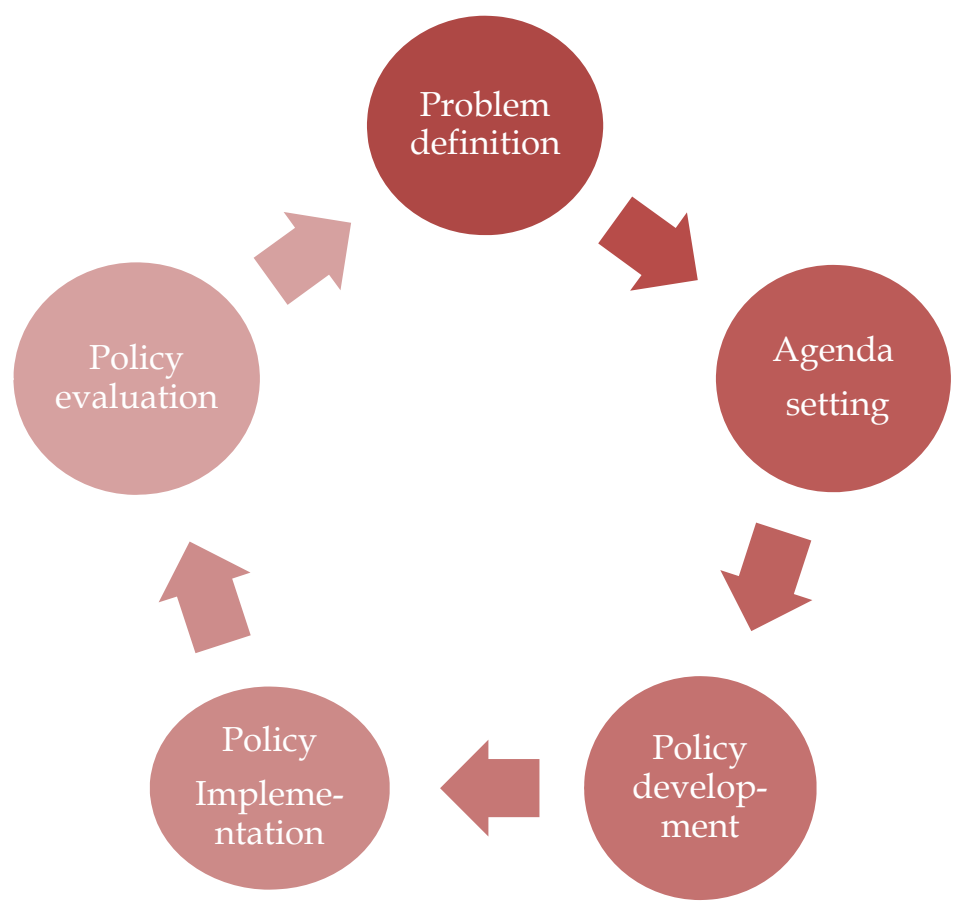

Figure 1 - The Policy Cycle (Crabbe and Leroy, 2008: 2)

The criterion of "clearly defined scope" is closely related to the problem definition and agenda-setting stages of the policy cycle. One must ask the question, what exactly is this policy in place to do? What problem is it attempting to solve? The development stage of the policy cycle is best captured with the criteria from the "equitability and inclusiveness" and "effectiveness and efficiency" categories and the "flexible toolkit" criterion. These criteria can be used to answer the questions: can this policy be expected to be successful or are changes needed? If changes are needed, are there mechanisms built in to the policy to allow for changing conditions? If the members of the public disagree with the policy or have input, is there a mechanism for participation and conflict resolution? The categories of "enforcement" and "applicability and feasibility" are most closely linked to the implementation stage of the cycle. Enforcement is one powerful tool to ensure that the policy is implemented successfully as public compliance can be a challenge. The evaluation stage of the policy cycle is represented by the greatest breadth of criteria, including "data collecting and reporting", "performance targets", "performance measures", "monitoring" and "evaluation". 
These criteria aim to assess whether the policy is successful in achieving the prescribed policy goals. In other words, is the policy actually doing what was intended?

\section{Significance}

It is important to discuss and define what is meant by the term "significant". This study will draw on the field of environmental assessment, because this field has discussed the meaning of the term for years (CEAA, 1994; Gibson, 2001). In order to be determined significant in a negative connotation, an environmental effect would need to be both "likely" and "adverse". An environmental effect likely to bring about substantial, lasting positive change would be significant in a positive sense.

\subsection{Experiences from Water Rich and Water Scarce Regions}

In order to make the best possible policy recommendations for the three selected Canadian provincial jurisdictions, experiences from international water scarce and water rich regions were researched. A region was considered if example of experiences of water scarcity were identified with similarities identified with the policy contexts of Alberta, British Columbia and Ontario. Background on characteristics of the selected jurisdictions and the selection process is discussed in Chapter IV. Experiences from international jurisdictions that support the policy recommendations for the Canadian jurisdictions are discussed in Sections 6.2.5, 6.3.3 and 6.4.6.

\section{$2.4 \quad$ Policy Recommendations}

Ultimately, the product of the analysis to be undertaken in this study was the creation of water conservation policy recommendations. The fundamental aim of the creation of policy recommendations is the improvement of public policy (Crabbe and Leroy, 2008).

The policy recommendations were created with the aid of the evaluation and examination of experiences from water rich and water scarce regions around the world. 
Consideration was given to which strategies, policy instruments or best practices would be a good fit to improve the policy context of the selected provinces.

A separate set of policy recommendations was written for each of the three selected jurisdictions. 


\section{CHAPTER III - LITERATURE REVIEW CHAPTER}

This two-part literature review chapter aims to summarize the important works and themes in the literature, published on the topic of this study as well as to demonstrate why this topic warrants academic study. Ultimately, this review of existing literature aims to show that this study is timely and warranted because it will fill a gap in existing work. The chapter is divided into two perspectives on this project. One part of the chapter explores the scientific understanding of water scarcity, for example the hydrologic cycle. To complement the science of this problem, the management and policy side of this issue is also discussed, for example the types of policy instruments that might be used to address the problem. Both of these foci are each germane with respect to this study.

The critical examination of water scarcity issues is an important and understudied field, especially in the Canadian context. There is a "gap" that needs filling, with comparative studies of water conservation issues and policy in Canada. In spite of the lack of attention to these issues, calls for change in the current water management system in Canada are increasing.

\subsection{PART ONE - POLICY}

\subsubsection{General Approach: Environmental Policy Evaluation}

The analysis and evaluation of environmental policy is important in order to improve policies (Loomis and Helfand, 2001; Hatch, 2005; Davis, 2014). The use of environmental policy analysis as a method dates back to the 1950s (Ashford, 1993), became increasingly popular in the 1960s, primarily focused on cross-state policy comparisons in the United States (Lightfoot, 2003). Jack Walker's 1969 paper focused on policy transfer between US states is considered a seminal work. The method gained both prevalence and popularity in the 1970s and 1980s (deLeon and Resnick-Terry, 1998). 
The technique is a growing phenomenon (Dolowitz and Marsh, 2000), with diverse uses in the field of environmental policy. For example, the method has been used to synthesize recommendations for species at risk policies in Canada (Illical and Harrison, 2007), compare environmental policies internationally (Davis, 2014), and even policy transfer learning for water policy (Swainson and de Loë, 2011).

\subsubsection{Comparative Policy Analysis}

Comparative policy analysis is a type of policy analysis that allows policy makers to improve policy by looking to other jurisdictions for innovation, ideas, successes, lessons learned, as well as policy instruments best avoided. Comparative policy analysis can be defined as the "systematic comparison and evaluation of alternatives in order to solve social problems" (Weimer and Vining, 2011).

In the 2000s, there was some debate in published academic literature about the exact definitions of each of these terms and how they differ. To a large degree, this discussion was simply over semantics. For the sake of clarity, each of the subsets of comparative policy analysis active in the literature is detailed here:

- Policy transfer: Policy transfer is used as an umbrella term for the rest of the subsets of comparative policy analysis. Policy transfer is defined as "the process by which knowledge about policies, administrative arrangements, institutions and ideas from one political system (past or present) is used in the development of policies, administrative arrangements, institutions and ideas in other political systems" (Swainson and de Loë, 2011). A variety of policy-related factors may be transferred, from ideologies to wholesale programmes.

- Policy diffusion: This term is very similar to policy transfer, referring to adoptions of policy without evidence of emulation (Walker, 1969). 
- Policy convergence: Policy convergence is a broad term that identifies similarities across a number of countries in terms of policy goals, content, instruments, outcomes and/ or styles (Bennett, 1991; Stone, 1999).

- Policy learning/lesson-drawing: A lesson is a "detailed cause-and-effect description of a set of actions that government can consider in the light of experience elsewhere, including a prospective evaluation of whether what is done elsewhere could someday become effective here" (Rose, 1993). Richard Rose is considered the primary expert on this method, having published works on it in 1991, 1993 and 2005.

- Indirect Coercive Transfer: Indirect Coercive policy transfer is considered voluntary, but driven by a perceived need of governance officials to change policy. For example, region A may feel obliged to adopt the policy of region B, either because region B is an important market for A's exports or due to public pressures (Dolowitz and Marsh, 2000: 13).

A strength of comparative policy analysis is that it often produces efficient and effective policy outcomes (Marsh and Sharman, 2009). Conclusions are drawn following careful evidence-based analysis of a similar policy in a different time or place. Another advantage is that the method allows the sharing of good ideas and the avoidance of poor ones (Dolowitz and Marsh, 1996). Ultimately, comparative policy analysis is about improving and shaping policy by learning what has been successful (or unsuccessful) in other jurisdictions.

Policy analysis and resulting policy recommendations have been used as the methods for a number of studies with an environmental focus. Policy recommendations have been created to improve policies focused on wide variety of environmental issues including climate change, energy and sustainable development (Guglyuvatyy, 2010; Gaviria, 2011; Gupta, 2012). Scholars in the past have utilized this powerful technique to help solve environmental problems by improving public policy. For example, 
comparative policy analysis has been used to develop recommendations for species at risk policies in Canada (Illical and Harrison, 2007).

The practice has been found to overcome some of the challenges of water governance and to help expedite changes to improve water policy in a jurisdiction (de Loë and Swainson, 2010).

Critics have claimed that the method could be strengthened if a set of established criteria was available in order to determine if an established policy is having the intended effect (Marsh and Sharman, 2009). Without criteria, the challenges of ambiguity and subjectivity can affect the determination of whether a policy is successful ${ }^{4}$ or unsuccessful.

\subsubsection{Key Policy Terms and Concepts}

The following are some key terms related to policy analysis, are important to define due to their relevance in this study. Science-related definitions can be found in the second part of this chapter.

\section{Governance}

Governance is a key term that was used in this study. Governance can be defined as "the ability of governmental actors and institutions to achieve policy goals" (Greenbaum and Wellington, 2010: 4). It is salient to note the inclusion of additional actors and stakeholders in the role of governance (Steurer, 2013), as often parties beyond governments have a role in contributing to the management of water in Canada. Insufficient water governance has been cited as a contributing factor leading to water scarcity crises in Canada (Dolan, Kreutzwiser \& de Loë, 2000; Saxe, 2000; de Loë, Kreutzwider and Neufeld, 2005).

\footnotetext{
${ }^{4}$ The term "success" in policy is difficult to define (Crabbe and Leroy, 2008). For what constitutes a successful policy, refer to policy evaluation criteria discussion.
} 
Policy

An understanding of the term "policy" or "public policy" is important for this study. The term "public policy" has many published definitions, with no single widely accepted definition within the literature (Pal, 1992: 2). Public policy can be defined as "a plan of action for tackling issues" (Howlett, Ramesh and Perl, 2009: 2) or as a "definite course or method of action selected from among alternatives and in light of given conditions" (Greenbaum and Wellington, 2010: 226) or "how, why and to what effect governments pursue particular courses of action or inaction" (Heidenheimer, et. al, 1990: 3).

An important characteristic in the creation of policy includes deciding upon objectives, setting goals and targets (Greenbaum and Wellington, 2010: 226). Often policy making is complicated, involving the possible inclusion of legislation and/or regulations and making trade-offs with other competing demands.

It is widely accepted that environmental policies are very important in the protection of the natural environment (Hatch, 2005: 1). It is important to improve policy in order to maximize the protection of the environment that policies provide.

In order for policies to be created, the timing must be right. Another important public policy-related term is a "policy window", defined as "a greater likelihood of developing new policies due to a temporary prominence on governmental decision-making agendas" (Solecki and Michaels, 1994). It is generally a surge in public interest that leads to the peaked interest by governments. If a policy window aligns with political will, there is an impetus for policy change. Policy windows open for a variety of reasons, such as a crisis, news story or another event drawing attention to the issue. In other words, "society deems the current state of affairs in some area of public policy is a problem" (Cohn, 2007: 579). Policy windows can open (or close) for mundane or simple reasons as well, such as available money in a budget. Additionally, policy windows 
could stem from the level of public concern that often follows an extreme weather event or similar crisis.

Policy instruments are "specific means whereby a policy, as a response to a problem, is implemented" (Pal, 1992: 11). It is common for more than one policy instrument to be used within a single policy.

The term "policy effect" refers to outcomes that result from a policy, which could be positive, negative or negligible. Policy outputs refer to the amount and type of products delivered by policy makers as the result of a policy, for example, the number of permits granted.

Some policy outcomes are not intended. These unexpected policy consequences are also referred to as policy side effects (Pal, 1992: 21). Analysis can show that policy side effects can create new and unintended problems, even though the intent of the policy was to solve a problem.

\section{The Precautionary Principle}

It has been argued that the precautionary principle should be built in to more environmental policies (Farthing, 1997: 3). The precautionary principle is a fundamental idea that asserts policies and decisions should take into account environmental uncertainty and "in cases where full scientific certainly cannot be demonstrated, this should not be used as a reason for inaction or delay in measures to prevent environmental degradation (Farthing, 1997: 4). The development of the precautionary principle was an important outcome of the 1992 United Nations Conference on Environment and Development held in Rio de Janeiro. Twenty-seven principles were proclaimed in total. The precautionary principle (principle fifteen) states: "in order to protect the environment, the precautionary approach shall be widely applied by States according to their capabilities. Where there are threats of serious or irreversible damage, lack of full scientific certainty shall not be used as a reason for postponing cost-effective measures to prevent environmental degradation" (UNEP, 2014). 
The precautionary principle has been incorporated into several pieces of Canada's environmentally-focused legislation. The Canadian Environmental Protection Act, 1999, S.C. 1999, c.33 (CEPA) is an important law that governs pollution prevention and environmental protection in Canada. The precautionary principle, as built into CEPA, states that "whereas the Government of Canada is committed to implementing the precautionary principle that, where there are threats of serious or irreversible damage, lack of full scientific certainty shall not be used as a reason for postponing cost-effective measures to prevent environmental degradation"(Canlii, 2014). Other Canadian environmental statutes that include the precautionary principle include the 1992 Canadian Environmental Assessment Act ${ }^{5}$, the 2000 Species at Risk Act (section 29), the 2002 Pest Control Products Act (section 20) and the 1996 Oceans Act (Greenbaum and Wellington, 2010: 405).

\section{Environmental Assessment (EA)}

Some concepts from the field of environmental assessment have been utilized in investigating and analyzing water conservation and water scarcity policy in this work. A widely accepted definition of EA is a tool used to improve decision-making by improving the planning or activities and determining mitigation measures prior to the start of developments or projects (Bastmeijer and Koivurova, 2008). Environmental assessment, as it is applicable in this context, will be defined as the identification, prediction, analysis and evaluation of environmental impacts. While this study does not directly utilize EA as a method, the technique is well respected and robust (Morris \& Therivel, 2001; Nobel, 2009; Hickey, Brunet \& Allan, 2010), so certain transferable concepts from the field will be borrowed and applied in this work.

\section{Principles of Good Governance}

As discussed in the Introduction chapter, the definition of governance used in this thesis is "the ability of governmental actors and institutions to achieve policy goals"

\footnotetext{
${ }^{5}$ Since updated in 2012.
} 
(Greenbaum and Wellington, 2010: 4). There are many different meanings and definitions of governance in the literature (Hood, Dixon \& Beeston, 2008; Andrews, 2010; Doeveren, 2011), however the desirability of good governance to help solve social problems is generally agreed upon. Good governance has been cited as a specific best practice to improve water scarcity issues (Taiken, 2010).

There is a body of literature devoted to these principles and how they can improve policies and management systems. The value in being cognizant of these principles comes from the struggles and experiences in the governance of any problem in any jurisdiction (Chiti, 1995; Taylor, 2000; Crabbe and Leroy, 2008).

The four agreed-upon principles of good governance are accountability, efficiency and effectiveness, openness and transparency, and participation (Doeveren, 2011) (Table 2). Other principles have been suggested in literature as well, but with considerably less consensus. Further, these four principles are salient for this study.

Table 2 - Definitions of the Principles of Good Governance (Doeveren, 2011)

\begin{tabular}{|l|l|}
\hline Component of Good Governance & Definition \\
\hline Accountability & $\begin{array}{l}\text { Those in charge are held responsible for carrying } \\
\text { out a defined set of duties and tasks and } \\
\text { conforming to rules or standards applicable to } \\
\text { their posts. }\end{array}$ \\
\hline Efficiency and effectiveness & Policy services must meet quality standards. \\
\hline Openness and transparency & Communication of policy decisions to the public. \\
\hline Participation & $\begin{array}{l}\text { When governments and non-state institutions } \\
\text { facilitate meaningful participation from citizens } \\
\text { and non-state institutions. }\end{array}$ \\
\hline
\end{tabular}




\subsubsection{Selected Barriers to Effective Governance}

\section{Policy Implementation Gaps}

Creating a policy alone is not enough to engage change. Policies must be implemented in order to achieve the policies' goals. Policy implementation, a key step in the policy cycle is also sometimes a challenge to effective public policy. Often, conflicting stakeholder's values can create tension at the implementation stage of the policy cycle. This can lead to a high degree of political tension and even legal conflicts (Hussey and Dovers, 2006).

A policy implementation gap is a term used to describe a situation where a policy is created but not implemented, which can happen for a variety of reasons. For example, a trend with environmental policies in general is for a lag to occur between the time that the policy is announced and the time that action is taken to implement it (Di Maria, Smulders and Werf, 2012). Implementation gaps can occur due to a lack of budgeted funds, shifting governmental priorities or closing policy windows. At times, policy implementation gaps occur in spite of the best intentions of the responsible government.

\section{The Role of Politics}

It is important to note that politics plays an important role in policy (Falkenmark and Lundqvist, 1996; Soroka, 2002; Crabbe and Leroy, 2008). Political will, the political party in power, individual leaders and the timing of elections all have influence on what policies governments create, focus on and implement. The issues that governments select can be influenced by the public will of the moment. For example, at the Federal level, Stephen Harper's Conservative party has been criticized by other political parties for putting the environment last on the list of priorities (Liberal Party, 2012; NDP, 2012; Green Party, 2014). 
It is recognized that the policy recommendations created in this study do not exist in a vacuum outside the influence of Canadian politics. That said, the influence of politics will not be fully explored as this would be a thesis topic in itself. Thus, political influence is recognized, but beyond the scope of this study.

\section{Stakeholders}

Stakeholders are not a true barrier to effective governance. On the contrary, stakeholders play an important role in governance (Steurer, 2013), including contributing to water management. Put another way, effective and meaningful consultation with stakeholders is an important component of effective policy. Given the importance of stakeholders coupled with the inherent complexity of water issues, stakeholders will be discussed here.

Key stakeholder groups related to these issues include, but are not limited to the following:

- Municipalities: Cities have key water use needs including drinking water and sewer water. Eighty-one percent of Canadians live in an urban center (Statistics Canada, 2015).

- Farmers: The irrigation of crops requires a great deal of water in many jurisdictions. Along with farmers who require the water to make their living, food security advocates also support prioritizing water to grow crops.

- Consumers: While water for irrigation is key, there is a variety of other water users who require water as well.

- Environmentalists and non-profit agencies: These groups support water for ecosystems and the protection of water resources.

- Industry and trade associations: A great number of industrial users rely on large water takings for large scale commercial use.

- Local watershed agencies: Many local groups feel that their love of the watersheds in their communities and site-specific knowledge should allow them 
a greater role in the management and protection of those resources. In some regions such as Ontario, local watershed groups are playing an increasingly large role.

- Conservation authorities: These groups are increasing playing an important role in these issues, especially in Ontario,

Managing the conflicting interests of diverse stakeholders will likely be a challenge to any government tasked with governing for these issues.

\subsubsection{Policy Instruments Currently Used in Water Quantity Management Strategies}

Common policy instruments used to manage these issues include legislation and regulations, strategies, administrative monetary penalties and economic measures

\section{Legislation and Regulations}

Legislation and regulations are very important tools for the governance of the environment in Canada, including water issues (Winfield, 2009: 47). Regulatory approaches to environmental governance have been praised for visibility, credibility and accountability (Webb \& Morrison, 1999: 230). However, in Canada the vast majority of water laws and regulations are focused on water quality, largely ignoring water quantity.

\section{Strategies}

Strategy is the anticipation of the changes in context and a set of the actions designed to take advantage of changes. For example, Alberta's Water for Life Strategy is the Alberta government's plan for water in the province for the next ten years. This Strategy was created given a specific context and policy window in the province, namely a lengthy and devastating drought. See Chapter IV for more detail on Alberta's Water for Life Strategy. 


\section{Economic Instruments}

A key economic instrument relevant to water scarcity is water pricing (Grafton and Kompas, 2007). Water pricing has been a policy instrument in the United Kingdom, Israel and Australia (Vander Ploeg, 2011). Water pricing is a controversial topic. Many people argue that charging money for water is wrong because access to clean water should be a basic human right. Others argue that water pricing is beneficial as it can encourage conservation with appropriate monetary incentives (Cummings and Nercissiantz, 1992).

\subsubsection{Key Enforcement Tools}

\section{Administrative Monetary Penalties}

Administrative monetary penalties (AMP) are an enforcement tool intended to promote compliance that requires regulatory violators to pay a fee, which is administered by a government and not a court of law (Rolfe, 1997). This is different than a fine in that a fine must be paid only after the finding of guilt in a court (Law Commission of Ontario, 2015). This creates an advantage in that administering an AMP is typically much faster than dealing with an environmental regulatory violation in a court. Another benefit of this tool is that it can effectively remove the financial incentive for rule-breaking (Environment Canada, 2015). An AMP can be appealed through an administrative process.

AMPs are currently in use by various government departments in Alberta, British

Columbia and Ontario. In Ontario, spills can lead to AMPs of up to $\$ 100,000$ per day (ON Gov, 2013a). The Alberta government also has AMP in its toolkit for environmental violations ( $A B$ Gov, 2009). BC can use AMPs to enforce the Environmental Management Act (Canlii, 2015). Another interesting component of administrative monetary penalties is that often AMP violations are published, which introduces a public shaming factor. 


\section{Prosecution}

In Canada, violators of some environmental laws and regulations face prosecution by the law. These tend to be for grievous violations. An advantage is that the possibility of prosecution is a significant deterrent to potential violators. A disadvantage is that the process is slow and very costly.

\subsubsection{Management Strategies in Water Policy}

\section{Water Management Issues as a Wicked Problem}

Water issues are inherently complex (Falkenmark, 1994; Gleick, 2002; Wolfe and Brooks, 2003; Bakker, 2007; Sandford, 2009). In general, the creation and implementation of water management strategies and water policies are complicated, with multifaceted issues between multiple stakeholders. In fact, the comprehensive and rational planning and management of water is known as wicked problem, based on the definition created by Rittel and Webber from 1973. A wicked problem is an issue that does not even have consensus on the definition of the problem. There is agreement lacking on what goals should be in place to address the problem, let alone how to achieve them.

Another way to consider this problem is using Reinhard Steurer's definition of order of policy problems. In his 2013 paper, Steurer argues that first order policy issues attempt to deal with "what to do" while second order policy issues are focused on "how to do $i t^{\prime \prime}$. These questions certainly do not have easy answers. With the issues of water management, one must take a step back and consider that there is not even a consensus on what the problem is in the first place.

In order to improve the state of affairs in the case of a wicked problem, Innes and Booher (2010) suggest that policy actors recognize that since water management is not a problem with an agreed upon optimal solution, it is important for actors to find a way to work together to jointly. 
Dovers (1997) also contributed to this field with a paper discussing some of the underlying reasons why environmental problems and water governance issues are so complex. These include:

- Often multiple, conflicting values play a role;

- Cumulative and often irreversible impacts;

- Root causes of problems that date back to settlement; and

- Influence by historical governance in the area.

Given that it is understood that water management is a wicked problem, next best practices in the sustainable management of water resources are discussed.

\section{Principles of Sustainable Water Management}

There are water management principles that aim to manage water in a sustainable manner, including consideration of biodiversity and ecological systems, a healthy economy and equity for present and future generations (Bakker, 2007: 340). The principles include: (1) recognition that water is a limited and valuable resource, with costs associated with its delivery. (2) encouragement of water conservation and the protection of water quality and (3) work to resolve water management issues conflicts planning, monitoring and research.

\section{Science and Policy-Makers}

A disconnect remains between science and policy-making in Canada (Walter and Duncan Gordon Foundation, 2007). For example, aquifer studies are being done in Canada in a limited fashion and only after large volumes have already been taken, so no baseline data will ever be available. In BC, there are 900 developed aquifers, but only a handful have had regional studies conducted, so we are essentially flying blind with respect to water management (Walter and Duncan Gordon Foundation, 2007: 5). It is important that policy-makers work to connect the science of these issues with policy making and communicate those connections to the public (Jury and Vaux, 2005). 


\subsubsection{The State of the Issue in Canada}

As discussed in the Introduction Chapter, water scarcity issues are simply not a priority in Canada. Governments are reactionary at best, focused only on physical scarcity and ignoring risks and costs (Wolfe and Brooks, 2003). Canada's provincially focused water management regime has been described as severely fragmented (Bakker, 2007: 4). Water scarcity and conservation experts agree that Canada's current water management strategies are unsustainable.

\section{Calls for Change}

Water conservation issues are of growing paramount importance today, and issues are expected to become both more common and more severe. Many Canadians believe that their country has abundant freshwater, but this myth may lead to cavalier attitudes towards water and overuse and abuse of the precious resource. Climate change, population growth and migration to cities are all putting unprecedented pressure on Canada's local freshwater resources. There is a need for this academic study of water quantity issues in Alberta, British Columbia and Ontario. This topic is especially timely given the current water policy context in the province of British Colombia, where that province is undergoing significant change regarding water conservation governance.

Non-governmental organizations (NGOs) have been calling for greater focus on water conservation and water scarcity issues in Alberta including the Pembina Institute (Griffiths and Woynillowicz, 2003), local watershed management organizations such as the Elbow River Watershed Partnership (Alberta Water, 2014) and Water Matters. In the early 2000s, growing concerns and pressures in the province led to the government's focus on water conservation via Water for Life Strategy (Block and Forest, 2005).

In British Columbia, respected NGOs including the David Suzuki Foundation and the Pembina Institute have been demanding greater attention to water conservation issues. The David Suzuki Foundation pressured the provincial government for an updated 
Water Act with a focus on water conservation issues like bulk withdrawals and integrated watershed management (Young, 2010). Support is echoed by the Pembina Institute, including concern for issues such as the increased pressure and competition for water by industrial users.

In Ontario, NGOs also play an important role in pressuring the government about water quantity issues. Organizations specifically devoted to water issues in the province include the Ontario Water Conservation Alliance and Ecojustice. NGOs such as these lauded the development and implementation of the 2010 Ontario Water Opportunities and Water Conservation Act (Ecojustice, 2010a; Water Conservation Alliance, 2013).

\subsubsection{Defining and Addressed the Problem}

Water scarcity is a growing concern globally, yet there is not an agreed-upon comprehensive definition of the meaning of the term. However, there are some definitions and indicators worthy of discussion in the literature.

A widely accepted simple definition comes from the Falkenmark Water Stress Indicator, dating back to the 1990s. Falkenmark defined scarcity using the relationship between the amount of water available and demand for that water by human beings (Falkenmark, 1994; Falkenmark and Lundqvist, 1996; Rijsberman, 2006). A threshold of $1700 \mathrm{~m}^{3}$ of renewable water resource per capita per year is used on a national basis to describe "water stress", which includes water for household use, industry and ecosystems (Table 3). Similarly, a threshold of $1000 \mathrm{~m}^{3}$ is used to describe "water scarcity" and below $500 \mathrm{~m}^{3}$ as "absolute scarcity" (Falkenmark, 1994). This indicator has been praised for its simplicity and ease of use. Limitations include lack of consideration of water infrastructure and lack of consideration for how water is used on a per capita basis in an area. 
Table 3- Scarcity Defined by Falkenmark

\begin{tabular}{|l|l|}
\hline Term & Threshold \\
\hline Water stress & $<1700 \mathrm{~m}^{3}$ \\
\hline Water scarcity & $<1000 \mathrm{~m}^{3}$ \\
\hline Absolute scarcity & $<500 \mathrm{~m}^{3}$ \\
\hline
\end{tabular}

While the Falkenmark Indicator is most common (Rijsberman, 2006), other water scarcity indicators have been developed as well due to the perceived over-simplification of this method. The Water Resources Vulnerability Index is based on the comparison of national water availability on a yearly basis with key water extraction sectors including agriculture, industrial and home water use. Yet another indicator measures the ratio of water withdrawals for human use to total renewable water resources (Rijsberman, 2006). Physical and economic indicators have also been derived for water scarcity. Jurisdictions with adequate renewable water supply but limited means to make that water available to people are called "economically water scarce".

The Water Poverty index was developed, building on the Falkenmark work and incorporating access to water quantity and quality. Multiple factors are considered for this index, including the environment, human access to water and water for food. This work has been praised for addressing shortcomings of the Falkenmark but criticized for complexity.

Environment Canada published a definition of a "high threat to water availability" as more than $40 \%$ of water from a river withdrawn for human use (Environment Canada, 2014). By this definition, there was a high threat to water availability (in 2009) in all three provinces selected for this study (Figure 2). Shortcomings of this definition include a lack of consideration of groundwater and the lack of a rationale for the selection of $40 \%$ as a threshold. 


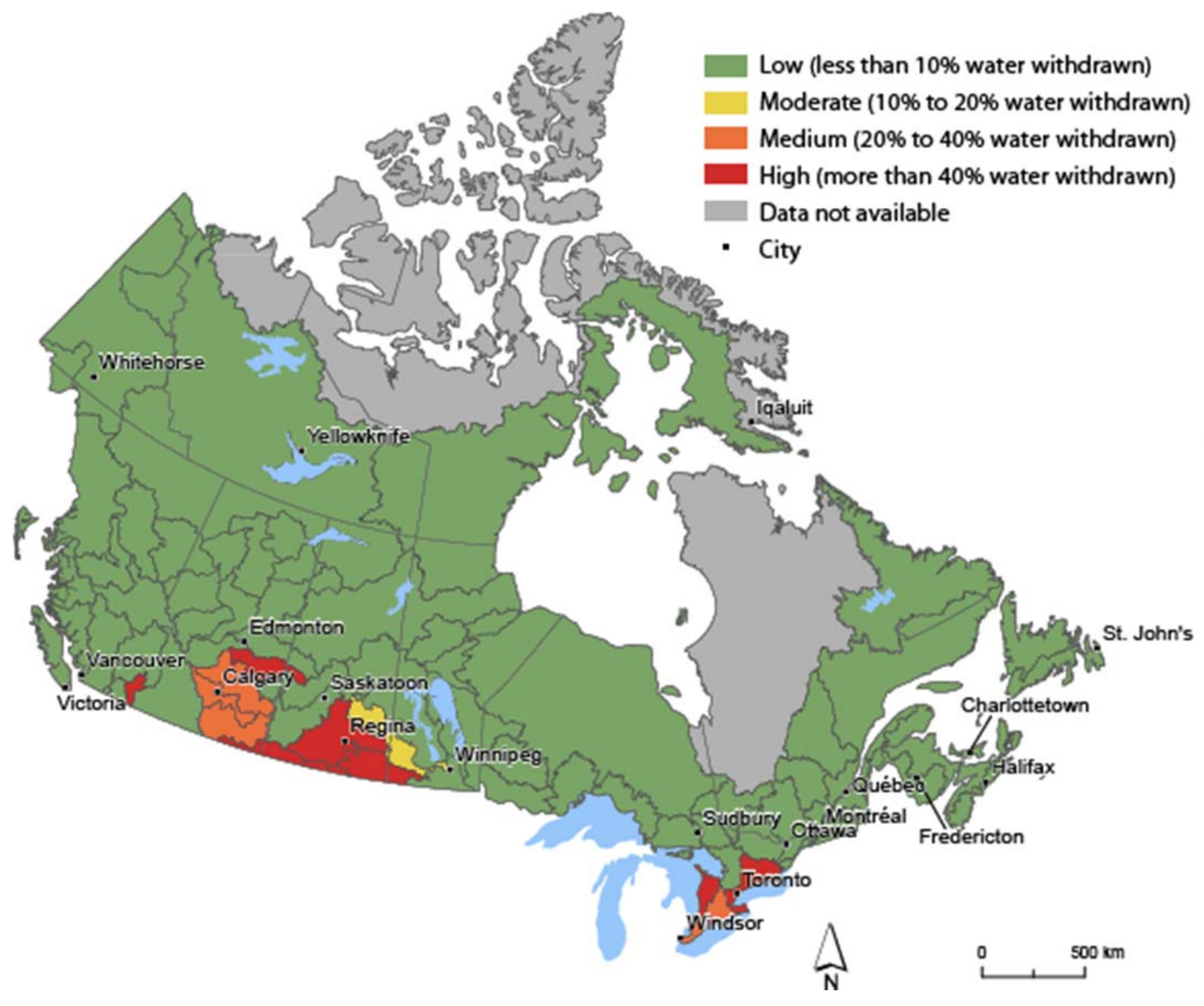

Figure 2 - Threats to Water Availability in Canada in 2009 (from Environment Canada, 2014)

Scarcity - Thinking Beyond the Physical

Water scarcity is often considered only in a physical sense. Falkenmark's commonly used scarcity definition has been criticized for its lack of context and lack of consideration of water use (White, 2012). The literature calls for new ways to think about water scarcity. Wolfe and Brooks (2003) argue that water scarcity should be defined using three orders of scarcity which are based on the type of solutions needed to prevent scarcity. 
First order scarcity: The term for jurisdictions predicted to be unable to meet water demands even through improved water management practices, infrastructure and irrigation efficiencies. These are called "physically water scarce" (Rijsberman, 2006). This type of scarcity is salient and germane in arid and semi-arid climates (Asian Development Bank, 2013). Indicators of this type of scarcity are discussed in greater detail below.

Second order scarcity: In this case, solutions go beyond physical scarcity to include either technological or institutional solutions to create efficiencies (Wolfe and Brooks, 2003). An example of a second order solution would be the concept of "crop more per drop", where farming and irrigation efficiencies are sought per unit volume of water.

Third order scarcity: Solutions in the third order go beyond technological solutions and move into social changes (Wolfe and Brooks, 2003). Demand for water would be decreased through political, cultural or societal changes.

Another important term worthy of definition is "water security", yet another term that lacks a single definition. The definition selected here is "sustainable access, on a watershed basis to adequate quantities of water, of acceptable quality, to ensure human and ecosystem health (Zubrcki et al., 2011). A benefit of this definition is that is considers both human and environmental components.

\section{Avoiding the Hard Path}

Supply and demand solutions: a key distinction among water management strategies is that between supply-side solutions and demand-side solutions. Supply-side solutions refer to solutions to water scarcity issues that aim to make available more freshwater. An example of a supply-side solution is an engineered pipeline to allow more water to be used in a specific place. An example of a demand side solution is a temporary water ban that reduces water demand during peak times. 
The soft path approach: Supply-side solutions are sometimes referred to as 'soft path' while demand-side solutions are also referred to as the 'hard path' (Gleick, 2002; Wolff and Glieck, 2002-2003). The 'soft path' approach moves beyond the scope of how to meet demands with the same or less water. A key difference between the two hinges on efficiency, conservation and limits. The fundamental idea behind this thinking can be attributed to Amory Lovins' 1976 essay in Foreign Affairs (Lovins, 1976). Lovins' work, focused on energy strategy in the US, introduces the idea of calculated switch to the use of renewable energy, the creation of energy efficiencies and consideration the end-use.

Demand-side solutions find a way to deliver more water in order to satisfy any demand, for example through engineered supply increases. This often includes technological solutions, for example building a reservoir, piping or pumps.

Rather than finding a way to simply deliver more water for use regardless of economic or environmental cost, soft-side solutions aim to address the questions like "do we need to use this water for this purpose in the first place?"(Bakker, 2007: 292). This approach involves more than just finding more water to use for a purpose and more than just creating efficiencies within existing water supply mechanisms. There are also greater considerations such as long-term planning for water use from the broad perspective of culture and society (Wolfe and Brooks, 2003).

\subsection{PART TWO - THE SCIENCE OF WATER SCARCITY}

\subsubsection{The Hydrology of Scarcity}

It is important to understand the basics of where fresh water is on the earth and some related key concepts.

Watershed:

A watershed is defined as an area of land that drains water into a particular body of water (Canadian Geographic, 2014a). This term is often used interchangeably with 
drainage basin. There is a strong and ubiquitous argument in the literature that water management should be done at the watershed level in many if not all cases (Deason, Schad and Sherk, 2001; Bakker, 2007; Crabbe and LeRoy, 2008).

\section{Groundwater:}

Groundwater is water under the earth's surface that occupies porous spaces in the ground. Many Canadians rely on groundwater for drinking water, especially in rural areas.

There are two zones where groundwater resides, called the saturated and unsaturated zones. In the unsaturated zone, close to the earth's surface (but varied in depth), water and air each exist in the porous spaces in the soil and rock of the subsurface. The unsaturated zone is crucial for plant and ecosystem health (Walter and Duncan Gordon Foundation, 2007:3). Deeper than the unsaturated zone is the saturated zone, where the spaces in the pores of the subsurface are saturated with water. Figure 3 is a visual demonstration of the saturated and unsaturated zones.

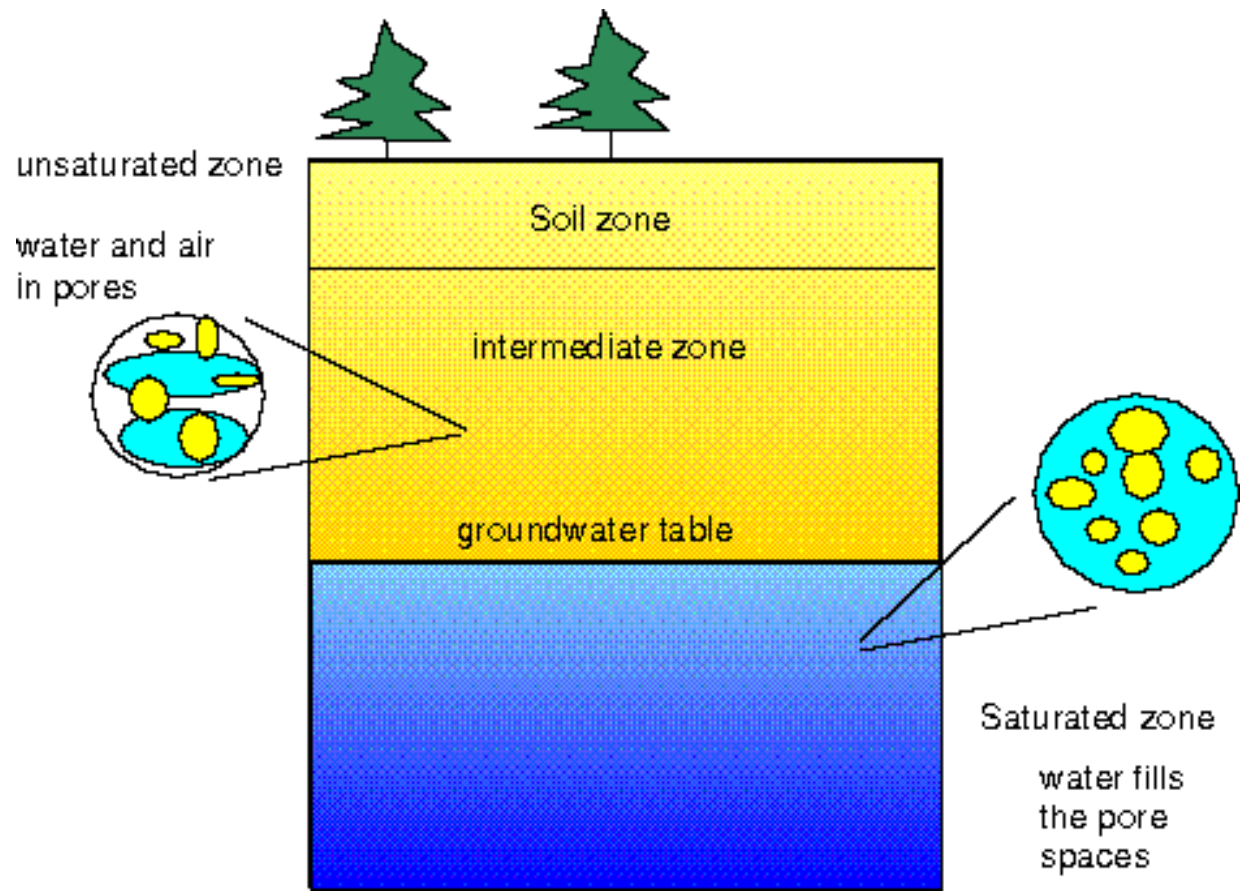

Figure 3 - Saturated and Unsaturated Zones (Tauxe, 2015). 
Recharge is the speed at which water moves down from the surface water to groundwater. In general, as precipitation increases, so does recharge; however, recharge is affected by many complex, interrelated factors and is therefore very challenging to predict and quantify (Jyrkama and Sykes, 2007). It is greatly variable, and can range from 2 weeks to 100, 000 years (Walter and Duncan Gordon Foundation, 2007: 3). Recharge is very important to the management of groundwater resources as once enough water in a well is extracted, one must wait for the well to recharge before more water can be extracted.

\section{Surface water}

Surface water is the water found on the surface of the earth, such as rivers, lakes and wetlands. Not all water is equal when it comes to sustainable use by humans. The flowing water in rivers make up just a small fraction of the total water in the water cycle, yet it is very important to humans (Allan and Flecker, 1993). Some water is not renewable, which is to say that once it is extracted and consumed by humans, it is effectively lost, at least from the perspective of human use.

\section{Water Classes}

Scholars have created differentiations in classes of water in order to encourage smart management of this precious resource. While these differentiations in detail are important to creation of water use efficiencies, they are only discussed at a high level here. Detailed discussion of these ideas is beyond the scope of this study, which is focused on water scarcity at the provincial level.

The term "blue water" is defined as liquid water, which is the type of water that is considered with respect to conventional water use planning. Examples of blue water include lakes, rivers and aquifers. Some water management experts are urging greater consideration of "green water", basically precipitation. Experts are encouraging human use of green water and less reliance on blue water in order to create efficiencies and 
promote sustainable use of water, especially in the agriculture industry (Falkenmark and Rockstrom, 2006; Rost et al., 2008).

Another term that is becoming increasingly prevalent is "grey water". "Grey water" is defined as urban waste water that does not have input from a toilet (Jefferson et al., 2004). This usually involves water from sinks, baths, showers, washing machines and dishwashers. The concept of grey water is important to a discussion of water management and water conservation as it has been cited as a way to increase water efficiencies in the home by up to $30 \%$. The most common use of grey water is to recycle that water to flush toilets (Surendran and Wheatley, 1998; Jefferson et al., 2004; Li, Wichmann and Otterpohl, 2009). Similar to the concept of blue and green water, these efficiencies are important in reducing the amount of high quality water used in peoples' homes.

\subsubsection{The Hydrologic Cycle}

The hydrologic cycle, also known as the water cycle, is an important concept to understand in order to frame problems of water scarcity (Figure 4). The hydrologic cycle, vital to climate, biodiversity and geochemistry (Vorosmarty and Sahagian, 2000) is defined as "the process by which water evaporates from oceans and other bodies of water, accumulates as water vapor in clouds, and returns to oceans and other bodies of water as rain and snow, or as run-off from this precipitation and groundwater" (Government of Alberta, 2003).

The amount of water in the hydrologic cycle does not change; however, the form and location of that water is changing all the time (Oki and Kanae, 2006). The amount of freshwater available for use can be insufficient in part due to its uneven spatial distribution. 


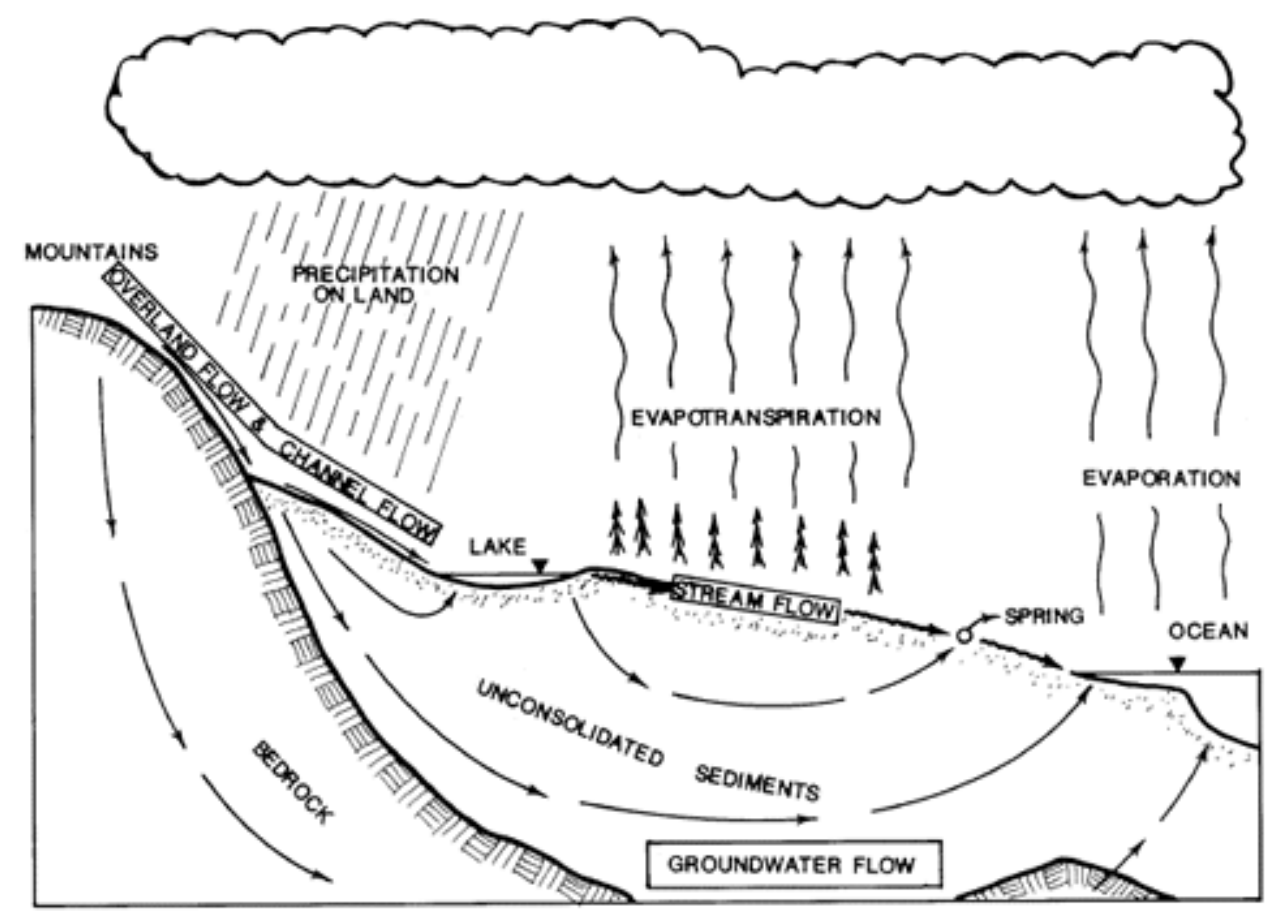

Figure 4 - Groundwater and Hydrologic Cycle (BC Gov, 2014d)

\subsubsection{Predicted Impacts of Climate Change on Water Supplies}

The literature notes that the climates in Canada are changing and water scarcity issues are expected to increase in different regions (Zhang et al., 2000; Pike et al., 2008). Regions that have water supplies dominated by snow or ice melt are predicted to see severe negative impacts on water availability (Barnett, Adam and Lettenmaier, 2005). There is consensus that climate change is predicted to increase and amplify water scarcity issues in many locations (Vorosmarty et al., 2000; Vorosmarty and Sahagian, 2000; Allen, Mackie and Wei, 2004; Huntington, 2005; Oki and Shinjiro, 2006; Leary, Conde and Kulkarni, 2007; Jyrkama and Sykes, 2007; Green et al., 2011). This literature urges action now before climate change upsets the water cycle. 


\subsubsection{Relevant Hydrology and Waterscape of Selected Provinces}

\section{Alberta Waterscape and Hydrology}

Over $80 \%$ of Alberta's water is in the northern part of the province, while in contrast approximately $80 \%$ of the demand for those resources is in the south of the province (AB Gov, 2014a). To compensate, Alberta relies heavily on reservoirs to support cities, agricultural irrigation and in some cases, hydropower. Irrigation, focused largely in the south, is responsible for over 4 billion cubic meters of water allocation in the province. For perspective, municipal water use requires less than 1.5 billion cubic meters (AB Gov, 2014a).

Many of the largest lakes, formed thousands of years ago by retreating glaciers, are in the northern part of the province. This includes the province's three largest lakes: Lake Athabasca $\left(7,770 \mathrm{~km}^{2}\right)$, Lake Claire $\left(1,436 \mathrm{~km}^{2}\right)$ and Lesser Slave Lake $\left(1,160 \mathrm{~km}^{2}\right)$.

Most of the rivers in Alberta are glacier-fed. This means that their waters originate in the glaciers and mountain snow pack in the Rocky Mountains (AB Gov, 2014a). This type of water regime is called a nuvial regime, where peak flows occur in the spring (Pike et. al., 2008), with flows varying both seasonally and annually. In the winter most surface water is frozen, so it is groundwater base flow that contributes most to river flows. In the summer months, rainfall becomes an important mechanism to replenish rivers in Alberta. This seasonality has a strong influence on water scarcity in Alberta. Times of scarcity are linked to lower flow years, the dry climate and varied geography.

Surface water is crucial to human water use in the province. Many Albertans rely on groundwater also, including over $90 \%$ of rural residents (AB Gov, 2014a). There are approximately 400,000 groundwater wells in Alberta, and over 4000 known new wells are drilled every year. Under the Alberta Water Act, just three percent of the total volume of licensed water use in the province comes from ground water (although drinking water wells are exempted under the Act). The province had published 
recognition that climate change could create poor groundwater recharge conditions $(\mathrm{AB}$ Gov, 2014a).

Seasonal flow variability, the semi-arid climate and variability in geography are all factors that make Alberta prone to scarcity issues (AB Gov, 2014a). Climate change is expected to exacerbate scarcity in Alberta, putting rural Albertans at risk.

\section{British Columbia Waterscape and Hydrology}

$\mathrm{BC}$ is known for being a water rich province. It is also a hydraulically diverse province. Much of the coastal areas have a pluvial water regime, also known as rain-dominated (Pike et al., 2008). Peak flows typically occur in the winter, with the lowest flows in the summer. However, not all of $\mathrm{BC}$ is rain-dominated. There are areas in the interior that are semi-arid and prone to scarcity. Climate change is recognized as a threat that may lead to more scarcity issues in the province, with expected negative effects on stream flows and groundwater recharge (Pike et al., 2008).

Three large rivers flow into the Pacific Ocean through British Columbia: the Fraser, the Columbia and the Yukon (Canadian Geographic, 2014b). The Fraser is the longest undammed river in Canada and of crucial importance to salmon. The Fraser is important to salmon reproduction because both Sockeye and Chinook salmon travel back to their natal streams to spawn and die. This is one key reason why the Fraser and its tributaries are ecologically sensitive to low flows (Morrison, Quick and Foreman, 2002).

The Okanagan valley is a region in BC that is especially sensitive to scarcity due to its climate, heavy irrigation demands in the summer and limited supply (Cohen et al., 2006; Sandford, 2009: 43). The valley is in the rain shadow of the coastal mountain range (Belliveau, Smit and Bradshaw, 2006), which results in the area receiving a fraction of the annual rainfall of the coastal areas. Several studies on this area have warned that climate change presents a risk to regional water supplies and fisheries in this area, especially surface water (Cohen et al., 2000; Hamlet, 2003; Allen, Mackie and 
Wei, 2004; Merritt et al., 2006). Increased conflict over water is projected for the area (Cohen et al., 2006; Steeves, 2012).

Vancouver Island is also known to be susceptible to scarcity. Vancouver Island has an especially vulnerable groundwater supply because in many areas of the island, aquifers are very shallow, which makes them especially vulnerable to surface contamination (Vancouver Island Water Resource Vulnerability Mapping Project, 2014).

Groundwater is a very important source of freshwater in the province of British Columbia. Up to one million people in the province use groundwater for their drinking water (Environmental Reporting BC, 2014). Groundwater is also an important source of water in the province for farming and agriculture. In 1961, the province established a network of 180 groundwater monitoring wells to monitor groundwater levels in key areas (Environmental Reporting BC, 2014). It is unclear if any new monitoring wells have been considered or if the province considers these historic wells sufficient for data collection and monitoring.

\section{Ontario Hydrology and Waterscape}

Ontario has over 250,000 lakes, including four of the five Great Lakes (ON Gov, 2014a). Together, Lake Huron, Lake Superior, Lake Michigan, Lake Erie and Lake Ontario represent one of the greatest volumes of freshwater in the world. Nearly $75 \%$ of Ontarian's get their water supply from surface water sources (TRCA, 2014). Ontario's two largest cities, Toronto and Ottawa are situated well to take advantage of surface water supplies. Torontonians are serviced using water from Lake Ontario, while the national capital is serviced with water from the Ottawa River.

Water from lakes and streams is also important in many areas in the northern part of the province characterized by the Laurentian Plateau, more commonly called the Canadian Shield. Precipitation (rain and snow) is important in replenishing surface water in Ontario. 
The literature on Ontario hydrology includes many studies that model annual and seasonal evapotranspiration, surface runoff and/or groundwater movement, each of which is very important to hydrology in the province (Rudra, 2007). Seasonal surface water runoff is an especially important mechanism in the Canadian Shield (Buttle, Dillon, and Eerkes, 2004), where soils depths tend to be shallow and variable. Little is published that focuses on resources at the watershed level in Ontario. There is a recent increase in the number of studies focused on predicting the impacts of climate change on Ontario watersheds (Crabbe and Robin, 2006; Jyrkama and Sykes, 2007; Ehsan, MacLeod and Fillion, 2011). There is a significant lack of studies focused on water scarcity issues in Ontario.

Economic sectors that rely heavily on the lakes are agriculture and manufacturing. Rivers are very important in Ontario, including water used as a primary supply, use by industry and the generation of electricity through hydropower. Over one-third of Ontario's electricity comes from hydropower (Ontario Power Generation, 2014).

Some of the greatest risks of scarcity are found in rural areas, where $90 \%$ of Ontarians rely on groundwater (Dolan, Kreutzwiser \& de Loë, 2000; de Loë, Kreutzwider and Neufeld, 2005; Environmental Commissioner of Ontario, 2012). An example of an area reliant on groundwater is the Waterloo region, where groundwater is used in conjunction with water from the Grand River. In dry and hot years, water loss to evapotranspiration and extended periods of water extraction can cause the water table to be very low (Lafleur et al., 2005). There has been a great deal of concern about the topic of groundwater safety in Ontario following the Walkerton tragedy (de Loë, Kreutzwiser and Neufield, 2005). The Region of Waterloo has taken steps to protect source water in the area, but vulnerability remains throughout the province (Ivey, de Loë and Kreutzwiser, 2006; Frind and Middleton, 2014).

Land management practices have an important impact on hydrology in Ontario (Rudra, 2007). This includes water loss to evapotranspiration in crop land (Davies and 
Allen, 1973), draw down from irrigation and the creation of impervious surfaces such as concrete (Brabec, Schulte and Richards, 2002). Thus, Ontario is vulnerable to the increasing pressures of population. For this reason, Ontario may experience the greatest economic costs of ignoring scarcity issues.

\subsubsection{Relevant Hydrology and Waterscape of Selected International} Jurisdictions

Experiences from different international jurisdictions were researched, including both water rich and water scarce regions. The research was focused on jurisdictions with the ability to provide evidence of experiences that can help to craft policy recommendations for the selected Canadian jurisdictions. This included a level of policy convergence. Policy contexts require enough similarities to Alberta, BC and/or Ontario to add value with respect to policy recommendations. Several jurisdictions were rejected due to limited scope of the study, lack of policy convergence with the selected Canadian jurisdictions or lack of applicable experience.

Given the importance of context as an indicator of success in policy learning (Lansford et al., 1975; Swainson and de Loë, 2011), policy contexts of the selected jurisdictions are outlined next. Jurisdictions are the US States of Georgia, Colorado, Oregon, California, and New Mexico, as well as the countries of Australia and Spain. Relevant experiences from the selected jurisdictions are discussed in Sections 6.2.5, 6.3.3 and 6.4.6.

\section{USA}

The United States is said to be heading towards a widespread water scarcity crisis (Glennon, 2004). There are numerous, long-standing conflicts over water between states including conflicts that have escalated to legal action. The increasing number of conflicts over water between states is telling of things to come should water policy fail to address these issues sufficiently (Cummings and Nercissiantz, 1992). 
In a 2003 survey, only 14 US states indicated that they did not expect to experience water shortages in the next ten years (Glennon, 2004). Current water use practices in the country have been criticized as unsustainable, damaging to the environment, made with disregard for the water needs of Aboriginal groups and other minorities, and not giving consideration to water for noneconomic purposes (Davis, 2001).

The US has been a key region for policy transfer learning, often called "laboratories of democracy" (Konisky and Woods, 2012). A large amount of the literature written on water policy analysis focuses on the United States (Deason, Schad and Sherk, 2001). Water resources are most often managed by individual states, under a combination of federal delegation and state law (FDEP, 2014).

\section{National Leadership}

The federal government took on a significant role in environmental policy in the US starting in the 1970s (Konisky and Woods, 2012). Federal statutes that are important to water conservation in the US include the Clean Water Act and the Safe Water Drinking Act. There is also an executive order from 2010 focused on water stewardship which includes protection of the Great Lakes. The Clean Water Act is the primary legislation for the protection of surface water using a variety of regulations as well as alternative policy tools (US EPA, 2014). This Act does not directly deal with water quantity issues, however there are spin-off repercussions. For example, the Act has caused many businesses to reduce the amount of water that they use in their processes, since this is one way to reduce the amount of impacted water discharged (Glennon, 2009: 43). The Safe Water Drinking Act safeguards the protection of drinking water in the country. Again, this Act is not a direct governance mechanism for water quantity issues, although there is overlap as this statute protects what is arguably the most important water use in the country. The US does not have a federal water policy, which has been criticized as being a mistake (Jorns, 2007). 
Individual states have great responsibility over environmental matters, including the implementation of major environmental statutes. Implementation has been varied, as states are quite diverse in terms of their commitment to environmental protection.

The United States has many similarities to Canada, including a shared continent and a democratic political system. The two countries are also similar with respect to the division of power between federal and state/provincial governments. US states have much to offer in terms of policy lessons and best practices for use in the creation of policy recommendations for Alberta, BC and Ontario.

\section{Prior Appropriation and the Riparian Doctrine}

There are two distinct systems of water governance currently applied in the United States. The western US states are generally characterized by the law of prior appropriation, also called First in Time, First in Right (FIT FIR). FIT FIR is a system used to prioritize water rights that is still used in Alberta today. This way of managing water evolved out of the historical settlement of the dry western states. However, some water rich states use the prior appropriation water governance system, for example Oregon. This fundamental water management paradigm is also used in British Columbia. For a more detailed discussion of prior appropriation, see Chapter IV.

A second governance system, referred to as the riparian doctrine, is characterized by limiting water use only by restrictions of the "reasonable" use of water shared with other users. Water rights also are limited to the land that has the resource or adjoining lands. This system, usually seen in water-rich eastern states evolved out of states where water was perceived to be unlimited. This type of water management is similar to that of eastern Canada (Boyd, 2011: 57). Some eastern US states have begun to adjust their approach in order to address increased conflicts between users, moving away from reasonable use and towards a permitting system (or similar) for withdrawals. The protection of minimum flows has also been an increasing priority (An and Eheart, 2006). 
Which system is better at the preventing scarcity? Each of these two different systems has been highly criticized in literature as doing little to encourage conservation and smart water management. While the prior appropriation system has been praised for defining water priority during times of scarcity, it has been criticized for a high degree of rigidity and lack of protection for the water resources. The riparian doctrine has been criticized as being exceeding vague, operating on the false assumption that water resources are unlimited and for the lack of environmental protection measures (Deason, Schad and Sherk, 2001).

The policy contexts of individual states are discussed next. Selected water rich states are Georgia, Colorado and Oregon. Selected water poor states are New Mexico and California.

\section{Georgia}

Georgia is a water-rich, riparian state, with abundant annual precipitation and ample streams, lakes and wetlands (Glennon, 2009: 25). In spite of a humid, subtropical climate, droughts in this area of the US are becoming more common, leading to threatened water supplies, crop devastation and legal conflicts between states (Manuel, 2008; Pederson et al., 2012).

Water distribution in the state has contributed to water scarcity issues. Most of the ample water resources are in the south of the state, while Atlanta, the largest city and the majority of the population are in the north (Glennon, 2009: 25). Georgia is one of the fastest-growing states in the USA, and population increase has also influenced the pressures on the water resources (Dellapenna, 2004). The amount of water used daily in the state is a staggering 1.3 billion gallons per day (Glennon, 2009: 25). Much of Georgia's water resources are shared with other states, many of which have feuded with Georgia over water (Dellapenna, 2004). 


\section{Colorado}

Similar to BC, the State of Colorado is geographically diverse, including mountains, forests and semi-arid flat lands. Colorado is considered a water-rich state, largely due to the strong flows of the Colorado River. Colorado is not immune to water scarcity issues, often linked to the state's drought-prone nature (Young, 1995). Further, many other states rely on the waters from the Colorado River, including New Mexico, Wyoming, Utah, Nevada, California and Arizona (Woodhouse and Lukas, 2006).

Like Alberta, Colorado has over-allocated its water resources using a FIT FIR-based water licensing system (Woodhouse and Lukas, 2006). The state has managed its water via a prior appropriation system since the 1870s (Glennon, 2009: 88), a commonality with Canada's western provinces. The notion that Colorado had adequate supply to meet demand contributed to a lack of consideration of longer term water planning in the area until the mid-1990s. A drought that began in 1995 and lasted until 2002 forced attention to the issue in Colorado (Woodhouse and Lukas, 2006).

A major water use in Colorado is the irrigation of crops. Most senior water license holders have rights to surface water. Many other farmers pump groundwater, since the water rights to the surface water were exhausted. Conflict between these two groups peaked with a legal action in 2006 after years of bad blood and a long drought. Colorado courts ruled in favour of the senior users and pumping water was disallowed for many farms. This brought great economic hardship to many farmers with the loss of crops and lack of income. Both sides of the conflict blamed those in charge of government for allowing the situation to reach the point that it did (Glennon, 2009: 89).

\section{Oregon}

Oregon is known for an abundance of water. Similar to British Columbia, the state has two climatic zones, separated by the Pacific Coast Mountains. The east side of the range tends to have less rainfall, while the west side is a rain-dominated regime (EPA, 2013). A key feature of this divide is that the majority of the populated areas in the state are in 
the drier areas (Farley, Tague and Grant, 2011). Another unique feature is Oregon's dependency on surface water. Oregon's water resources are based about $87 \%$ on surface water, with only 13\% coming from groundwater. It is because of this dynamic that Oregon is heavily reliant on precipitation to prevent water scarcity (EPA, 2013). Lastly, another factor in the state's water scarcity vulnerability is the seasonal nature of rainfall in the state. Just ten percent of the precipitation that falls in Oregon is in July and August, but those months are very important to a key group of water users, recreational users (Farley, Tague and Grant, 2011).

Like so many places, Oregon uses a great deal of its water for the irrigation of crops. In drier years, this practice can deplete rivers and waterways to critical levels (EPA, 2013). A second troubling issue in Oregon is the depletion of groundwater by cities. In several areas, the groundwater is being depleted faster than it is replaced. Similar to British Columbia, Oregon's population is expected to continue to grow. Climate change has already caused drought in Oregon, and effects are predicted to get even worse (Farley, Tague and Grant, 2011; US Drought Monitor, 2015). In 2007, salmon populations in the state were decimated due to a lack of water (Glennon, 2009: 18).

\section{California}

The State of California has policy convergences with the contexts of Alberta and British Columbia. Water resources in the state are under great pressures, including the needs of a population of over 18 million Californians. The state is also an interesting study in water scarcity due to the great engineering efforts that have been undertaken to move water in California. The state is heavily reliant on a system of mass water transfer and storage. Water is transferred from the Colorado River and the northern part of the state and transferred vast distances to the populous and dry south. For example, the California Aqueduct is $714 \mathrm{~km}$ in length, stretching from the Sacramento River Delta to the southern part of the state (MacDonald, 2007). 
California has long been prone to droughts, and the state is currently experiencing unprecedented water scarcity. A drought began in 2011 that continues to the time of the writing of this paper in 2015 (US Drought Monitor, 2015). The drought may be the worst the state has seen in a thousand years, and scientists indicate that both overuse of water resources and climate change have exacerbated the issue (Fountain, 2015).

There are severe economic and environmental consequences to the drought. For example, Santa Barbara has begun using desalination to create potable water, in spite of the great costs and inefficiency of the method (Nagourney, 2015). Companies are going out of business over a lack of access to freshwater. State and federal agencies have been forced to drive millions of salmon smolts to the Pacific Ocean as their natural swimming routes were too dry and too warm (CBC, 2014). The agricultural sector central to California's Central Valley has been hit extremely hard, with a state-wide emergency declared in early 2014.

New Mexico

New Mexico has a semi-arid climate, great variability in precipitation received and a history of water conflicts and shortages (Martinez, Verhines and Lopez, 2013). Water is managed using the prior appropriation method common to the dry western states (Perramond, 2013). Lessons from New Mexico are especially valuable for Alberta and $\mathrm{BC}$, as the two jurisdictions are both water scarce and manage water with a prior allocation system.

In spite of the high risk due to climate, New Mexico only began to deal with scarcity policy in 2003 with the New Mexico State Water Plan. The state of New Mexico has been criticized in the literature for having a poor understanding of the water resources within its borders (Perramond, 2013). Robust and up-to-date data are very important in order to make informed water management decisions.

New Mexico highlights an important consequence of water scarcity: economic strife. Water in the state has been called the "foundation of all economic activity" (Martinez, 
Verhines and Lopez, 2013). New Mexico reported economic losses due to water scarcity that included decreased state park tourism, less economic output from the livestock industry and devastation to the agricultural industry.

Spain

Spain is a water scarce European country that has been forced to deal with severe water shortages. Population growth, reliance on irrigation for farming, and a naturally dry climate have all contributed to acute water shortages and conflicts. Rising air temperature due to climate change contributes significantly to drought through evaporation in the region (Climate Adaptations, 2015).

The city of Barcelona, home to almost 2 million people, experienced unprecedented water scarcity that peaked in 2007 following a long drought. These water woes reached a level of severity where government officials turned to the delivery of water for the city by tanker truck at a total estimated cost of $\$ 68$ million dollars US (Sandford, 2009: 153). This water was being supplied by other regions in Spain. Citizens, especially farmers, were extremely displeased by this course of action. The irrigation of farmland had been disallowed in these regions in order to supply the city with water. The Government of Spain decided to financially compensate the farmers for the portion of their water licenses that they did not use. Canada has the opportunity to learn from Spain's delayed action and severe water problems.

\section{Australia}

Australia is a semi-arid continent where the natural water scarcity situation has been exacerbated by a ten year stretch of drought (Vander Ploeg, 2011). Due to these circumstances, the Australian government has responded to this unprecedented water scarcity with strong policy responses. Forest fires of unprecedented scale have been an emerging problem Australia as a result of extreme heat waves caused by climate change (Australian Government, 2014). It is this experience, as well as similarities in the political context between Canada and Australia that makes Australia worthy of 
inclusion in this study. This is similar to BC's experience of pine beetle infestation affecting forests province-wide, leaving soils rootless, eroded, and unable to hold water. Pine beetles decimated areas of British Columbia that had formerly been climatically unfavorable to them (Carroll et al., 2003).

In 2004, Australia began the National Water Initiative (NWI), a blueprint for water reform in the country. The NWI is an unprecedented national policy framework that incorporates regulations, market-based instruments and an educational component (Hussey and Dovers, 2006).

Objectives of this policy include preparation of water plans that include allocation of water for the environment, expansion of the trade in water and meeting and managing urban water demands. The NWI provides monetary incentives to Australian states that reform their water policies. This federal leadership aims to encourage re-use and recycling of wastewater to encourage market forces to be a driver for water conservation, and to increase water use efficiency (Brynes, Crase and Dollery, 2006). It is expected that fully implementing the National Water Initiative will be a challenge as it is a complex and multifaceted policy (Hussey and Dovers, 2006).

Historically, the Australian government has asserted leadership during times of crisis and helped to settle conflicts over water between states. For example, the Commonwealth intervened in 1978 by creating a federal statute to provide funding for states for long-term water conservation planning in response to a long-lasting drought. National leadership on water scarcity issues is especially valuable given that regional management systems and laws are diverse (McKay, 2005).

The ongoing water scarcity crisis in Australia is believed to have been caused by many factors including increasing population size, lack of investment in water infrastructure, high patterns of consumption and lack of accountability in water governance (Grafton \& Kompas, 2007). As in Canada, a great deal of the powers of water governance fall to individual Australian states (McKay, 2005). A great deal of water is used in Australia 
for the irrigation of agriculture (Hussey and Dovers, 2006). Water protection and distribution have been called the most important issues currently in Australia (Godfrey, 2011). Impacts from lack of water in Australia have included soil salinization resulting from heavy use of irrigation, conflicts between states and impacted ecosystems (Grey and Sadoff, 2007). 


\section{CHAPTER IV - ANALYSIS: BACKGROUND POLICY CONTEXTS FOR SELECTED JURISDICTIONS}

This chapter details the background water governance policy contexts for the three selected provinces, as well as the federal context. Policy contexts have been given careful consideration as this has been determined to be important to the successful use of policy evaluation (Swainson and de Loë, 2011).

\subsection{Division of Powers in Canada - Water Governance}

As per federal powers under the Constitution, Canada's national government has responsibilities for fish and fish habitat, navigation, First Nations peoples and water, federal lands, oceans and trans-boundary flows (Muldoon and McClenaghan, 2007: 250). An example of "federal lands" is a National Park. The federal government is also responsible for the management of bulk water exports, should any occur. Ambiguities in governance responsibilities between the federal government and provinces have arisen at times (Phyper and Ibbotson, 2003; Zubrcki et al., 2011).

Canada has important federal water legislation such as the Canada Water Act of 1970. The Water Act aims to facilitate cooperation between federal and provincial governments with respect to water management, often in the form of cost sharing agreements (Booth and Quinn, 1995). The functional role of the federal Water Act is to provide funding coordination and does not change the fact that the lion's share of governance responsibility lies with the provinces. Table 4 shows key federal legislation related to water and Table 5 lists federal guidelines and policies that are related to water governance in Canada. 


\begin{tabular}{|l|}
\hline Table 4 - Important Federal Legislation Related to Water \\
\hline The Canada Water Act \\
\hline The Fisheries Act \\
\hline Canadian Environmental Protection Act \\
\hline The Constitution Act \\
\hline The Navigable Waters Act \\
\hline Canadian Environmental Assessment Act, 2012 \\
\hline International Boundaries Water Treaty Act \\
\hline Canada National Parks Act \\
\hline
\end{tabular}

\section{Table 5 - Federal Guidelines and Policies Related to Water}

Guidelines for Canadian Drinking Water Quality

The Federal Water Policy

\subsubsection{National Governance and The Federal Water Policy}

A discussion about the role of the federal government of Canada in water governance would not be complete without discussing the Federal Water Policy, which was created in 1987. The policy was created in a time when there were a number of proposed bulk water transfers to the United States, which it aimed to prevent. The Federal Water Policy acknowledges that the federal government must provide leadership with respect to water management in Canada (Zubrcki et al., 2011). The overall objective of the Federal Water Policy is to "encourage the use of freshwater in an efficient and equitable manner consistent with social, economic and environmental needs of present and future generations" (Environment Canada, 2013). The Federal Water Policy had two main goals: "to protect and enhance the quality of the water resource and to promote the wise and efficient management and use of water" (Environment Canada, 2013).

The Federal Water Policy has been praised as being "thoughtful and well developed" (Brooymans, 2011: 98). The Federal Water Policy is a good example of an implementation gap preventing a policy from being successful. Environment Canada 
has acknowledged on its website that the policy is "inadequate" (Environment Canada, 2013). While the written policy was sound, the overall objective of encouraging the use of freshwater in an efficient and equitable manner in a sustainable fashion clearly has not been met twenty-eight years later.

The benefits of a stronger national water strategy would be many, including increased accountability, increased stakeholder participation in the governance, strengthened national capacity to respond to threats and crises affecting Canada, and greater public acceptance of governance and management of water resources (de Loë, 2008). A stronger national water policy would be logical when one considers that water does not flow with respect to political boundaries. Rather, water commonly crosses jurisdictional boundaries such as provincial lines, which makes provincial-based governance complicated and can lead to conflict (Saunders and Wenig, 2007: 120).

Nongovernmental organizations (NGOs) are calling for stronger federal leadership for water governance in Canada. For example, water interest groups such as the Council of Canadians, the Canadian Water Resources Association, Pollution Probe, the Council of Canadians and Friends of the Earth have called for a stronger national leadership on water issues.

Research does not yield any evidence that the Canadian federal government has any upcoming plans to create the stronger national approach that the NGOs seek. The focus of this paper will be on changes at the provincial level, as provinces remain the key players in water governance in Canada.

The National Action Plan to Encourage Water Use Efficiency

In 1994, the federal government worked together with provinces and municipalities to encourage Canadians to use water efficiently. The National Action Plan to Encourage Water Efficiency was created from this initiative (Boyd, 2011: 50). The group responsible for this work was the Canadian Council of Ministers of the Environment (CCME), an intergovernmental forum focused on environmental issues in Canada (CCME, 2014). 
Under this plan, the federal government encouraged staff to decrease their own water use. The plan also included a public education component and funding for water related research. Other strategies including water pricing, the encouragement of strong water science, integrated planning, legislation and public awareness also failed to meet the overall objective of the policy. The policy demonstrates that the federal government recognized the importance of wise water use; however, this policy is over 20 years old and clearly not enough given the current state of affairs in Canada.

\section{Bulk Water Exports}

The concept of bulk water exports - the selling of Canada's freshwater to other countries - is a controversial scheme that has met great public opposition. The Federal Water Policy explicitly stated that the federal government was opposed to bulk water exports (Boyd, 2011: 57). However, the proposed legislation that would have made the practice illegal, the Canada Water Preservation Act was never enacted. There are two mechanisms in place, the Accord for the Prohibition of Bulk Water Removal from Drainage Basins and components of the Boundary Treaties Act with the US (Shrybman, 2000).

Without stronger federal protection against bulk exports, companies have tried to take advantage of Canada's freshwater supply and may attempt to do so again in the future. Bulk water removal is expected to have serious negative environmental consequences (Hipel et al., 2008).

An example of water quantity issues in the Canadian context comes from Ontario. In 1998, a company called Nova Group proposed to fill tankers with water from Lake Ontario and export it to Asian markets. This proposal was to include 160 million gallons of Great Lakes Water per year (Glennon, 2009: 97). The Ontario Ministry of the Environment and Climate Change approved a five-year permit that would have allowed Nova Group to remove the water from Lake Superior (Boyd, 2011: 57). The permit was rescinded by the MOECC following public outcry over the plan. 
The three provinces selected for this study are reviewed in the next section regarding their water policy history and current policies dealing with water quantity issues; Alberta, British Columbia and Ontario.

\subsection{Background Policy Context: Alberta}

In order to understand the modern water policy context in Alberta, one must understand the history of policy development as many of the laws and policies have roots in Alberta's history (Table 7). Some of the key principles of the current context come from historical mechanisms, but are still important to the policy context today. Alberta Environment and Sustainable Resource Development is a key provincial governmental department responsible for the management of water in Alberta.

\subsubsection{The Early Years}

Historically, control of water in Alberta was governed at the federal level. In the late 1800s, power shifted to the provinces in Western Canada (Percy, 2004). The existing federal system at the time was modelled after the geography of eastern Canada. The riparian rights-based system remains germane in eastern Canada today. To encourage settlement of western Canada, the federal government studied legislative options and decided to model Alberta's system after the prior appropriation system in the western United States (Percy, 2004). This federal system was much more fitted to a water-scarce region reliant on agriculture that required water from distant sources. In 1894, a national piece of legislation called the North West Irrigation Act (Irrigation Act) established governance and management for water in western Canada, with a focus on irrigation. The Act established a system for water allocation that helped develop western Canada (Percy, 1996).

This legislation is the origin of the FIT FIR. In times of scarcity, senior license holders have priority regardless of intended water use (Block and Forrest, 2005). The FIT FIR system has been criticized as no longer being congruent with the current water situation in Alberta and in dire need of a change (Vander Ploeg, 2010). 
In 1930, the Natural Resources Agreement granted Alberta legislative power over the province's water resources (Canada West Foundation, No Date). While control shifted from federal to provincial powers, Albertans enjoyed the same water rights that they did before with the Irrigation Act (Block and Forrest, 2005). Just one year later, Alberta passed the Water Resources Act, which affirmed that Alberta held the rights to water in the province. The province then would grant users the rights to use the water via government license.

A key issue with the Irrigation Act and the 1931 Water Resources Act was that neither included incentives for conservation (Block and Forrest, 2005). The underlying purpose of each of these pieces of legislation is to encourage water use for economic development (Hienmiller, 2013). Water licenses could be obtained with minimal cost. In fact, in many ways the system encouraged users to take all that they were allowed in order to maximize agricultural output.

\subsubsection{The Alberta Water Act}

Alberta passed legislation that began a new era of water governance in the province in 1999. With the first significant legal and regulatory change that the province had implemented in decades (Hienmiller, 2013), Alberta replaced the out dated Water Resources Act with the new Water Act. Growing public concern over water scarcity issues may have contributed to this response. This included conflicts between environmentalists and irrigation water users that peaked in the conflict surrounding the Oldman Dam that lasted through the late 1980s and early 1990s (Hienmiller, 2013). A lawsuit against the federal government was launched when a group of Alberta citizens had concerns about the possible environmental impacts of a large-scale dam on the Oldman River (Ecojustice, 2015b). The dam was constructed, but the case triggered important changes to federal environmental assessment process.

The Water Act was progressive with respect to water conservation in that it began to consider water use on a per water basin basis as opposed to the previous demand-based 
piecemeal approach. In addition, the legislation included policy instruments that could be used to temporarily restrain or reduce human water use in the interest of the environment (Hienmiller, 2013). In 2000, the Irrigation Districts Act was added; it was provincial legislation that refined details of water license management.

Alberta's Water Act has been described as "a patchwork attempt to update 19th century legislation to the $20^{\text {th }}$ century context" (Schmidt, 2011; 1). The focus on water use and economic development is still at the heart of the Act today (Hienmiller, 2013). The legislative changes in 1999 did not change some of the core principles of the precursor legislation, namely the use of the FIT FIR prioritization system. An important difference was the addition of an allowance of transferability of rights under water licenses (Christensen and Droitsch, 2008).

The Water Act created four categories of water users: household users, traditional agricultural users, existing licensees and new licensees. There are currently over 187,000 license holders in the province (AB Gov, 2012a). Household users have priority over all other types of license holders. A second water allocation category of users was called 'traditional agricultural users', including those who could use up to $6250 \mathrm{~m}^{3}$ of water each year with a registration. Water licenses come with a priority number that dictates their rights. The holder of a lower number has the right to take all their allocation before the next number is allowed to take any. Existing licensees retain the rights that had been granted via prior legislation. These users retained their original priority numbers and could use water based on the conditions of their license, even if those conditions are inconsistent with the Water Act. In contrast, new licensees are subject to all the rules of the 1996 Water Act.

While the Water Act made some innovations, notable exclusions from consideration were water rights of First Nations peoples, considerations of water needs for the environment, and lack of effective groundwater regulation. The priority for water use 
by First Nations ${ }^{6}$ is not considered in Alberta's allocation system (Schmidt, 2011). The Act has also been criticized for a 'false division' between surface and ground water, allocating water in absolute quantities and separating water rights from water responsibilities (Schmidt, 2011).

\subsubsection{The Water for Life Strategy}

In 2004, the government of Alberta took an important step towards improving water governance in the province with the creation of the Water for Life strategy. The release of the strategy followed a severe multi-year drought which had elevated Albertans' concerns about water scarcity (Vander Ploeg, 2010). This strategy was produced as part of a requirement under the Water Act to establish a framework for water management planning as well as a strategy for the protection of the aquatic environment in the province.

With the Water for Life Strategy, the Alberta government recognized that the province faced significant and unprecedented pressure on its water supplies, due to population growth, economic development and droughts. Water conservation is one of the key actions listed in Water for Life (Government of Alberta, 2003). Water for Life has the following goals:

- Ensure safe, secure drinking water;

- Protect and maintain the province's aquatic systems; and

- Safeguard reliable, quality water supplies for a sustainable economy.

While the goals and aims of this strategy are clearly a step in the right direction, Water for Life has been criticized for its lack of implementation and lack of legislative backing and lack of enforcement (Block and Forest, 2005; Christensen and Droitsch, 2008). Lack

\footnotetext{
${ }^{6}$ While First Nations water issues in Alberta and the rest of Canada are a crucial public policy problem (Eggertson, 2008; Farahbakhsh and McCullough, 2012; Mascarenhas, 2012; Matsui, 2012; White, Murphy and Spence, 2012; Plummer et al., 2013), they are beyond the scope of this study.
} 
of political will and lack of funding have been cited as two of the shortcomings (Christensen and Droitsch, 2008).

\subsubsection{Strengths of Alberta's Water Governance}

Alberta has been praised for leadership in allowing license holders to trade extra water allocation amounts (Boyd, 2011: 47), a process which encourages conservation. The province has been successful in promoting water use for social and economic benefit, as the system promotes investment in water infrastructure (Canada West Foundation, No Date). Those users with water licenses can make long-term investments knowing that they will have enough access to water in the future to recuperate their investment and reap profits. Alberta's governance strategy has also been praised for a growing recognition of the importance of wise water management (Christensen and Droitsch, 2008).

The Premiers of several western provinces including Alberta have created the Western Water Stewardship Council (Sandford, 2009: 38), which is responsible for preventing, solving and mitigating water-related conflicts. This is an example of management at the watershed level, a governance strategy that has been highly praised in the literature (Deason, Schad and Sherk, 2001; Brandes et al., 2005; Crabbe and LeRoy, 2008; MartinDowns, 2010; Brooymans, 2011).

\subsubsection{Criticism of Alberta's Policy Context}

Alberta's water governance system had been criticized as having little regard for scarcity issues. Water use is not prioritized based on its intended use, but rather the FIT FIR principles. There is little or no incentive to conserve water resources built into the current system (Percy, 1986; Vander Ploeg, 2010). Many of the more senior water license holders were granted licenses in a time when water resources were considered unlimited and unending. Consideration is not given to conservation measures or maintaining flows of water for ecosystems. Alberta has also been criticized for overallocating rights to water resources. For example, water withdrawals for irrigation 
alone are believed to be the cause of an average 30\% decrease of the flow of the South Saskatchewan River (Sandford, 2009: 141).

Over recent years, water flows in Alberta have been lower and less reliable (Canada West Foundation, No Date). In the academic literature, Alberta has been accused of ignoring scarcity issues in the province (Percy, 1986; Vander Ploeg, 2010). In times of scarcity, local ecosystems suffer when water flows are low but water usage stays the same. Also, shortages stemming from depleted groundwater resources have caused areas to turn to piping in water from a distance, which has negative environmental repercussions (Griffiths and Woynillowicz, 2003).

Alberta's policy system has also been criticized for creating inequality between water users, contributing to stakeholder conflicts. In times of scarcity, more junior license holders are restricted from water taking, regardless of intended use, economic or social benefits. The current regime favours the license holders who have held licenses for the longest time without consideration for possible efficiencies, or the economic or social benefits of use by more junior licensees.

Alberta's policy system is both broad and has a substantial amount of ministerial discretion (Percy, 2004). This is considered a criticism because ministerial discretion allows for the potential for nothing to be done if the current Minister so wishes.

The current regime has also been criticized for its licensing complexity (Block and Forest, 2005). The set of rules that applies to a licensee varies depending on when a license was obtained, due to the grandfathering of the rights of early license holders. As mentioned above, lack of implementation of the Water for Life Strategy has been discussed as a weakness of the current governance strategy (Christensen and Droitsch, 2008). 


\subsubsection{Conflicts and Shortages}

The water governance regime in Alberta has been tested by localized scarcity issues (Christensen and Droitsch, 2008). These include conflicts in the southern part of the province that relies heavily on agricultural irrigation (Hienmiller, 2013) and controversy over the use of freshwater by the oil and gas industry (Grant, Angen and Dyer, 2013).

In October of 2006, water scarcity concerns caused the Alberta government to cease offering new water licenses for three major rivers in the province (Christensen and Droitsch, 2008). There was a major water conflict in 2007 in the town of Balzac, a small community to the north of the Calgary (Pollock, 2011). A moratorium on new licenses caused developers to look elsewhere for water supply for a large project. It was proposed that water be piped over two hundred kilometers from the Red Deer River Basin. Public outcry led developers to purchase a portion of a water allocation from an existing licensee (Christensen and Droitsch, 2008). This case was key in initiating the policy response of the province to allow some license trading.

Alberta farmers have adamantly opposed policy changes with respect to these issues. The farmers of Alberta rely heavily on irrigation for their crops. In the past, discussion of the water governance regime in Alberta has sparked the argument from farmers that changing the status quo is an attack on the "history, heritage and economic foundation" of the province (Sandford, 2009: 143).

The current water governance strategy in Alberta has been criticized for lack of regulation of the oil and gas industry's use of fresh water (Griffiths and Woynillowicz, 2003; Kelly et al., 2009; Gosselin et al., 2010; Kurek et al., 2012; Grant, Angen and Dyer, 2013). The industry uses approximately $187 \mathrm{~m}^{3}$ of fresh water annually for the production of bitumen from the oil sands (Canadian Association of Petroleum Producers, 2015). The Athabasca River is the source of extraction for the majority of this water. There is conflict in the province on these issues, with proponents arguing that the freshwater use is necessary for oil and gas industry which is so important for the 
economy. Environmentalists argue that the province is irresponsible to continue approving projects given the heavy extractions and the current context of water quantities in Alberta (Pembina Institute, 2015).

\section{Table 6 - Relevant Alberta Water Governance Mechanisms}

The Alberta Water Act

The Water for Life Strategy

Table 7 - Timeline of Policy Instruments in Alberta

\begin{tabular}{|l|l|l|}
\hline Item & Date & $\begin{array}{l}\text { Events that May } \\
\text { Have Led to the } \\
\text { Policy Response }\end{array}$ \\
\hline $\begin{array}{l}\text { Western Canada adopts FIT FIR system } \\
\text { similar to those found in western US states. }\end{array}$ & $1800 \mathrm{~s}$ & $\begin{array}{l}\text { Settlement of } \\
\text { Western Canada }\end{array}$ \\
\hline $\begin{array}{l}\text { Alberta given legislative power over water } \\
\text { resources with the Irrigation Act and Water } \\
\text { Resources Act. }\end{array}$ & $1930 / 1931$ & $\begin{array}{l}\text { Harsh drought hits } \\
\text { Alberta in the late } \\
\text { 1990s and 2000s }\end{array}$ \\
\hline $\begin{array}{l}\text { The Water Resources Act is replaced with the } \\
\text { Water Act. }\end{array}$ & 1999 & $\begin{array}{l}\text { No policy response } \\
\text { has followed the } \\
\text { identification of this } \\
\text { deficiency }\end{array}$ \\
\hline Water for Life is released & 2003 & 2008 \\
\hline Water for Life is renewed & 2009 & $\begin{array}{l}\text { Alberta Water Council review of Water for } \\
\text { Life concludes that two goals, water } \\
\text { conservation and protection of aquatic } \\
\text { ecosystems, are not being met. }\end{array}$ \\
\hline
\end{tabular}

\subsection{Background Policy Context: British Columbia}

In British Columbia, a key governance player in the current water conservation provincial policy context is the Ministry of the Environment (BC MOE). The BC MOE is divided into two branches, the Water Stewardship Division and the Environmental Protection Division. 


\subsubsection{The British Columbia Water Act}

The primary legislation to protect and manage water in British Columbia is the $B C$ Water Act (Table 8). The Water Act governs water licensing, groundwater well protection and water management. The BC Water Act was initially established in 1909, with the most recent version dating back to 1996 (BC Gov, 2014a). In 2001 the BC Water Act was amended to include protection of groundwater.

The $B C$ Water Act is also the primary legislation with respect to water quantity issues, as it governs water removal rights and water diversions. Management responsibility for the $B C$ Water Act falls to the Water Stewardship Division of the British Columbia Ministry of the Environment.

\subsubsection{BC's Living Water Smart Strategy}

A water conservation strategy called "Living Water Smart: British Columbia's Water Plan" was released in 2008. With the strategy, BC recognizes that "water defines British Columbia" (Sandford, 2009: 45). It is the British Columbia government's vision and plan to protect the province's water resources in the future (BC Gov, 2008). The strategy was created in recognition of the increasing pressures on water supplies in the province from population growth, climate change and the economy (BC Gov, 2014b). The plan includes an overall vision for protecting BC's water into the future, as well as detailed short-term targets to achieve this (Brandes and Curran, 2009: 2). These government commitments are designed to build on existing legal protections for British Columbia's water resources. The goals of the strategy are targeted towards achieving water use efficiencies. An interesting note on Living Water Smart is its recognition of the threat that climate change poses to the future of British Columbia's water resources.

$B C^{\prime}$ s Water Conservation Strategy

The Water Conservation Strategy is a government policy statement that aims to encourage efficient water use, promote the value of the resource and engage 
stakeholders (BC Gov, 2013a). The strategy was created in 1999, with key goals and objectives including improving the efficiency of water use in the province and making available a wide variety of tools and techniques aimed at water efficiency (BC Gov 2014d).

\subsubsection{Proposed Changes: Modernizing BC's Water Act}

The $B C$ Water Act has been criticized as no longer being reflective of the current provincial context. For example, the population in British Columbia has significantly increased, putting a great deal more pressure on the province's watersheds and water resources.

The current $\mathrm{BC}$ water governance system was created when the province was relatively unpopulated, as a means to draw people to the province and promote industry and agriculture (Brandes and Curran, 2009: 1). There were only 350,000 people in the province when the Water Act was created in 1909, compared with 4.6 million people living in the province today (BC Gov, 2014c). The trends of more citizens living in cities than ever before and climate change are expected to exacerbate the situation. The Water Act does not reflect the modern situation in BC in terms of growing water demands and water conflicts. There is recognition of the need for an updated water conservation governance strategy (Nowlan and Bakker, 2007; Brandes and Curran, 2009: 1; BC Gov, 2014f).

A policy proposal for a statute called the Water Sustainability Act was released in 2009 as an initial step to modernizing the Water Act. Work began with the government seeking input on the issues of water sustainability from citizens, stakeholder groups, and First Nations peoples (BC Gov 2014c). The feedback identified concerns about the future of water in the province given the increasing demands on the resource and was a key first step towards reform.

The Water Sustainability Act received Royal Assent in May of 2014. The new Act will replace the old Water Act and make BC a leader in water stewardship. The province is 
in the process of developing supporting regulations for the Act (BC Gov, 2014c). The Act aims to strengthen water governance in the province, manage growing demand, manage groundwater use (a previous governance gap) and ultimately to ensure that future generations of British Columbians have the freshwater they need to thrive. The Water Sustainability Act will strengthen the existing Water Act in seven key areas (BC Gov, 2013c):

- To provide better protection for BC's aquatic environments;

- To consider of water in land use decisions;

- To close the gap of lack of regulation of groundwater resources;

- To regulate of water use in times of scarcity;

- To improve water security and the promotion of water conservation in the province; and

- To measure water use in cases of large extractions.

- To expand the range of governance options utilized by the province.

A great deal has yet to be decided, including the regulations under the Act. Only time will tell how two key steps of the policy cycle - implementation and evaluation - will occur. In addition, specifics of regulations under the Act are still to be determined.

\subsubsection{Other Important Provincial Legislation}

The Water Protection Act is also very pertinent to water quantity issues in $\mathrm{BC}$, as it was created to encourage the sustainable use of water in the province. Specifically, this Act prohibits unlicensed water removals and stipulates the limits to bulk water removals in the province. British Columbia has its own tool to govern the diversion of surface water called Water Licenses and Approvals. In order to divert, use or store water in BC, a license or approval must first be sought from the province under the Water Protection Act (BC Gov, 2013a). There are varying fees associated with water licenses and approvals (BC Gov, 2011). 
There is other provincial legislation relevant to water that is of secondary relevance to water conservation in British Columbia, including the Drinking Water Protection Act, the Fish Protection Act, the Environmental Management Act, the Environmental Assessment Act and the Forest and Range Practices Act. Each of these pieces of legislation have a different focus other than water; however, they have an effect on the governance of water scarcity in the province, even as a secondary measure. For example, under the Fish Protection Act, fifteen streams have been designated as "sensitive" due to concerns over low flow levels and resulting impacts to fish. This is basically the same as the concept of water for ecosystems discussed throughout this paper, so clearly there is some overlap of this legislation and water scarcity issues in the province (Nelitz, M., Douglas T., and Rutherford, M. 2009).

\subsubsection{Issues and Criticism of the Current Policy Context}

Literature has been published that includes criticisms and suggested areas of improvement in the current policy context for water quantity issues in BC. Nowlan and Bakker (2007: 10) noted the following:

- An ad hoc and fragmented approach;

- Lack of watershed-based management opportunities;

- Inequalities across regions with respect to water management; and

- Legislative gaps on important issues such First Nations water matters.

Nestle Canada Controversy and Groundwater Extractions

A recent controversy has British Columbians upset about water extractions. Nestle Canada has been highly criticized in the media for the company's free annual usage of 319.5 million liters of British Columbia's groundwater (Fumano, 2013; Moore, 2013; the Council of Canadians, 2014; Hunter, 2014). The granting of water to Nestle may be especially offensive to some people because the product is essentially unchanged. That is, Nestle removes groundwater, a resource owned by the Crown on behalf of 
Canadians and sells it back to them as "pure and natural spring water" in bottled form (Hunter, 2014).

Nestle Canada is a division of a Switzerland-based, multi-billion dollar company. The situation has brought to light gaps in BC's water governance framework that have allowed the company to profit from the province's lack of regulation of groundwater use, including large volumes.

British Columbia is currently the only province in Canada that does not regulate largevolume groundwater extractions (Moore, 2013). If passed, the Water Sustainability Act would close the loophole and require companies such as Nestle to measure and pay for extractions.

A representative from Nestle indicated that the company was willing to pay for the water use, but drew attention to the lack of clarity in potential changes to the regulatory framework. Moreover, Nestle spokesman John Challinor has met with the BC government specifically regarding the Water Sustainability Act (discussed next) and offered to fund an independent study on water use but no action had been taken to date.

Table 8 shows relevant laws and strategies currently in use in British Columbia.

\begin{tabular}{|l|}
\hline Table 8 - Relevant British Columbia Water Governance Mechanisms \\
\hline The BC Water Act \\
\hline The Water Protection Act \\
\hline The Water Utility Act \\
\hline Living Water Smart Strategy \\
\hline Water Conservation Strategy \\
\hline
\end{tabular}


Table 9 - Timeline of Policy Instruments in British Columbia

\begin{tabular}{|c|c|c|}
\hline Item & Date & $\begin{array}{l}\text { Events that May } \\
\text { Have Led to the } \\
\text { Policy Response }\end{array}$ \\
\hline The BC Water Act is first released. & 1909 & $\begin{array}{l}\text { Settlement of } \\
\text { Western Canada. }\end{array}$ \\
\hline $\begin{array}{l}\text { The Water Protection Act is passed, which } \\
\text { reaffirms provincial ownership of water } \\
\text { resources and governs water licenses and } \\
\text { allocations. }\end{array}$ & 1996 & \multirow{5}{*}{$\begin{array}{l}\text { Increased } \\
\text { environmental } \\
\text { awareness and } \\
\text { prioritization of } \\
\text { water as a } \\
\text { provincial value in } \\
\text { BC. Recognition of } \\
\text { modern threats to } \\
\text { this value and } \\
\text { resource. }\end{array}$} \\
\hline $\begin{array}{l}\text { Water Conservation Strategy, a policy } \\
\text { statement that aims to encourage water } \\
\text { conservation. }\end{array}$ & 1999 & \\
\hline $\begin{array}{l}\text { Water Act amended to include } \\
\text { groundwater. }\end{array}$ & 2001 & \\
\hline Living Water Smart Strategy released. & 2008 & \\
\hline $\begin{array}{l}\text { The Water Sustainability Act receives Royal } \\
\text { Assent. }\end{array}$ & May 2014 & \\
\hline
\end{tabular}

\subsection{Background Policy Context: Ontario}

The current water conservation policy context in Ontario is governed by two provincial governmental departments, the Ontario Ministry of the Environment and Climate Change (MOECC) and the Ontario Ministry of Natural Resources. A number of other key parties have lesser roles in water governance in Ontario as well, including municipalities and conservation authorities. The following is a discussion of the current water policy governance regime in the province of Ontario with a focus on legislation and other policy instruments that govern these issues.

\subsubsection{The Environmental Bill of Rights}

The Environmental Bill of Rights (EBR) is a unique provincial environmental law passed in 1993. The law creates a requirement for the government to consult the public on environmental decisions. Under the EBR, government departments (including the MOECC) are subject to a published Statement of Environmental Values, intended to guide each Minster and staff in decisions that may affect the environment. The EBR is 
included here in the background section as it is relevant to the analysis later in this work.

\subsubsection{The Ontario Water Resources Act}

\section{Permits to Take Water}

A key water allocation mechanism in Ontario is the Permit to Take Water Program (PTTW) under the Ontario Water Resources Act. Since 1961, water users extracting more than 50,000 liters of water per day from a lake, river or stream have been required to obtain a permit to take water from the MOECC. Fees are required to obtain a permit; however, this cost is very small, ranging from $\$ 750$ to $\$ 3000$ (ON Gov, 2005) which was only a fraction of the government's cost to run the program (ON Gov, 2012b).

Exceptions are water taking for fire-fighting, livestock watering and domestic use. These three exceptions are the only three water use priorities specifically mentioned in the legislation (Kreutzwister et. al, 2004). Outside of the three exceptions, remaining water use priorities outlined by the MOECC are municipal water supply, and taking for industrial use, and withdrawals for commercial purposes (Kreutzwister et al., 2004). There are currently over 6100 active permits to take water, most of which are clustered in the more densely populated southern part of the province (Environmental Commissioner of Ontario, 2012b).

Under the Ontario Water Resources Act, Ontario Regulation 387/04 specifies additional details about water takings in the province, such as which watersheds are considered high use and the specific requirements for actions of permit holders. Other Ontario water laws that also affect water takings in the province, if less directly, include the Conservation Authorities Act the Lakes and Rivers Improvement Act and the Drainage Act (Kreutzwister et al., 2004). The federal Fisheries Act could also impact water takings that affect fish in some circumstances. 
The Permit to Take Water Program has been criticized for its inadequacy with respect to environmental protection. Other criticisms of PTTW in the literature include a weak foundation with respect to laws, inexplicit goals, fragmented responsibilities, lack of public input, uncertainties surrounding priorities in water use, impaired stakeholder involvement, lack of monitoring, lack of enforcement and unregistered groundwater extractions (Hofmann and Mitchell, 1995, Leadlay and Kreutzwiser, 1999, Kreutzwister et al., 2004). There are a growing number of leave to appeal complaints via the Ontario Environmental Bill of Rights related to Permits to Take Water (Environmental Commissioner of Ontario, 2001).

Literature has been published on the subject of how to improve the permit to take water process in Ontario. Greater stakeholder input, legally established and more clearly defined water use priorities and a fee structure based on volumes withdrawn have all been suggested by experts as ways to improve the system (Kreutzwister et al., 2004). Some important and tangible suggestions for improving the Permit to Take Water Program have been proposed as part of the Water Opportunities and Water Conservation Act, discussed next. For greater detail and analysis of the Permit to Take Water Program, please see Section 5.3.

\subsubsection{The Water Opportunities and Water Conservation Act}

In 2010, Ontario created a new policy instrument, the Water Opportunities and Water Conservation Act. This legislation aimed to help municipalities improve the efficiency of infrastructure and services, identify new technologies and best practices, optimize existing water systems, and promote water conservation around the province, among other things. A key objective of this legislation is to "conserve and sustain water resources for present and future generations" (MOECC, 2010). Environmental NGOs have praised the enactment of this legislation, indicating that the Act has the potential to save money, energy and water while improving Ontario's economy (Ecojustice, 2010 a and b; Martin-Downs, 2010). Key measures include: 
- Creating accountability through the setting of mandatory reporting and monitoring of targets;

- Appointing a Chief Water Conservation Officer;

- Educating Ontarians about water conservation;

- Requiring conservation plans for all Permit to Take Water Holders;

- Linking water with land use planning; and

- Fostering a culture of water conservation.

Others have criticized the Act as not going nearly far enough to prevent scarcity and promote conservation (Gage, 2014). A key criticism is that the Act is merely permissive; the Act enables the government to create conservation measures through regulations, but will it? It remains to be seen if the Water Conservation and Opportunities Act will make a difference with respect to water conservation in Ontario.

\subsubsection{Proposed Legislation}

\section{Ontario Low Water Response}

The Ontario Low Water Response is a provincial policy that aims to mitigate the impacts of drought through short term strategies to be used in periods of low water (Kreutzwiser et al., 2004). The strategy divides water levels into three categories based on the severity of low water condition and calls for a level of action corresponding to that allocation. Actions range from a request for voluntary water use restrictions to imposition of stipulations. While a provincial policy, the plan assigns important responsibilities to municipalities and conservation authorities (Durley et al., 2003).

\section{Great Lakes Protection Act}

The Great Lakes Protection Act was legislation intended to protect the Great Lakes tabled in 2014 but not yet passed. The Act would have attempted to coordinate current actions to protect the Great Lakes by coordinating groups and promoting collaboration including First Nations, governments, non-governmental organizations and 
environmental groups. If passed, this Act would be part of the larger Great Lakes Strategy.

Table 11 shows selected Ontario legislation relevant to this study while Table 12 lists proposed mechanisms. Table 13 shows important Acts in Ontario and the context that may have led to their creation.

\begin{tabular}{|l|}
\hline Table 10 - Relevant Ontario Water Governance Mechanisms \\
\hline Ontario Water Resources Act (OWRA) \\
\hline Water Opportunities and Water Conservation Act \\
\hline
\end{tabular}

Table 11 - Proposed Ontario Governance Mechanisms

Ontario Low Water Response

Great Lakes Protection Act

Table 12 - Timeline of Policy Instruments in Ontario

\begin{tabular}{|l|l|l|}
\hline Item & Date & $\begin{array}{l}\text { Selected Events that } \\
\text { May Have Led to the } \\
\text { Policy Response }\end{array}$ \\
\hline $\begin{array}{l}\text { Permit to Take Water Program } \\
\text { begins under the Ontario Water } \\
\text { Resources Act. }\end{array}$ & 1961 & $\begin{array}{l}\text { Increased government } \\
\text { regulation of natural } \\
\text { resources. }\end{array}$ \\
\hline $\begin{array}{l}\text { Canada and the USA agree to } \\
\text { protect the mutual water } \\
\text { resources with the Great Lakes } \\
\text { Water Quality Agreement, } \\
\text { focused on water quality. }\end{array}$ & $1972 / 1978$ & $\begin{array}{l}\text { International/National } \\
\text { pressures }\end{array}$ \\
\hline $\begin{array}{l}\text { The Environmental Protection Act } \\
\text { focuses on pollution prevention, } \\
\text { including water. }\end{array}$ & 1990 & $\begin{array}{l}\text { The growing } \\
\text { environmental } \\
\text { movement }\end{array}$ \\
\hline $\begin{array}{l}\text { The Safe Water Drinking Act is } \\
\text { created as part of a policy } \\
\text { response to Walkerton. The } \\
\text { Nutrient Management Act, } \\
\text { governing agriculture } \\
\text { spreading of biosolids is also } \\
\text { passed in response to the }\end{array}$ & 2002 & $\begin{array}{l}\text { In the year 2000, } \\
\text { Ontario residents are } \\
\text { sickened and killed by } \\
\text { a contaminated water } \\
\text { supply in Walkerton. }\end{array}$ \\
\hline
\end{tabular}




\begin{tabular}{|c|c|c|}
\hline tragedy. & & \\
\hline $\begin{array}{l}\text { Ontario signs the Great Lakes- } \\
\text { St. Lawrence River Basin } \\
\text { Sustainable Water Resources } \\
\text { Agreement. }\end{array}$ & 2005 & $\begin{array}{l}\text { International/National } \\
\text { pressures }\end{array}$ \\
\hline $\begin{array}{l}\text { The Clean Water Act is passed, } \\
\text { focused on drinking water } \\
\text { safety. }\end{array}$ & 2006 & The Walkerton tragedy \\
\hline $\begin{array}{l}\text { Ontario amends the Ontario } \\
\text { Water Resource Act with the } \\
\text { Safeguarding and Sustaining } \\
\text { Ontario's Water Act. }\end{array}$ & 2007 & $\begin{array}{l}\text { Amendment allows } \\
\text { Ontario to honour } \\
\text { commitments the } \\
\text { Great Lakes-St. } \\
\text { Lawrence River Basin } \\
\text { Sustainable Water } \\
\text { Resources Agreement. }\end{array}$ \\
\hline $\begin{array}{l}\text { Proposal Paper released: } \\
\text { “Stewardship, Leadership, } \\
\text { Accountability - Safeguarding } \\
\text { and Sustaining Ontario's Water } \\
\text { Resources for Future } \\
\text { Generation" including } \\
\text { proposed conservation } \\
\text { objectives, as required under } \\
\text { the Great Lakes-St. Lawrence } \\
\text { River Basin Sustainable Water } \\
\text { Resources Agreement. }\end{array}$ & 2009 & \multirow[t]{3}{*}{$\begin{array}{l}\text { Increased awareness of } \\
\text { threats to Ontario's } \\
\text { water, including } \\
\text { population growth and } \\
\text { climate change }\end{array}$} \\
\hline $\begin{array}{l}\text { Water Opportunities and Water } \\
\text { Conservation Act comes into } \\
\text { effect. }\end{array}$ & 2010 & \\
\hline $\begin{array}{l}\text { The Great Lakes Water Quality } \\
\text { Agreement between Canada } \\
\text { and the US updates the original } \\
\text { agreement. }\end{array}$ & 2013 & \\
\hline $\begin{array}{l}\text { The Great Lakes Protection Act is } \\
\text { proposed, but not passed }\end{array}$ & 2014 & $\begin{array}{l}\text { International/National } \\
\text { pressures }\end{array}$ \\
\hline
\end{tabular}




\section{CHAPTER V - POLICY CONTEXT EVALUATION: ALBERTA, BRITISH COLUMBIA and ONTARIO}

This Chapter details the evaluation of selected water policy contexts of Alberta, British Columbia and Ontario. To evaluate each context, key policy instruments were selected for their relevance in governance related to scarcity. Due to limited space, only the most germane policy instruments to address water scarcity issues were evaluated. The policy instruments selected for evaluation are the following: Alberta's Water for Life Strategy, BC's Living Water Smart Strategy, BC's proposed Water Sustainability Act, and Ontario's Permit to Take Water Program (PTTW).

For each policy instrument selected, the analysis is conducted with the aid of selected evaluation criteria. Please refer to Chapter II for definition of the criteria and rationale for their selection. The criteria are clearly defined scope, impact, feasibility and operational practicality, flexible toolkit, engagement with the public and stakeholders, data collection and reporting, performance measures and targets, monitoring, enforcement and evaluation. Please note that it is the policy contexts that are evaluated in this chapter. Evaluation of the performance of these policy instruments is beyond the scope of this study.

\subsection{Policy Evaluation - Alberta}

\subsubsection{Context: The Alberta Water for Life Strategy}

In 2003, the Alberta Government released the Water for Life Strategy ("the Strategy" or "Water for Life") a plan and commitment to safeguard the province's water. The Strategy was created as part of a requirement under the Water Act, as a policy response to a long drought and increased public concern over water in the province, and following government approval of a number of projects with sustainable water supply impacts. 
The Strategy is an excellent example of shared water governance, as defined in Nowlan and Bakker (2010). Shared governance is a structure where governments share responsibility for the development and delivery of programs and policy with other stakeholders. General advantages of this style include the empowerment of stakeholders, adaptability to local conditions and access to local expertise (Nowlan and Bakker, 2010). Disadvantages are that this style of governance often takes longer to implement, costs more and can lead to options that please most parties rather than being optimal from an environmental perspective due to an emphasis on consensus (Nowlan and Bakker, 2010). The analysis of Water for Life follows, under a category heading of each of the evaluation criteria.

\section{Clearly Defined Scope}

The three goals of the Water for Life Strategy are published on the Water for Life website. The goals of the Strategy are safe, secure drinking water for Albertans, healthy aquatic ecosystems and reliable, quality water supplies for a sustainable economy. The Alberta Government plans to achieve these goals through research, the use of partnerships and the promotion of water conservation (AB Gov, 2015).

Water for Life is a broad and general framework. For example, detailed watershed planning for each basin in Alberta is not included within Water for Life (Saunders and Vlavianos, 2010) but the overall blueprint and high level priorities are strong and clearly defined. A key action with respect to scarcity published as part of Water for Life is to set conservation objectives for the major basins in the province. This is an important step for scarcity prevention in Alberta. It is also telling of just how little attention has been given to scarcity issues previously. When the conservation objectives are set, conflict among stakeholders is likely to emerge, as water issues are almost always contentious.

Impact 
As an umbrella plan, the Water for Life Strategy has the potential to create significant, positive change in Alberta with respect to water scarcity prevention. If the Strategy's series of strong water-related goals are fully realized, a high degree of positive change is possible (Bjornland, Nicol and Klien, 2007; Saunders and Vlavianos, 2010). However, there is currently an implementation gap that has hindered the Strategy from successfully achieving its goals. A great deal more effort and funding is required to fully implement Water for Life (Block and Forest, 2005; Christensen and Droitsch, 2008). Detailed plans, legislative commitments and funding are all currently lacking.

\section{Feasibility and Operational Practicality}

Water for Life names partner institutions tasked with implementing the Strategy (Saunders and Vlavianos, 2010). A great deal of responsibility is out of the hands of the province. The governance by local-level organizations has been described as fragmented, and underfunding is an ongoing issue (Hill et al., 2008).

Partnership organizations which include local Watershed Planning Advisory Councils (WPACs), Watershed Stewardship Groups, and the Alberta Water Council are responsible for the overall implementation of the Strategy (Saunders, 2010). However, the details of how these partner organizations plan to reach the ambitious goals of Water for Life are not clear. In addition, it is unclear if funds will be made available for these organizations to conduct the work or what government oversight will be provided, if any. Another question is whether the Alberta government will be accountable should the partner organizations fail to implement the Strategy.

\section{Flexible Toolkit}

As a vision statement, Water for Life follows the ecosystem approach to water management, operating at the watershed level (Hill et al., 2008) calling on numerous government departments to achieve the Strategy. For example, Alberta Environment and Water, Alberta Agriculture and Rural Development, Alberta Energy and Alberta Municipal Affairs are, in part, responsible to achieve the goals of the Strategy. Water 
for Life encompasses a great deal of flexibility that allows for adaptation to changing conditions and local needs (Nowlan and Bakker, 2010). A challenge stemming from this approach is the risk of fragmented implementation.

The Government of Alberta shares water governance with other institutions, for example the Alberta Water Council, a diverse stakeholder group that is mandated to aid in the overall implementation of Water for Life in Alberta. The Council is meant to be the mechanism through which citizen consultation on water issues in the province occurs (Saunders and Vlavianos, 2010). Advantages of partnerships with other institutions such as these include the wide breadth of ideas and perspectives brought to the decision-making process, the empowerment of stakeholders, and the potential for great local “buy-in” (Nowlan and Bakker, 2010).

\section{Engagement with the Public and Stakeholders}

Water issues commonly have stakeholders with conflicting interests (Mahmoud et al., 2009; Black, Wallbrink and Jordan, 2014). Stakeholder involvement is a very important evaluation category for this study. The province of Alberta engaged with stakeholders for two years prior to the publication of Water for Life plan (Taylor, 2009).

In 2013, the province put a renewed emphasis on conversing about water with Albertans, including key stakeholders (AB Gov, 2014b). This included community meetings, social media use, specific stakeholder meetings and an online survey about Water for Life. While these efforts are positive, more could and should be done. For example, given the established link between water use by the agricultural sector and total water use in the province, engagement with that key stakeholder group is especially important. There is currently no process for conflict resolution nor are there hearing mechanisms available, which are significant deficiencies given the contentious nature of water scarcity issues. 


\section{Data Collection and Reporting}

The Alberta Water for Life website lists the creation of the Water Use Reporting System as a major accomplishment to date (AB Gov, 2015). This reporting system allows water license holders to report their daily, monthly or annual water takings online. Reporting is currently done on a voluntary basis. The Alberta Water Council has recommended this reporting be mandatory. The Strategy also lists an important milestone; the creation of an online groundwater mapping initiative. Currently, coverage of this initiative is limited to land between the two major cities, Calgary and Edmonton.

\section{Performance Measures and Targets}

Water for Life lays out short, medium and long-term goals, which are useful for measuring performance. The most recent publications listed short-term goals as those requiring completion in 2012, medium-term goals as those requiring completion by 2015 and long-term goals as those with a deadline of 2019. In 2003, Alberta committed to increasing the overall productivity and efficiency of water use by $30 \%$ by 2015 , as compared with 2005 levels. Information was not published on Alberta's success or failure at reaching this target. However, based on a 2012 review of the Strategy by the Alberta Water Council, it is likely that Alberta failed to make this target.

Unfortunately, the Strategy lacks any legislative mandates or government timelines to create law to support the Strategy. For this reason, Water for Life has been described as lacking "teeth" (Saunders and Vlavianos, 2010). Enforcement options for a strategy will be much weaker, if present at all, as compared to legislation A strategy is generally very broad - simply a policy intent or direction by a government. Often laws are one component of a government strategy. In contrast, a law has repercussions for those that contravene this more detailed policy instrument. Repercussions can range from simple measures like fines to those that would be interpreted in a court of law. The addition of legislation under the Strategy would force the government to develop details with 
respect to how the goals of Water for Life objectives would be achieved. An example is BC's creation of the Water Sustainability Act under the Living Water Smart plan.

\section{Monitoring and Enforcement}

In 2009, a project called the Integrated Monitoring, Evaluation and Reporting Framework Project began under the Strategy (AB Gov, 2012). This project was meant to create a comprehensive system that, in part, will improve monitoring and enforcement not only for water issues but also for land use, biodiversity and air. This project was ultimately meant to build a system that will provide monitoring, evaluation and transparent reporting (AB Gov, 2012). Even six years later, the system is merely at an "idea" stage. The only action thus far has been to appoint a panel of experts to brainstorm how to create such a comprehensive system. Water for Life would be greatly improved if the comprehensive system is created and fully implemented.

\section{Evaluation}

In general, the Strategy is lacking government expectations, timelines and built-in evaluation mechanisms. Evaluation specific to water conservation and water scarcity is currently non-existent.

The Alberta Water Council conducted a review of the Strategy's implementation to date, published in 2012. The Council concluded that four of the six original elements of Water for Life are on track. Most relevant to this work and scarcity issues are the two categories given a failing grade: water conservation and healthy ecosystems. These are two categories consistently stressed as important in the literature in order to prevent scarcity (Forest and Block, 2005; Christensen and Droitsch, 2008; Sandford, 2009: 141, Vander Ploeg, 2010; AB Gov, 2012).

\section{Conclusion}

The Water for Life Strategy has laid groundwork that could allow Alberta to proactively govern scarcity in the province, encourage conservation and show water leadership in 
Canada. However, Water for Life is likely underachieving with respect to water scarcity issues and water conservation. Much more needs to be done to implement the Strategy. Alberta continues to undervalue and take for granted water in spite of the province's reliance on irrigation for agriculture, semi-arid climate and drought vulnerability. The Water for Life Strategy is a strong umbrella plan, but in order to minimize costs, protect the environment and prevent scarcity, Alberta must turn that plan to tangible action.

\subsection{Policy Evaluation - British Columbia}

\subsubsection{Context: BC's Living Water Smart Strategy}

The Living Water Smart Strategy (the "Strategy" or "Living Water Smart") is a policy instrument of paramount importance to water in British Columbia (Sandford, 2009: 45). Living Water Smart is the British Columbia government's plan of action to protect the province's water resources now and in the future (BC Government, 2008).

A key action of Living Water Smart is to modernize the province's water laws with the proposed Water Sustainability Act. The proposed Act is evaluated below, following the assessment of Living Water Smart.

\section{Clearly Defined Scope}

The scope of Living Water Smart is clearly defined on the BC MOE website dedicated to the plan. This includes the following key intentions (BC Gov, 2014b):

- protection of sources of drinking water, strengthening flood and drought protection measures and preparing for climate change;

- protection and rehabilitation of wetlands and waterways;

- modernization of water laws;

- development of strong water efficiency targets and working with all sectors to achieve them; and 
- securement of funding for scientific study in order to be better prepared for the impacts of climate change.

Impact

The implementation of Living Water Smart has the potential to lead to significant positive change in preventing scarcity and conserving water. If fully implemented, BC's Living Water Smart could make the province a world leader in water conservation and protection. The term "significant" is used here with consideration given to the definition in Chapter II. Positive change is expected in both short and long term timeframes.

Unfortunately, when it was first released, the BC Government was slow to implement the Living Water Smart Strategy, especially following the economic downturn of 2008. However in recent years, efforts and funds to implement the policy have increased (Sandford, 2009: 47).

\section{Feasibility and Operational Practicality}

Implementation of the Strategy is practical from a feasibility perspective and from an administrative perspective. This includes each of the different components of the Strategy. Substantial funding is needed in order to carry out the plan to achieve the goals of Living Water Smart.

\section{Flexible Toolkit}

Living Water Smart includes a wide variety of approaches to achieve the goals of the policy instrument. The key achievements, discussed below, are demonstrative of the flexibility and adaptability incorporated in this policy instrument. Other provinces could learn a great deal from the exemplary flexible and diverse toolkit that this policy instrument includes. 


\section{Engagement with the Public and Stakeholders}

The province of $\mathrm{BC}$ underwent a multiyear stakeholder engagement process prior to releasing the Living Water Smart Plan (Nelitz, Douglas and Rutherford, 2009). The BC government has continued to encourage citizens to engage in the principles of the plan. This includes simple measures like a Living Water Smart blog that encourages public questions, comments and stories to promises of future planning that works with First

Nations and local watershed groups. Delivery of Living Water Smart involves numerous government ministries and many other stakeholders. The Minister can establish a process to engage local water planning in a designated area, at his or her discretion (Nowlan and Bakker, 2010). However, this is on a case-by-case basis and not mandatory.

\section{Data Collection and Reporting}

British Columbia has a strong mechanism for data collection and reporting which includes Living Water Smart. The statement in the plan "we can't manage what we don't measure" (BC Gov, 2008: 27) demonstrates the recognition of the importance of data collection and reporting. With the website "Environmental Reporting BC", the BC government aims to make available unbiased scientific data relevant to the environment. These data are intended to benefit policy-makers, decision-makers and the public. Several of the data collection tools achieved by the policy are discussed next.

\section{Performance Measures and Targets}

The Living Water Smart website lists multiple achievements of the policy instrument to date. The following are some of the key achievements:

- The development of the Water Science Strategy, a collaborative multistakeholder effort intended to share information and research on water science.

- The creation of the Drought Response Plan, a key scarcity prevention piece that helps to make the province a leader in the prevention of water scarcity issues in 
Canada. The Drought Response Plan aims to specify priorities and actions to be taken before, during, and after times of drought in order to minimize the impact of the drought (BC Gov, 2010a).

- The creation of the Water Balance Model, a tool to promote sustainability through rainwater management. The tools functions on a community scale, evaluating the effectiveness of applying storm water source controls.

- Efforts to create greater water efficiency in the irrigated agriculture sector, with two tools, the Agricultural Water Demand Model and the Irrigation Scheduling Calculator. These tools aim to help decrease the amount of water used for irrigation in the province with the help of data for decision-making.

- The passing of the Water Sustainability Act is a significant accomplishment.

The Strategy is bold and forward-thinking with its conservation-based targets and defined milestones for action. By 2015, the government plans to develop a tool to incorporate the use of aboriginal traditional knowledge in decisions on water (Nelitz, Douglas and Rutherford, 2009). By 2020, the BC government plans to work toward the goal of having water use in BC become $33 \%$ more efficient that it is curretly, with $50 \%$ of new urban demand met through conservation (BC Gov, 2015).

\section{Monitoring and Enforcement}

The Living Water Smart policy proposal claims that this instrument includes a robust framework for enforcement and compliance assurance. The power and responsibility of enforcement is held entirely with the provincial government. A key piece of enforcement will be created as part of the Water Sustainability Act, which is discussed below.

\section{Evaluation}

With Living Water Smart, the British Columbia government has built in two specific commitments for water conservation that include specified timelines. This will be 
useful data for evaluating the success of the policy instrument in the future. The targets are $33 \%$ more water efficient by 2020 , with $50 \%$ of new municipal demand met by conservation measures by the same year.

There are also a number of other specific government commitments under the plan that are useful in the evaluation of the policy instrument. Table 13 summarizes provincial government commitments under the plan. Quite a few of the commitments have delays with respect to the government's original deadlines.

Table 13 - Key BC Provincial Commitments Under Living Water Smart

\begin{tabular}{|l|l|}
\hline Commitment & Committed Date \\
\hline $\begin{array}{l}\text { Education of land and water managers on } \\
\text { healthy streams. }\end{array}$ & 2012 \\
\hline $\begin{array}{l}\text { Improvement of provincial water legislation to } \\
\text { consider ecosystem requirements. }\end{array}$ & 2012 \\
\hline $\begin{array}{l}\text { Initiation of regulation of provincial } \\
\text { groundwater sources in key areas and for } \\
\text { large withdrawals. }\end{array}$ & 2012 \\
\hline $\begin{array}{l}\text { Require all large water users to measure } \\
\text { takings. }\end{array}$ & 2012 \\
\hline \begin{tabular}{l} 
Improve water efficiency provincially by 33\%. \\
\hline $\begin{array}{l}\text { Meet half of municipal demand through } \\
\text { conservation efforts. }\end{array}$
\end{tabular} & 2020 \\
\hline $\begin{array}{l}\text { Introduction of new water management } \\
\text { practices that consider the changing water } \\
\text { cycle and climate change. }\end{array}$ & 2012 \\
\hline $\begin{array}{l}\text { Mandate water efficiencies in new } \\
\text { construction projects. }\end{array}$ & 2010 \\
\hline $\begin{array}{l}\text { All school children are to have at least one } \\
\text { learning session on the topic of stream health. }\end{array}$ & 2012 \\
\hline Set and implement a direction for water & 2010 \\
\hline
\end{tabular}


science in BC.

Publish a document on the state of $\mathrm{BC}$ water

Beginning in 2012

every five years, beginning in 2012.

5.2.2 Context: The BC Water Sustainability Act

The Water Sustainability Act is legislation proposed under the Living Water Smart Strategy that would make BC the leader in conservation-related water legislation in Canada. In late 2014, the Water Sustainability Act passed the third reading and received Royal Assent. Provisions in the Act come into force as defined in the Act in Section 29 (Table 14). Significant portions of the Act come in to force at the discretion of the Lieutenant Governor in Council via regulations.

Table 14 - Provisions of the Water Sustainability Act.

\begin{tabular}{|c|l|l|}
\hline Item & $\begin{array}{l}\text { Column } 1 \\
\text { Provisions of Act }\end{array}$ & $\begin{array}{l}\text { Column } 2 \\
\text { Commencement }\end{array}$ \\
\hline 1 & Anything not elsewhere covered by this table & The date of Royal Assent \\
\hline 2 & Sections 1 to 144,146 to 175 and 177 to 214 & $\begin{array}{l}\text { By regulation of the Lieutenant } \\
\text { Governor in Council }\end{array}$ \\
\hline 3 & Section 215 & $\begin{array}{l}\text { On the date the Drainage, Ditch and } \\
\text { Dike Act, R.S.B.C. 1996, c. 102, is } \\
\text { repealed }\end{array}$ \\
\hline 4 & Sections 216 to 218 & $\begin{array}{l}\text { By regulation of the Lieutenant } \\
\text { Governor in Council }\end{array}$ \\
\hline
\end{tabular}

\section{Clearly Defined Scope}

BC's proposed policy context has a clearly defined scope that aims to improve BC's regulatory water context in seven key areas. The seven areas are:

- protection of stream health and aquatic environments;

- consideration of water in land-use decisions; 
- regulation and protection of groundwater;

- regulation of water use during times of scarcity;

- improvement of security;

- improvement of water use efficiency and conservation; and

- measurement and reporting of large-scale water use and provision of a range of governance approaches.

This policy instrument has the potential to make British Columbia the premier forwardthinking province with respect to water scarcity. An employee of the University of Victoria Environmental Law Centre described it as, "Overall, one of the best pieces of environmental legislation in the past 15 years" (Gage, 2014). The Act recognizes that water in British Columbia is of utmost importance and is also under pressure.

\section{Impact}

The components of the Act, discussed next and summarized in Table 15, have the potential to make significant positive change in British Columbia.

Table 15 - Key Sections of the Water Sustainability Act

\begin{tabular}{|l|c|}
\hline Measure & Section of the Act \\
\hline Water for ecosystems & 15,87 \\
\hline Mitigation measures & 16 \\
\hline Review of license terms and conditions & 23 \\
\hline Water reservations & 39 \\
\hline Water sustainability plans & $64-85$ \\
\hline Temporary protection orders & $86-88$ \\
\hline Enforcement measures & $89-113$ \\
\hline Groundwater protection measures & $48-63$ \\
\hline
\end{tabular}

Water for Ecosystems and Temporary Protection Orders: The Act has built-in protection of water for ecosystems (called environmental flow needs) in Section 15, as well as Sections 86-88, temporary protection orders. Section 15 mandates that decision makers consider water for ecosystems in the assessment of water license applications. Another 
key provision is the requirement that the amount of water flow required for the environment actually be calculated. However, there is a provision that exempts the decision makers from considering water for an ecosystem under regulation. It not yet clear what might be exempted, just that this power lies with the Lieutenant Governor in Council. Temporary protection orders also have a second discretionary component. If the Minister considers a stream to be at risk of falling below its critical flows of water for ecosystems or putting fish at risk, he or she can make a temporary order. With an order in force, an area's water comptroller ${ }^{7}$ must determine if the stream or streams in question meet three criteria: (1) regional significance of the stream, (2) water is being diverted from that stream or a connected aquifer under the Act, and (3) granting water priority to that stream would assist in preventing significant or irreversible harm to the aquatic ecosystem. If all three criteria are met, the comptroller may then determine the amount of water to be allocated to the stream based on degree of benefit to the aquatic environment. The requirement to calculate water for ecosystems would be greatly improved if the requirement included existing license holders. It currently applies only to new applicants.

Mitigation Measures: A decision maker8 can request a plan for mitigation measures if a water license is likely to cause a significant adverse effect to aquatic ecosystems. Measures could be taken for that stream or could be compensatory (a different stream). Once again this demonstrates a recognition of the importance of water for ecosystems and provides a level of protection.

Review of License Terms and Conditions: Section 23 details a review requirement of license terms and conditions for long-term licenses that were issued before the Act. Permit holders with a remaining term of thirty years or more will undergo this review, with a few exceptions (for example, water used for power generation). If a license

\footnotetext{
7 Under the BC Water Act, a comptroller is defined as "as person employed by the government or a government corporation and designated in writing by the minister as the Comptroller of Water Rights and includes any persons designated in writing by the minister as acting, deputy or assistant comptrollers"

${ }^{8}$ Defined as "the person authorized to make the decision under the Act".
} 
holder has this review requested, the holder must submit self-assessment information, including a water conservation audit. The specific requirements of a water conservation audit are to be defined in regulations. This has the potential to be a powerful tool to conserve water.

Water Reservations: The Lieutenant Governor in Council $^{9}$ can chose to reserve all or part of the water in a stream or aquifer. In addition, he or she can enable a person to investigate the suitability of a stream or aquifer for specified use and retain water for the Crown. There are some exceptions, for example agricultural water. These exceptions aside, this is another possible protection for water in ecosystems.

Water Sustainability Plans: Water Sustainability Plans are not new to BC (Gage, 2014), however this new law will make them a more powerful tool. Plans were originally developed as a watershed management tool, as well as created out of concern for fish population health. With section 87 of the Act, $\mathrm{BC}$ recognizes that surface water and groundwater are interconnected and that it is crucial to use each in a sustainable manner (Christensen, 2015). An interesting component of the new Act is that other statutes can be superseded in order to implement the plans. The changes have the potential to make these plans an even more powerful tool in the effective management of watersheds.

Groundwater Regulation and Protection: A key gap in BC's water governance regime will be closed: the of lack groundwater regulation in the province. This alone is a significant improvement over the current policy context, but other positive impacts are expected as well. Currently, groundwater is exempt under the Water Act and only surface water can be regulated in times of scarcity (BC Gov, 2013c). Groundwater will no longer be exempt from regulation with the addition of the Water Sustainability Act.

The Water Sustainability Act requires governments to consider water for ecosystems when making decisions about water use (Gage, 2014). This stipulation includes a

${ }^{9}$ The Lieutenant Governor in Council is the head of the Cabinet of the BC provincial government. 
requirement to calculate the amount of water needed for stream flow. However, an important gap is that current water license holders are not bound to this requirement. Another limitation is that exceptions are possible through regulation; however, details of the regulations have yet to be published.

The fundamental FIT FIR framework that BC operates will not be changed with the new Act. The continuance of the FIT FIR framework has been criticized (Gage, 2014).

\section{Feasibility and Operational Practicality}

This proposed policy context fits well with the existing water governance regime in BC. The new legislation would upgrade, modernize and improve current provincial water laws. From an operational and administrative perspective, the implementation of the Act will take efforts and funds due to the multifaceted nature of the policy instrument.

\section{Flexible Toolkit}

This policy instrument is intended to enable a range of approaches to water governance in the province (BC Gov, 2013c). Increased governance flexibility is planned, with greater delegation to partnerships while maintaining a clear and consistent provincial framework. The Act is intended to be just one tool within a dynamic water governance toolbox that includes non-statutory components as well.

\section{Engagement with the Public and Stakeholders}

A requirement under Section 68(1)f of the proposed Act states that "the terms of reference for a proposed water sustainability plan must include a process for public and stakeholder communications and consultations which process must meet any prescribed minimum requirements." This is in reference to the water sustainability plans required under the Act. However, some concern has been expressed that the public process was not expanded as part of this legislation (Gage, 2014). 


\section{Data Collection and Reporting}

Section 131 of the proposed Act allows the Lieutenant Governor to make regulations under the Act with respect to measuring, testing and reporting. Additionally, local governments would have data collecting and reporting responsibilities as well. The Water Science Strategy is a key mechanism for monitoring and reporting as well. It is intended to facilitate water-related knowledge and information between groups such as scientists, water-based organizations and policy makers. This would be a key data collecting and reporting mechanism under the Act.

\section{Performance Measures and Targets}

The Act includes a provision for the creation of regulations that will constitute key performance measures and targets. This includes the setting of water conservation targets and carrying out audits to measure the performance of water used in meeting those targets (BC Gov, 2013c). The Water Sustainability Act and Living Water Smart work together in an attempt to achieve British Columbia's greater water conservation goals.

\section{Monitoring and Enforcement}

Enforcement is a strong component of the Act with powerful and diverse tools available. Offenses under the Act range from general offenses to high penalty offenses. High penalty offenses can lead to enforcement measures that include imprisonment and fines up to one million dollars a day in some circumstances. Also available as enforcement measures are administrative monetary penalties. Refer to Chapter III for a discussion of AMPs as a policy instrument.

\section{Evaluation}

The Act itself, as a policy instrument, does not have an evaluation mechanism embedded. However, evaluation with respect to overall water governance will be included with an evaluation of Living Water Smart and BC's water conservation goals. 


\section{Other Anticipated Challenges}

While this Act has many anticipated advantages, it is likely to causes challenges are well. Criticism of the Act has come primarily from NGOs that believe the British Columbia government missed an opportunity by not taking the Water Sustainability Act far enough. Key criticisms are summarized as follows (Gage, 2014):

- Discretion on behalf of the Lieutenant Governor in Council concerning the creation of regulations is key to the coming of force of significant portion of the Act.

- Retention of the FITFIR system;

- Creation of a new power for the BC government to grant short-term approvals of water for use in fracking; and

- Exclusion of increased public process suggested in an early version of the Act.

\section{Conclusion}

The province of $\mathrm{BC}$ is very forward-thinking in this multifaceted approach to tackling these complex issues, stakeholder outreach and more. With Living Water Smart and the new Water Sustainability Act, the province of British Columbia has risen to the forefront of Canada's water scarcity prevention leadership. Challenges remain ahead, including the creation of regulations under the Act.

\subsection{Context: Ontario's Permit to Take Water Program}

Ontario's Permit to Take Water Program requires users extracting 50,000 liters of water per day or more to apply for a permit from the Ministry of the Environment and Climate Change. The PTTW policy instrument is based in legislation, the 1990 Ontario Water Resources Act and Ontario Regulation 387/04. Eligible extractions include both surface and groundwater, with a few exceptions. For example, water for firefighting is exempt from permitting. 
The general public has also expressed concern about the PTTW system, including a lack of transparency and concern over the cumulative and individual amounts of water extracted from Ontario's watersheds. In 2001, the Environmental Commissioner of Ontario criticized the PTTW following a review triggered by the Walkerton tragedy. The Commissioner found inconsistencies in the Ministry's application of an ecosystem approach, regional differences of PTTW evaluation of applications, and lack of consideration for the amount of available water in a watershed when granting permits (Environmental Commissioner of Ontario, 2001).

Recently, Ontario posted to its website the intention to enhance the PTTW system, which has been the subject of negative feedback for years. Specifically, the MOECC intends to ensure that the water takings under the PTTW system are managed to the standards of the Great Lakes-St. Lawrence River Basin Sustainable Water Resources Agreement, which is an agreement between the Great Lakes states and provinces to protect the lakes. Within this agreement, individual states and provinces are in agreement to create local programs and legislation to protect the Great Lakes. The agreement is a "good faith" agreement, which means that each of the states and provinces are trusting each other to take action, but are not legally bound to do so.

\section{Clearly Defined Scope}

Ontario's Permit to Take Water Program has been criticized in the literature for a lack of clearly defined scope and the absence of explicit goals (Kreutzwister et al., 2004). Information regarding the scope of the PTTW water system is not posted on the Ministry and the Environment and Climate Change website. Based on the literature, scarcity issues have not been addressed within the PTTW system at all. Without goals intended to prevent scarcity or consider water quantities, it is very hard to picture Ontario successfully dealing with these issues. 
Impact

The PTTW policy instrument has not led to significant change (Kreutzwister et al., 2004). It has been criticized for its lack of direction, deficiency of leadership in defining water use priorities and a shortfall in environmental protection (Hofmann and Mitchell, 1995, Leadlay and Kreutzwiser, 1999, Kreutzwister et al., 2004). There is a growing number of leave to appeal complaints via the Ontario Environmental Bill of Rights (EBR) related to Permits to Take Water (Environmental Commissioner of Ontario, 2001).

\section{Feasibility and Operational Practicality}

Ontario's PTTW program has been managing water extractions since the program's inception in 1961. The system has been implemented for a long period of time, which demonstrates feasibility from operational and administrative perspectives. There have been some challenges with operational practicality as demonstrated by the criticism of regional differences in applying PTTW. Another criticism is that the program costs far more to operate than it recovers from users (ON Gov, 2012b). However, in spite of being feasible, this policy instrument has little value.

\section{Flexible Toolkit}

This system does not have a flexible toolkit to adapt to changing situations. For example, Ontario does not adapt the number of permits issued or volumes allowed based on local conditions to watershed volumes, or number of existing permits of uses in a particular watershed. No consideration for the widely-cited predicted impacts of climate change on scarcity are included.

\section{Public and Stakeholder Participation}

The Permit to Take Water Program has been criticized for its lack of transparency and inadequacy with respect to allowing stakeholders or the public to participate in the process. In addition, municipalities in Ontario have complained about lack of citizen 
involvement, and marginal economic benefits for the municipalities where the water is being extracted (Hoffman and Mitchell, 1995).

\section{Data Collection and Reporting}

Permit holders must report their daily takings on an annual basis via an online system. In the past, reporting was voluntary and before that, not required at all. It is not clear what, if any repercussions or enforcement actions are faced should a permit-holder fail to report. Tracking and recording daily use is the responsibility of the permit holder. Due to the 50,000 liter per day threshold, the province would not have data on cumulative takings, each individually less than this amount.

In a 2001 review, the Environmental Commissioner of Ontario found that PTTW staff used a mix of metric and imperial measurement units, creating complication in tracking, assessing and managing volumes. The Commissioner also identified a major failing of the PTTW with respect to scarcity. Staff granted permits without the data to have a clear picture on the state of existing takings (Environmental Commissioner of Ontario, 2001). Overall, data collection and reporting for this policy instrument is very weak.

\section{Performance Measures and Targets}

Ontario's PTTW does not set measures or targets for performance. This is closely linked with criticisms that this policy instrument does not protect Ontario's freshwater or have any mechanism to encourage conservation.

\section{Monitoring and Enforcement}

The academic literature has described monitoring and enforcement measures of the PTTW system as "virtually non-existent" (Kreutzwiser et al., 2004). The MOECC does state that anyone contravening the terms and conditions of a permit are guilty of an offense. Further, the ministry does inspections in order to confirm compliance (ON Gov, 2013b). Information on the number of inspections and enforcement outcomes was 
not available. The MOECC likely does not publish this information. The PTTW system does not have diverse enforcement measures, for example, a toolkit that includes a range of options, from warnings to administrative monetary penalties is lacking. Enforcement of PTTW is made difficult by the weak legal foundation of the policy (Leadley and Kreutzwiser, 1999).

\section{Evaluation}

The PTTW does not have a built in mechanism to evaluate the policy instrument. This weakness may have contributed to the PTTW remaining as the primary water allocation mechanism in Ontario for so long. Without goals, targets and measures, it is more difficult to demonstrate that the PTTW system is underperforming.

Conclusions

Ontario's Permit to Take Water Program is out of date, directionless and failing to protect or effectively manage Ontario's water. 


\section{CHAPTER VI - POLICY RECOMMENDATIONS and EXPERIENCES FROM OTHER JURISDICTIONS}

This chapter focuses on policy recommendations for the provinces of Alberta, British Columbia and Ontario. Relevant experiences from international jurisdictions that support the policy recommendations are also included.

International jurisdictions have been selected where value and applicability was found from the experiences of those regions. A limited number of regions were selected due to the finite scope of this study. For rationale for jurisdiction selections, evidence of policy convergence and background information on the selected jurisdictions, see Sections $4.2,4.3$ and 4.4 .

\subsection{Best Practices or Principles for all Jurisdictions}

To start the chapter, best practices are discussed first. These are recommended for any jurisdictions, including the three selected Canadian provinces. A recommendation for stronger federal leadership is also discussed.

\section{National Leadership}

It is recommended that Canada step forward at a federal level to assume national leadership on these issues. All the provinces would benefit from stronger leadership at the federal level. Climate change will alter the water cycle, so national leadership will be needed in order to smooth conflicts between provinces over shared water resources. Other benefits include increased accountability with increased stakeholder participation in governance, strengthened capacity to respond to crises affecting all Canadians, and increased resources and ability to target public awareness.

This recommendation is supported by the much stronger national leadership on water issues demonstrated in the USA and Australia. Each offer Canada examples of strong federal leadership in association with regional powers. A key challenge would be limits of the powers of the federal government as per the Canadian Constitution. 


\section{Prioritize Action Now}

Of the international jurisdictions researched, many had reactionary, slow policy responses following negative events such as lasting droughts, water shortages and intense stakeholder conflicts. In California, drastic measures like shipping fresh water vast distances are the norm, and policy responses are lacking. It is recommended that Canada address the looming scarcity threat and create policy change now. This could prevent the hardship of physical scarcity but also minimize the high economic and environmental costs and reduce the risk of stakeholder conflicts. Canada cannot afford to risk continuing the ways of poor water management and fragmented governance.

\section{No Silver Bullets}

There is no single perfect solution or "silver bullet" when it comes to water governance (Gleick et al., 2003:17). No single solution will "fix everything" with respect to this complex, multifaceted, uncertain and dynamic issue. International jurisdictions such as Australia have demonstrated that change will be difficult, time consuming and may require numerous policy efforts to improve the situation. Further, it is expected that successful solutions to complex water scarcity issues will come from a combination of policy instruments and via a multidisciplinary approach (Lansford et al., 1975). Thus, it is the aim of this chapter to create several policy recommendations for each province, each of which will do a part to improve the situation and decrease the risks.

\section{Good Governance and Sustainable Water Management}

It is recommended that Canadian provinces follow the principles of good governance (see Section 3.1.2) and the principles of sustainable water management (see Section 3.1.6) to manage this issue. Similarly, it is recommended that efficiencies through conservation and best management practices be embraced by all of the selected jurisdictions. The literature agrees that these practices are important, so provinces would be wise to take steps towards implementing these practices. 


\section{Work Towards Social Change}

It is recommended that Canada create initiatives for social change to improve scarcity issues on a third-order level. The literature is clear that cultural changes would be the optimal way for any jurisdiction to improve their situation with respect to these issues (Gleick, 2002; Wolfe and Brooks, 2003; Bakker, 2007: 292).

Second-order scarcity solutions, also known as technological solutions to scarcity issues are recommended as well as social change. An example is encouraging water efficiencies through increased use of alternative water sources such as grey and green water. This has many benefits including energy savings (Zhe, Boyle and Reynolds, 2010). For example, the use of grey water reduces energy required to treat water and rainfall does not require pumping for the end use.

First-order scarcity solutions are important, for example the increase of water distribution efficiencies via the installation and use of water infrastructure. However, these first order solutions alone are not enough. It is recommended that Canadian provinces move beyond first order solutions and towards social change.

\section{Pursue Soft Path Solutions}

It is recommended that provinces pursue soft path solutions rather than bearing the environmental and economic costs associated with the hard path. This is fundamentally the same as the recommendation above to move towards solutions that come from fundamentally changing the way that we look at freshwater resources and adopting a mentality that includes conservation and protection of this precious resource.

\section{Protect Water for Ecosystems}

The importance of ensuring allocation of water for ecosystems is widely cited in the literature (Deason, Schad and Sherk, 2001; Richter et al., 2003; Rogers and Hall, 2003; Glennon, 2009: 317; Sandford, 2009: 24; Asian Development Bank, 2013). This 
recommendation is important for any jurisdiction, water scarce or water rich. Water for ecosystems is discussed further in the context of individual provinces below.

\subsection{Policy Recommendations for Alberta}

The policy recommendations for Alberta have been summarized below in Table 16 . Policy recommendations were intended to fit in with the existing policy context in the province. While the FIT FIR system has been criticized as no longer being congruent with the current water situation in Alberta (Vander Ploeg, 2010) banishing this system entirely might be unrealistic. FIT FIR has been in place since the settlement of the province. At the very least, changing the system entirely would be controversial. Thus, it is proposed that the following policy recommendation improve upon the existing policy framework in the province due to the increased likelihood that the changes will happen and the feasibility of implementation. 
Table 16 - Policy Recommendations for Alberta

\begin{tabular}{|c|c|}
\hline Policy Recommendations & Key Points \\
\hline $\begin{array}{l}\text { Reinforce and Strengthen the } \\
\text { Existing Priorities within Water } \\
\text { for Life Strategy }\end{array}$ & 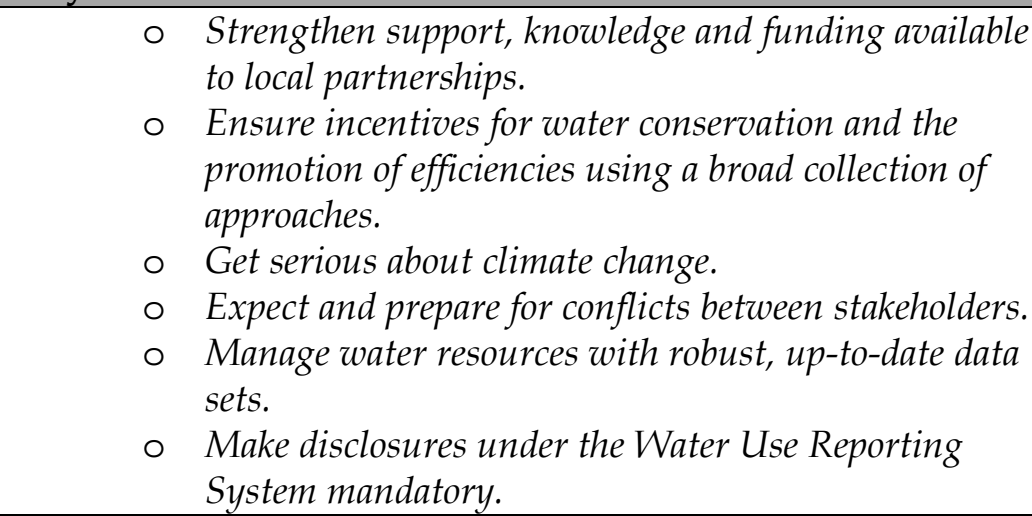 \\
\hline $\begin{array}{l}\text { Add a Scarcity Prevention } \\
\text { Priority within Water for Life }\end{array}$ & $\begin{array}{ll} & \text { Get drought ready (create a Drought Act) } \\
\circ & \text { Prioritize conservation and wise water use over } \\
& \text { seniority. } \\
\circ & \text { Enact legislation focused on water sustainability } \\
& \text { (following BC's lead). }\end{array}$ \\
\hline $\begin{array}{l}\text { Take Measures to Safe-Guard } \\
\text { Against Over-Allocation of Water } \\
\text { Resources }\end{array}$ & $\begin{array}{l}\text { - Marry water allocation with the responsibility to } \\
\text { prevent the degradation of the quality and quantity of } \\
\text { both surface and groundwater. } \\
\text { Enforce minimum flows for the protection of aquatic } \\
\text { ecosystems. } \\
\circ \text { Link water scarcity policy and agricultural policy. } \\
\circ \text { Ensure incentives for water conservation and the } \\
\text { promotion of efficiencies using a broad collection of } \\
\text { approaches. }\end{array}$ \\
\hline $\begin{array}{l}\text { Create an Environmental Bill of } \\
\text { Rights }\end{array}$ & $\begin{array}{l}\text { Follow Ontario's lead with legislation that protects } \\
\text { the rights of Albertans to participate in } \\
\text { environmental decisions. }\end{array}$ \\
\hline
\end{tabular}

\subsubsection{Reinforce and Strengthen the Priorities of the Water for Life Strategy}

The Water for Life Strategy has great potential for significant positive change in Alberta, but it currently falls well short. In general, Water for Life is strong as an umbrella plan; however, it lacks the detailed plans and commitments to achieve the strategy's goals. Improvement is needed, especially at the level of implementation of the policy. It is recommended that the fundamental weaknesses of Water for Life be remedied. 
Strengthen Support, Knowledge and Funding to Local Partnerships

According to Water for Life, local watershed groups are very important for the implementation of Water for Life, yet it is unclear what actions will be taken to achieve the goals. In order to support the local watershed groups in achieving the Strategy, it is important for Alberta to provide leadership, guidance, knowledge, funding and support to those groups. Water for Life may be an example of reluctance by provincial governments to transfer power to these groups, as described by Hill et al. (2008). There also simply may be inaction on the part of the provincial government.

\section{Create Incentives for Water Conservation}

The policy instrument currently has few incentives for wise water use and conservation. It is recommended that Alberta act to promote conservation using a broad selection of methods and incentives under Water for Life.

\section{Get Serious about Climate Change}

A key piece that requires change with this policy instrument is the lack of preparedness for climate change. Due to its semi-arid climate, Alberta is especially at risk of summer droughts triggered by climate change. If Alberta continues to be blind to this risk the results could be disastrous. Policy adaptation and mitigation actions would also minimize economic and environmental costs of the current wasteful water practices in Alberta.

\section{Prepare for Conflicts Between Stakeholders}

An additional area where Water for Life is severely lacking is the management of stakeholder issues and conflict resolution mechanisms. In general, water issues have diverse stakeholders and conflicts can be expected. Literature recognizes that jurisdictions should be prepared for stakeholder tensions (Mahmoud et al., 2009; Black, Wallbrink and Jordan, 2014) and to have a mechanism built in to the policy to mitigate conflicts (Mickwitz, 2003). Due to Alberta's semi-arid nature the province is especially 
at risk of scarcity issues and stakeholder conflicts, yet Alberta is unprepared. It is recommended that the province build into Water for Life a mechanism to deal with stakeholder conflicts. Further, it is recommended that Alberta pass legislation similar to Ontario's Environmental Bill of Rights that would allow the public to have input into the government's decisions regarding environmental issues. This would benefit the environment in Alberta beyond the scope of water scarcity issues.

Manage Water Resources using Robust, Up-to-Date Data Sets.

Alberta has only just begun to take steps to gather data that are valuable in the management of the province's precious water resources. Without robust, up-to-date scientific data on those water resources, management is impeded. It is recommended that Alberta do much more to strengthen data sources by investing in the gathering and management of this data in order to make informed decisions regarding water use. This includes expanding data gathering resources including expansion of the online groundwater mapping initiative which currently has limited scope.

\section{Make Disclosures Under the Water Use Reporting System Mandatory}

A key piece of the missing data set could come from a requirement for mandatory water taking data from permit holders using the Water Use Reporting System. These data are currently only collected on a voluntary basis. In addition, this policy recommendation includes providing funding for scientific research related to water resources and water management in the province. The use of incentives and/or penalties is recommended in order to achieve compliance with reporting.

\subsubsection{Add a Scarcity Prevention Priority to Water for Life}

It is recommended that Alberta get serious about the prevention of scarcity, especially when one considers the province's vulnerability due to scarcity. It is recommended that Alberta strengthen the existing Strategy to include a priority to focus on sustainability and prevent scarcity. There is currently a conservation goal under Water for Life; 
however, the Alberta Water Council gave water conservation a failing grade during a recent evaluation of this policy instrument (AB Gov, 2012). It is recommended that Alberta refocus this priority.

\section{Get Drought Ready}

The enactment of drought protection legislation in Alberta is recommended. Alberta's current system has been criticized for lack of forethought and formalization of a policy to deal with times of drought (Block and Forest, 2005). Alberta's climate is such that droughts can be expected and should be anticipated. Alberta should define, ideally in

legislation, what actions will be taken in times of scarcity. Which water allocations will be suspended first? How will water for ecosystems be protected?

\section{Prioritize Water for Ecosystems Over Seniority}

It is within this policy instrument that it is recommended that Alberta make alterations to the long standing practice of FIT FIR. As mentioned previously, it is recommended that Alberta facilitate change while continuing to use this system as a framework. However, an important change would be to prioritize water for ecosystems and consider smart water use in allocation. This would be a major change to the current allocation and conflict would be expected. None the less, this would be beneficial at any point, but especially during low water events. For example, drought legislation should provide legal protection for water for ecosystems during times of scarcity and define scaled back or suspended water use by other users, for example water extractions for agricultural irrigation. Factors should be included such as the intended use of the water, rather than simply the length of time that the water allocation permit has been held.

\section{Enact Legislation Focused on Water Sustainability}

It is recommended that Alberta pass legislation focused on promoting water sustainability. To find an example of such a policy instrument, Alberta needs only to look to British Columbia. It is recommended that Alberta learn from the excellent work 
that $\mathrm{BC}$ has done in the creation of the Water Sustainability Act. British Columbia is a water rich province, yet it has done much more to prevent scarcity within its borders than drought prone Alberta. British Columbia has also done much more to create sustainability with a prior allocation framework, while Alberta remains rigid with a policy context that is no longer reflective of the water situation. This Act has been created to tailor to the unique needs and geography of British Columbia. Alberta would be wise to use the Water Sustainability Act as a guide to create similar legislation for Alberta. The creation of such an Act might be easier in Alberta now that British Columbia has passed the Water Sustainability Act.

\subsubsection{Take Measures to Safe-Guard Against/Reverse the Over-Allocation of Water Resources}

Sandford (2009: 56) believes that much of Canada, especially Alberta, has also overallocated their freshwater resources. A clear weakness of Alberta's policy context is the risks and costs of inefficient use and over-allocation of water resources. This is especially an issue in hot dry years, especially in the summer season. FIT FIR water governance systems can value senior permit holder rights to a fault. Senior water rights have no value if overuse leads to a situation where there is no water for anyone. Scarcity experiences in the states of New Mexico and Colorado also provide support (Lewis, Hilton and Vocke, 2005; Funk, 2007; MacDonald, 2007). In these states, the overallocation of water resources led to conflict.

Other jurisdictions have demonstrated the link between over-allocation of water resources based on a prior allocation system and the use of historic data taken during wet years for decision-making. This use of data for the allocation of water in Colorado, now believed to have been taken when water resources were at an extreme high, may have contributed to water scarcity issues (MacDonald, 2007). 


\section{Require License Holders to Protect Fresh Water Resources}

It is recommended that the province should require that water license holders do more to protect Alberta's watersheds. Water licenses should be tied to the responsibility to prevent the degradation of surface and groundwater (Schmidt, 2014). Permit holders should be required to prevent the overall degradation of water quantity and quality. This could be done through the requirement of a conservation plan as a condition of the granting of a permit. Water users that fail to do so should not only lose their permits, but also face enforcement measures like fines or even prosecution.

\section{Water for Ecosystems}

The importance of maintaining minimal flow requirements for the environmental protection of aquatic ecosystems is widely cited in the literature (Gleick, 1993; Deason, Schad and Sherk, 2001; Richter et al., 2003; Rogers and Hall, 2003; Rijsberman, 2006; Bakker, 2007; Glennon, 2009: 317; Sandford, 2009: 24; Brooymans, 2011; Asian Development Bank, 2013).

Sandford (2009: 99) explains the importance of water for ecosystems in the context of water management: "the issue at stake is not how much water we need to allocate for nature at the expense of people so that nature can be sustainably maintained. The really important question is how much water can be allocated for driving current trends of

global population and economic growth without reducing and degrading ecosystem services to the point that they no longer support either people or nature." Water for Life does include ecosystem protection through water allocation (Saunders and Vlavianos, 2010). This component of the policy could be greatly strengthened if the mandatory allocation of water for ecosystems were to be protected with legislation.

While this idea is ubiquitous in the literature, it is dangerously lacking in practice in Canada. In the United States, more and more states are implementing a form of this policy. This includes both water scarce and water rich states (Deason, Schad and Sherk, 2001). 
The South Saskatchewan River Basin no longer issues new licenses, as of 2006. Because of the moratorium on new licenses, a market-based system has been created for this basin. No new licenses are issued, but they can be traded on a voluntary basis if there exists both a willing seller and buyer (Alberta Water, 2015). The province governs this process, including an up to ten percent holdback that is sometimes not reallocated for conservation purposes. Agricultural use and household water use are exempt from this market transfer process, but there is no provision for water for ecosystems. Alberta should clarify water rights in times of scarcity (in part with a Drought Act) and ensure the protection of public interest and the environment within this system. Without protections in place, this system has a risk of breaching the line between water as a commodity with monetary value and water as a human right.

\section{Marry Water for Life and Agricultural Policies}

Dating back to the 1960s, Alberta's agricultural industry is responsible for about half of the water use in the province (Alberta Water, 2015). In spite of this, Alberta's water allocation policies are not considered together with agricultural policies in order to save water and promote conservation. For example, it is recommended that Alberta encourage greater use of rainwater for irrigation via Water for Life. If the two are considered together, the potential to reduce the heavy water use of this industry is vast. Any policy change related to agriculture is likely to create a great deal of stakeholder interest and probably spark conflict (Sandford, 2009: 143). However, Alberta cannot continue to ignore the linkages connecting water scarcity and agricultural policies. Changing agricultural policies to encourage conservation of water and greater use of rainwater would be complex and challenging, but it is worth pursuing for the potential positive change would be gained.

\section{Conservation Incentives and Water for Life}

Lastly, it is recommended that Alberta take steps to ensure incentives for water conservation and the promotion of water efficiencies and wise water use. A single approach is much less likely to be successful than the implementation of a wide variety 
of approaches targeting multiple sectors and working together to reduce waste, encourage smart water use and prevent scarcity.

\subsubsection{Create an Environmental Bill of Rights}

Ontario's environmental governance framework includes a unique environmental law called the Environmental Bill of Rights. The EBR in Ontario has led to increased public powers and participation in the regulatory decisions (Greenbaum and Wellington, 2010: 308). Key requirements of the EBR for the provincial government are to post proposed policies and regulatory instruments, the right to comment, the potential to request an appeal or review of government decisions related to the instruments and even the power to bring forth a civil lawsuit over these matters. For example, in Ontario, the public has the right to comment on a proposed Permit to Take Water.

Benefits included include increased government accountability and transparency via the posting of proposed permits and the possibility of the public appealing a permit. It is recommended that the government empower Albertans with improved transparency and public participation with a similar mechanism. With respect to scarcity issues, it would facilitate a greater level of public participation and increase government accountability.

\subsubsection{Experiences from Other Jurisdictions to Support AB Policy}

\section{Recommendations}

International jurisdictions have valuable experiences to support the creation of policy recommendations for Alberta, especially water scarce and climate-change affected regions. Experiences from Australia, Colorado, Georgia and Spain were selected for Alberta. 


\section{Australia}

Major policy reform was initiated in Australia following a serious water crisis in the Murray-Darling basin area. Key changes included reallocation of water for the environment via a policy instrument called "environmental water allocations" (Reid and Brooks, 2000; Thoms and Sheldon, 2002). As the name suggests, this policy commitment is progressive as it mandated the protection of water for ecosystems. Unfortunately, pressure from agricultural interest groups has significantly weakened what was once considered very progressive policy (Hussey and Dovers, 2006). Still, the Murray-Darling Basin in Australia demonstrates the importance of protecting water for ecosystems, as well as the importance of safeguarding against the over-allocation of water resource.

A unique policy response from Australia is the buy-back of water entitlements from the Murray-Darling Basin. The buy-backs are intended to counter over-allocation of the system. They are planned over the ten year period with a total expected cost of $\$ 50$ million dollars (Nelitz, Douglas and Rutherford, 2009). This is one possible solution for Alberta's over-allocation issue.

\section{Colorado and Georgia}

The state of Colorado has many similarities to Alberta with respect to fresh water, including substantial use of this resource for the irrigation of crops. Like Alberta, the state has not done enough to understand the links between agricultural policy and water policy (LeRoy, 1995).

Colorado also demonstrates the importance of ensuring water resources are not over-

allocated. Senior water license holders in Colorado have rights to much of the surface water in the state. As a result, many farmers that could not get a license resorted to pumping groundwater to irrigate, since the water rights to the surface water were exhausted. This has resulted in depletion of aquifers at an alarming rate. Conflicts between senior license holders and farmers peaked with a legal action in 2006 after 
years of stakeholder conflicts and a long drought. Colorado courts ruled in favour of the senior users and pumping water was disallowed for many farms. This brought great economic hardship to many farmers through the loss of crops. Both sides of the conflict blamed those in charge of governance for allowing the situation to reach the point that it did (Glennon, 2009: 89). Colorado's experiences also demonstrate the links between water scarcity issues and food security.

Georgia's experience demonstrates the importance of a drought act. In 2000, the State of Georgia tried an interesting policy idea. With the introduction of the Flint River Drought Protection Act, the state offered substantial cash subsidies to farmers who agreed to stop pumping water from the Flint River during times of drought. As a result of this policy, the strain on the river and its tributaries was substantially decreased during drought times (Dellapenna, 2004).

The state's experiences show the importance of a mechanism to mitigate stakeholder conflicts. In 2007, Atlanta was four months away from running out of water following a two-year drought (Glennon, 2009: 23). Atlanta's watershed commissioner publicized that unless it rained, the city's water supply would run dry within a year. Lake Lanier, the key water source in the area, experienced significant negative impacts. The city's response included voluntary measures and a ban on new housing developments, which met with major resistance, especially amongst the business community.

Georgia offers an example of the allocation of water for ecosystems (Elfer, McDowell and Robin, 2004). When the 2007 water crisis peaked, the use of water for ecosystems and water governance practices were criticized by Governor Sonny Perdue (Dellapenna, 2004), who is an advocate for water conservation measures in Georgia. Water from Lake Lanier had recently been released via the Buford Dam to protect endangered species downstream, including protected mussels that live in the Apalachicola area in Florida (Glennon, 2009: 27). This triggered requests by politicians for exemptions to endangered species legislation. A Georgia ecology professor was 
quoted on the topic, "blaming the endangered mussels for our water woes is as silly and misdirected as blaming the sick canary for shutting down the mine" (Glennon, 2009: 27).

Along with demonstrating an example of conflict from water shortages, Georgia's experience also demonstrates for Alberta the importance of long-term water planning. In 2004, the Comprehensive State-wide Water Management Planning Act allowed Georgia to conduct long-term water planning in its ten districts (Georgia State's Water Plan, 2015). This policy aims to facilitate the sustainable management of water in Georgia though 2050.

Alberta could look to Georgia's approach to these issues as an example of: (1) the importance of water for ecosystems (2) conflict over water resources that Alberta should avoid, and (3) comprehensive regional water use planning across the entire jurisdiction.

Spain

Additional demonstration for the need to integrate of agricultural and water policies in Alberta comes from the experiences of Spain.

Spain is a water scarce European country that has long experience of water shortages that Canada is only starting to see. Population growth, reliance on irrigation for farming, and a naturally dry climate now hotter and drier from climate change have all contributed to acute water shortages and conflicts. Thus, we can look to Spain for water scarcity policy lessons for Canada. Spain's experiences show Alberta the potential consequences of continuing to ignore these issues.

Alberta would be smart to plan ahead before scarcity issues force policy change. Water scarcity issues may drive change, but economic, environmental and human struggles would be decreased if Alberta planned ahead. Other jurisdictions provide evidence of the necessity of water for ecosystems, preventing the over-allocation of resources and exploring the linkages between agriculture and large volume water use. 


\subsection{Policy Recommendations for British Columbia}

While the new Water Sustainability Act makes BC the leader in Canada at this time, there are experiences from international jurisdictions that are useful for British Columbia to strengthen their water governance approach even further. Table 17 summarizes the policy recommendations created for British Columbia.

Table 17 - Policy Recommendations for British Columbia

\begin{tabular}{|l|c|}
\hline Policy Recommendations & Key Points \\
\hline Implement ${ }^{10}$ and Enforce the & $\begin{array}{l}\text { Create strict regulations under the Act immediately. } \\
\text { Water Sustainability Act }\end{array}$ \\
\hline $\begin{array}{l}\text { Remove the discretionary language. } \\
\text { Require existing license holders to protect water for } \\
\text { ecosystems, not just new users. }\end{array}$ \\
\hline $\begin{array}{l}\text { Create an Environmental Bill of } \\
\text { Rights }\end{array}$ & $\begin{array}{l}\text { Follow Ontario's lead with legislation that protects } \\
\text { the rights of British Columbians to participate in } \\
\text { environmental decisions. }\end{array}$ \\
\hline
\end{tabular}

\subsubsection{Implement and Enforce the Water Sustainability Act}

\section{Create Robust Regulations Immediately}

It is recommended that strong and robust regulations be developed as soon as possible. On May 29, 2014, Bill 18 received Royal Assent, making this policy instrument officially an Act. The Water Sustainability Act is expected to come into force in April of 2015; however, much of the Act is to simply enable action via regulations. Unless regulations are created, changes to water management under the new act will not be as robust.

\section{Remove Discretionary Language}

The Lieutenant Governor in Council is given a great deal of power with the Act in the form of the ability to make regulations under the Act. If the Lieutenant Governor in Council selects to make regulations, impacts could be significant. For example, this

\footnotetext{
${ }^{10}$ Bill 18 (the Water Sustainability Act) has received Royal Assent, but regulations have not yet been created. Regulations are a key component of the implementation of the Act.
} 
could include dividing BC into water districts, further empowering water comptrollers, protecting sensitive streams and more.

It is recommended that this language be changed to be less discretionary and stronger, for example by replacing "may" with "shall". There is widespread discretionary language used with respect to the Lieutenant Governor in Council and Minister. This could significantly weaken the Act, if for any reason, either party decided not to take action. Either party could decide to do less or simply do nothing.

Require Existing License Holders to Protect Water for Ecosystems, Not Just New Users.

Section 15 of the Water Sustainability Act mandates the consideration of water for ecosystems during the assessment of water license applications. It is recommended that the requirement to calculate water for ecosystems be extended to existing license holders as it currently applies only to new applicants. Further to the point above, it is recommended that the Water Sustainability Act use stronger language. As the Act is written, the assessment of new applications must consider water for ecosystems. The word "consider" once again adds a discretionary component which weakens the policy instrument.

\subsubsection{Create an Environmental Bill of Rights}

British Columbians would benefit from greater input into the decisions that affect the water in their province. As described in Section 6.2.4, Ontario's environmental governance framework includes a unique protection for its citizens with the Environmental Bill of Rights.

If British Columbia were to create a similar Act, the potential benefits with respect to the prevention of water scarcity issues would be many. British Columbians would be empowered have input on or even challenge the granting of water permits in the province. With respect to scarcity issues, it would facilitate a greater level of public participation and increase government accountability. 


\subsubsection{Experiences from Other Jurisdictions to Support BC Policy}

\section{Recommendations}

There are valuable experiences from both water rich and water scarce jurisdictions to support the policy recommendations for BC. British Columbia is hydrologically diverse, with water rich areas along the coast line, but also has semi-arid areas in the interior. Comparisons have been drawn between water policy in British Columbia with Oregon, California and New Mexico.

\section{Oregon, California and New Mexico}

Oregon is a state known for an abundance of water. However, the state has two climatic zones separated by the Pacific Coast Mountains, similar to British Columbia's wet west coast and dry interior. The east side of the range can be dry, while the west side is generally very rainy (EPA, 2013). A key feature of this divide is that the majority of the populated area in the state is on the drier east side. Another unique feature of Oregon's waterscape is the state's dependency on surface water. Oregon's water resources are based about $87 \%$ on surface water, with only $13 \%$ coming from groundwater (EPA, 2013). It is because of this dynamic that Oregon is heavily reliant on precipitation to prevent water scarcity.

Oregon uses a great deal of its water for the irrigation of crops. In drier years, this practice has been depleting rivers and waterways to critical levels (EPA, 2013). In several areas in the state, groundwater is being depleted faster than it is replaced. Similar to British Columbia, Oregon's population is expected to continue to grow. Climate change is predicted to negatively affect water quantities in Oregon, leading to changes in timing and quantities of stream flows, among other negative effects (Farley, Tague and Grant, 2011). In 2007, salmon populations in Oregon were decimated due to lack of water (Glennon, 2009: 18).

California's water scarcity crisis offers valuable experience for British Columbia. Over the last 150 years, groundwater has been pumped for consumptive use, depleting the 
groundwater supply to an extent unknown and leading to land subsidence and groundwater contamination in some places (MacDonald, 2007; Glennon, 2009, 17; Clarke, 2014). The state of California did not regulate or track groundwater withdrawals until September of 2014 when the Sustainable Groundwater Management Act was passed in response to the devastating and long-lasting drought (Christensen and Brandes, 2015). The urgent policy response by California came at a valuable time for British Columbia, as that province develops its groundwater regulations framework over the next few years. Some elements that California's Sustainable Groundwater Management Act does well that could be beneficial for BC to consider are (Christensen and Brandes, 2015):

- A strong balance between State oversight and partnerships with local agencies with respect to groundwater sustainability plans.

- A clear definition of sustainability criteria that are a requirement under the Act. In contrast, $\mathrm{BC}$ has not yet defined sustainability criteria or set minimum performance requirements under the Water Sustainability Act.

- A legal protection measure for water for ecosystems. Consideration of environmental flows is the only requirement in $\mathrm{BC}$, which is a substantive difference.

New Mexico also offers valuable experiences for British Columbia, as the province does not regulate groundwater. There is a deep aquifer under the city of Albuquerque that is considered a non-renewable groundwater resource due to very slow recharge. It was determined that this water was being overused and that the aquifer was being rapidly depleted as inadequate recharge time was being allowed (Flemming and Hall, 2000). The New Mexico case supports the argument that British Columbia would be wise to monitor and regulate groundwater withdrawals (which the province will do shortly under the Water Sustainability Act). 
Experiences from the states of Oregon and California demonstrate the importance of maintaining water for ecosystems, especially salmon habitat. Oregon and New Mexico demonstrate the importance of safeguarding against the overuse of non-renewable water sources, in this case the depletion of groundwater resources. The current crisis in California illustrates the severe environmental and economic costs of inaction. California is a striking example of "what not to do".

In the next section, policy recommendations and rationale for the province of Ontario are discussed.

\subsection{Policy Recommendations for Ontario}

The current policy approach in Ontario is insufficient. While Ontario is water-rich, it also has the largest population in Canada. As result, Ontario bears a high cost of inaction on these issues, and a high risk of damage to the environment. In order to strengthen the approach in the province, a number of policy improvements are recommended, divided into five broad categories.

First, it is recommend that Ontario overhaul and modernize its water allocation policy, the PTTW water system. This dated policy instrument is drastically lacking with respect to effective management and conservation of water. Another key policy gap is Ontario's lack of goals and targets towards water conservation. It is recommended that the 2010 Water Opportunities and Conservation Act be strengthened to include the best elements of the BC Water Sustainability Act. It is recommended that Ontario create depth and robustness in its drought preparation policy. Finally, it is recommended that Ontario strengthen its strategy on Great Lakes protection with dedicated legislation. Table 18 below summarizes the policy recommendations for the province of Ontario, with discussion following the table. 
Table 18 - Policy Recommendations for Ontario

\begin{tabular}{|c|c|}
\hline Policy Recommendations & Key Points \\
\hline $\begin{array}{l}\text { Overhaul the Permit to Take } \\
\text { Water Program }\end{array}$ & $\begin{array}{l}\text { - Revisit and clearly define the goals of the program } \\
\text { and include water conservation. } \\
\text { - Recover the full cost of administering the program } \\
\text { from users. } \\
\text { Include a mechanism for the allocation of water for } \\
\text { ecosystems. } \\
\text { Require permit holders to submit conservation plans } \\
\text { using the Water Opportunities and Conservation } \\
\text { Act. Create incentives for water conservation and } \\
\text { efficiencies. } \\
\text { Manage water resources using robust, up-to-date } \\
\text { data sets. Use the data to plan and manage water at } \\
\text { the watershed level. } \\
\text { Allow greater public and community input into } \\
\text { decisions that impact their watersheds. } \\
\text { Introduce strong enforcement measures such as } \\
\text { AMPs. }\end{array}$ \\
\hline $\begin{array}{l}\text { Set and Commit to Province- } \\
\text { Wide Conservation Goals }\end{array}$ & - Commit to conservation and efficiency goals. \\
\hline $\begin{array}{l}\text { Strengthen the Water } \\
\text { Opportunities and Conservation } \\
\text { Act }\end{array}$ & $\begin{array}{l}\text { O Create significant regulations to prevent water } \\
\text { scarcity. } \\
\text { Strengthen and create depth under the Act by adding } \\
\text { elements of the BC Water Sustainability Act. }\end{array}$ \\
\hline $\begin{array}{l}\text { Build on the Ontario Low Water } \\
\text { Response Plan }\end{array}$ & $\begin{array}{l}\text { o Turn plan into Act. } \\
\circ \text { Harmonize with the PTTW system. }\end{array}$ \\
\hline $\begin{array}{l}\text { Strengthen Protection of the } \\
\text { Great Lakes }\end{array}$ & $\begin{array}{l}\text { - Pass and implement the Great Lakes Protection Act } \\
\text { as part of the Ontario's Great Lakes. Strategy. }\end{array}$ \\
\hline
\end{tabular}

\subsubsection{Overhaul the Permit to Take Water Program in Conjunction with the Water Opportunities and Water Conservation Act}

Ontario's Permit to Take Water Program is very weak with respect to water scarcity prevention and water conservation, so it is recommended that this policy instrument be overhauled. 
Revisit and Define the Goals of the Program and Include Water Conservation

Without setting goals and targets, wasteful water use and the high associated costs are likely to continue unchecked in Ontario. Goals and targets for PTTW could be an important part of the overall provincial targets, as discussed below. This is because PTTW governs the biggest water takings in the province.

Require Users to Pay for the Program and Add Monetary Incentive for Permit Holders to Conserve Water

With the current system, users pay very low fees to extract water in spite of the fact that water management is expensive for the province. Permit holders in Ontario pay a pittance for water extractions. The rate for industrial extractions is $\$ 3.71$ per million liters of water, which does not begin to cover the government's $\$ 15$ million annual cost to administer the program (ON Gov, 2012b).

Another key issue with the low cost of water extractions is that it does not create any financial incentive for permit holders to conserve water. The current system may even lead to the continued perception that all freshwater in the province in unlimited and without costs. It is recommended that Ontario recover the full cost of administering the PTTW program and in so doing create monetary-based water conservation incentives for permit holders. The Ontario Ministry of Finance and the Environmental Commission of Ontario have each published support for full cost recovery (Environmental Commissioner of Ontario, 2012a).

Water for Ecosystems

The issue of ecosystems and PTTW was addressed by the Environmental Review Tribunal (ERT) when local residents in the Tay Watershed area challenged a permit to take water by means of the Environmental Bill of Rights (Greenbaum and Wellington, 2010: 557). In part, the case hinged on a government commitment to apply an ecosystem approach that was published in a Statement of Environmental Values. The ERT ruled that the MOECC was required to take an ecosystem approach as committed, 
including health of aquatic ecosystems and cumulative effects. However, it appears that Ontario has yet to follow through with the commitment to the ecosystem approach.

It is recommended that Ontario create an effective mechanism for the allocation of water for ecosystems under PTTW or through the creation of another policy instrument. Currently, the MOECC could deny a permit that proposed extraction from a watershed already impacted by significant extractions (Nowlan, 2005). However, it does not appear that this has ever actually happened in practice. Further, this alone is not enough action for the protection of water for ecosystems. Stronger protections are recommended so that ecosystems do not suffer during times of scarcity, including a requirement for conservation plans, mechanisms for increased public input and strengthened enforcement measures.

\section{Require Conservation Plans as a Condition of Using Permits}

It is recommended that Ontario require conservation plans as co or pre-requisites for holding a permit to take water. As of 2010, the government is enabled to require conservation plans from municipalities and public agencies under the Water Opportunities and Conservation Act. Requiring conservation plans is a key win for this new Act, however this currently only applies to municipalities (Ecojustice, 2015). The framework could be used to improve PTTW by applying the requirements to permit holders. If a conservation plan did not meet a certain benchmark deemed acceptable by the province, a permit would not be granted. It is recommended that commitments in a conservation plan be enforceable. If a company failed to conserve water or create efficiencies as per its commitments, it would be subject to enforcement measures such as AMPs.

\section{Manage Water at the Watershed Level}

It is recommended that Ontario manage water allocations on a watershed level, a practice that is widely supported in the literature (Deason, Schad and Sherk, 2001;

Brandes et al., 2005; Crabbe and LeRoy, 2008; Martin-Downs, 2010; Brooymans, 2011). 
The science demonstrates that water is connected on a watershed level (Canadian Geographic, 2014a) and it should be managed as such.

Manage Water with Quality Data

Similar to Alberta, it is recommended that Ontario manage water resources using robust, up-to-date data sets. A component of this is to track trends in water use by license holders and to utilize that data to manage water appropriately to prevent scarcity. In the past, this tracking has been reportedly inconsistent (AB Gov, 2012).

\section{Public and Community Input}

It is recommended that Ontarians be allowed greater public and community level input into decisions that impact their watersheds. The Environmental Bill of Rights is legislation to protect the rights of the citizens of Ontario and to allow input by the public on government decisions important to the environment, including permits to take water. However, a common criticism remains that Ontario is not doing enough to facilitate input and complaints from Ontarians on these issues. A study on this public input into the Permit to Take water Program concluded that there was no empirical evidence that public comments influence the likelihood of a government denying a permit (Deaton, Lintner and Harrington, 2008).

\section{Strengthen Enforcement Measures}

It is recommended that Ontario get serious about enforcement measures. For example, users that violate permits should face repercussion such as having their permits revoked, administrative monetary penalties (AMPS) or even prosecution. An example of failing to comply with terms and conditions would be failing to report a water taking or violating a water conservation requirement (as recommended). Of course before this is possible, the terms and conditions mentioned above would need to become part of PTTW. 


\subsubsection{Set and Commit to Province-Wide Conservation Goals}

It is recommended that Ontario commit to water conservation and efficiency goals. The province demonstrated some recognition of this need with the release of the 2009 proposal paper titled "Stewardship, Leadership, Accountability - Safeguarding and Sustaining Ontario's Water Resources for Future Generations".

Ontario is required under the Great Lakes-St. Lawrence River Basin Sustainable Water Resources Agreement to set goals for water conservation for the Great Lakes. Further, the third "purpose and target" of the Water Opportunities and Conservation Act is to "conserve and sustain water resources for present and future generations". Unfortunately, this target is not measurable or quantifiable, and therefore the government cannot be held accountable.

It is recommended that Ontario take these components further and set province-wide conservation and efficiency goals. In the 2009 proposal, a suggested goal was reducing water use in cities by $15 \%$ of total water use below 2000 levels. It is recommended that Ontario aim for conservation goals for all users in Ontario, not just cities, and aim for closer to BC's goal of $33 \%$. It is recommended that the Water Opportunities and Conservation Act be used as a framework for this action.

\subsubsection{Strengthen the Water Opportunities and Water Conservation Act}

Create Significant Regulations to Prevent Water Scarcity.

Ontario passed legislation focused on water sustainability in 2010. The Water Opportunities and Water Conservation Act could have made Ontario the leader in Canada on water sustainability. Unfortunately, the Act does not live up to the powerful words in its preamble section. The preamble states, "Wise water stewardship and conservation of water, for both the present generation and future generations are of great importance to all Ontarians" (Service Ontario E-laws, 2010). 
A significant weakness of the Water Opportunities and Water Conservation Act is that it enables the government to create actions targeted at water sustainability, but only should the government so choose. This discretionary piece effectively allows the government to do nothing. It is recommended that these changes be required rather than discretionary.

Strengthen the Water Opportunities and Water Conservation Act with Elements of the BC Water Sustainability Act

It is recommended that the Water Opportunities and Water Conservation Act be strengthened with elements of BC's Water Sustainability Act currently missing from this Act that have the potential to prompt significant positive change. This could be a change to the statute or come in the form of regulations under the act.

Some key recommended additions based on BC's approach for the Ontario Water Opportunities and Water Conservation Act are as follows:

- Extend the water sustainability planning beyond municipalities. It is recommended that regulations require these plans from all PTTW holders.

- Remedy the lack of province-wide goals and targets for conservation.

- Utilize strong enforcement measures.

- Consider the end use of the water in planning and permitting decisions.

Currently, there is just one regulation under the Act, Ontario Regulation 40/11. This regulation creates the Water Technology Acceleration Project, which is basically a corporation to support the creation of efficiencies in the water and wastewater sectors. It is recommended that Ontario create a number of strong and robust regulations under this Act. 


\subsubsection{Build on the Ontario Low Water Response Plan}

\section{Drought Legislation}

It is recommended that Ontario build on the Low Water Response plan by enacting drought legislation. The current policy instrument, the Low Water Response, is very weak. The Low Water Response defines three levels of action in the case of low water (Levels I, II and III). The first two levels stipulate only minor actions, a 10\% and or 20\% voluntary reduction of water takings by users. Mandatory actions by water users are only triggered by a level III event, when supply does not meet demand and social and economic impacts. Risk to environment is not recognized as a factor (ON Gov, 2015b). A significant weakness of this plan is the lack of defined actions during a level III incident. It is recommended that Ontario enact drought legislation that defines a much more specific plan of action. Which water uses will be required to be suspended first? By what volume or percentage will water extraction be reduced, and for what duration? What enforcement actions are available if permit holders or others fail to comply? These details should be negotiated with stakeholders and then clearly legislated before a crisis hits.

\section{Harmonize with the PTTW System.}

The Low Water Response plan is well short of the prioritization and planning that could come from dedicated legislation. Ontario is leaving itself open to the risk of major stakeholder conflicts without an Act that defines water priorities and conservation actions for times of drought. The current Low Water Response is not robust and it does not provide protection for water for ecosystems. In addition, it is not connected to the PTTW system. In times of low water levels, it only makes sense to tie the plan of action to the largest water users. Ontario's plan is very poor, yet the province expects low water approximately once every fifteen years (ON Gov, 2015b). Once again, Ontario could learn from BC's approach by tailoring BC's drought legislation in Ontario. 


\subsubsection{Continue to Strengthen Great Lakes Protection Measures}

The water from the Great Lakes is relied upon by many Ontarians. Water is used for drinking water and much more, including diversions, withdrawals and consumptive uses. Yet the Great Lakes only replenish at a rate of $1 \%$ annually (Glennon, 2009: 97). In general, the lakes are not doing well both in terms of water quality and quantities. Lake Superior is at its lowest level since measurements began in 1918 (Glennon, 2009: 98). LeRoy (1995) asserts that we must use only renewable water resources that are not diminished over the long term by human use to be congruous with sustainable development.

\section{Pass the Great Lakes Protection Act}

The Act, focused on the protection and restoration of the Great Lakes, was intended to work in conjunction with and provide backing to the Strategy. In addition, the Act would have obliged the Minister to maintain the Strategy. Without this protection, the Strategy could be cancelled at any time. For example, the government could change and the new government may have different priorities. Thus, it is recommended that Ontario reintroduce and pass this Act to work with the Strategy to protect the Great Lakes. Measurable targets for water quality and water quality are key inclusions. The amount of water diverted and withdrawn should also be minimized. The passing of the Great Lakes Protection Act should be done so that Canada meets its commitments under the Great Lakes-Saint Lawrence River Basin Sustainable Water Resource Agreement. Until now, Ontario may have been taking advantage of the fact that this agreement is not binding. It is recommended that Ontario do the right thing, honour its agreement and protect these precious fresh water resources.

In a 2014 Mandate Letter to Glen Murray, the Minister of the Environment and Climate Change, Premier Kathleen Wynne announced that protecting the Great Lakes is a priority in Ontario. The letter called for the reintroduction of the Great Lakes Protection Act (ON Gov, 2014b). 


\subsubsection{Experiences from Other Jurisdictions to Support ON Policy}

\section{Recommendations}

\section{Water Rich Regions are Not Immune to Scarcity}

Other jurisdictions have experiences that support the policy recommendations for Ontario. Water rich regions are not immune to scarcity issues and have demonstrated the high costs of ignoring these issues. Selected jurisdictions that have experiences to support Ontario are the states of Georgia, New Mexico.

\section{Georgia}

The Georgian government requires that a conservation plan be submitted in order to receive a permit to take water over a threshold volume (Elfer, McDowell and Robin, 2004). This policy instrument, which is in the form of regulations, was created following a harsh drought in the late 1980s. A similar policy instrument is recommended for Ontario.

Georgia's permitting approach is not without criticism. Georgia has been criticized for continuing to issue water permits in times of dire scarcity, effectively ignoring the problem. Further, withdrawals under 100, 000 gallons per day do not require a permit. The system has also been described as rigid to a fault (Dellapenna, 2004).

Georgia demonstrates the importance of conservation plans tied to large water takings, and presents an example warning against overuse of water, bad planning and waiting much too late to react with policy responses.

\section{New Mexico}

The state of New Mexico has been criticized in the literature for having a poor understanding of the water resources within its borders (Perramond, 2013). Lack of data and lack of knowledge on the water resources in a jurisdiction create limitations in effective management of that resource. Robust and up-to-date data is very important in 
order to make informed water management decisions. There is already a large uncertainty involved with these issues.

\subsection{Conclusion}

Other jurisdictions around the world have experienced water hardships that provide clear support for the policy recommendations discussed in this chapter. On a world scale, there are many different approaches and policy frameworks that different jurisdictions have used to try to solve and prevent these issues. One commonality among the researched international jurisdictions is that many virtually ignored water scarcity issues until they were faced with physical scarcity issues. Due to inaction, they experienced costs, environmental damage, hardships and conflicts related to water scarcity. Canada should avoid this by learning from the experiences of other jurisdictions. 


\subsection{THESIS CONCLUSIONS}

In Canada today, water scarcity issues are largely ignored in spite of great risk to the environment and people, and great uncertainty about the future. Even with major economic and environmental costs associated with poor water governance, risk of physical scarcity and predicted stakeholder conflicts, these issues remain understudied and under-funded. Canadian provincial governments are ignoring to the risks and costs.

Water quality and water quantity are intimately linked, and both need to be protected. Provinces should not wait for an acute scarcity event to create policies to protect people and the environment.

Policy reforms should be considered in all of the provinces considered in this study. Water issues are inherently complex, yet most Canadian provinces have not yet begun to tackle this wicked problem.

\subsection{Key Policy Recommendations}

\section{Any Jurisdiction}

The literature on water scarcity issues consistently addresses broad best practices for any jurisdiction, which Canada has largely ignored. It is recommended that provincial policies in the selected jurisdictions prioritize and incorporate these ideas. Any jurisdiction would benefit from assessing whether these best practices are a key part of their governance, and implementing them. International jurisdictions have demonstrated the importance for governments to prioritize the prevention of water scarcity issues before acute shortages occur in order to minimize costs, conflict and hardship.

It is recommended that Canada strengthen national leadership for these issues at the federal level. For example, at the federal level, the government could set a minimum bar with respect to policy, encourage policy learning across provinces and fund 
research into water-related issues. Again, the federal government would likely be limited by Constitutional powers, but regardless greater leadership is needed and possible. Water-related issues are inherently complex and implementation is expected to have challenges over an extended timeframe. Thus, it is important to prioritize water scarcity now. Further to the complexity of water issues, the literature indicates consistently that Canadian governments would be prudent to use several different approaches in combination to solve this problem. There is unlikely to be one "silver bullet" policy instrument that solves everything. Rather, it is many changes working together that will make a difference. It is recommended that Canadian provinces tackle scarcity issues with first-, second- and third-order solutions, moving beyond physical scarcity prevention to encouraging social change via policy. Finally, the literature indicates that environmental and economic costs would be minimized if Canada pursued soft path solutions. It is best practice for provinces to create policy instruments that encourage conservation and efficiencies rather than simply allowing more water to be used to satisfy demands at any cost.

\section{Alberta, British Columbia and Ontario}

For Alberta, key policy recommendations include the need for the province to prioritize scarcity prevention and water conservation. Alberta should act to prevent (or reverse) the over-allocation of water resources, including safeguarding fresh water allocation for ecosystems. International jurisdictions that have experiences most clearly demonstrate the importance of these measures are Australia's over-allocated and stressed MurrayDarling River Basin and Colorado's over-allocated system. In addition, experiences of Spain and the US state of Georgia demonstrate the importance of recognizing the connectedness of water conservation, agricultural policies, and climate change in Alberta.

There are improvements that can be made and experiences of other jurisdictions that can benefit British Columbia. Oregon and California are two jurisdictions whose experiences have demonstrated the importance of regulating groundwater. 
Key policy recommendations for Ontario are overhauling the current water allocation system and setting water conservation goals and targets. It is important that Ontario strengthen the protection of the Great Lakes. This is supported by experiences of other water-rich jurisdictions.

\subsection{Future Studies}

There are additional academic studies that would be beneficial to this understudied topic. To conclude, some of the additional topics that could be researched to complement this study are discussed here.

\section{Greater Scope in the Canadian Context}

Future studies could see policy recommendations for additional Canadian provinces. The province of Saskatchewan, a second drought-prone province with an agricultural dominant economy (Marchildon et al., 2006), would benefit from further study. Manitoba, a western Canadian province heavily reliant on agriculture, would be a second excellent candidate for inclusion in future studies.

\section{International Scope}

Additional applications for this study fall outside of Canada. This topic is also understudied in other jurisdictions, especially those not currently experiencing water scarcity issues. For example, the framework for this study could be used to undertake policy evaluation and then comparative policy analysis of water conservation policy frameworks in various states in the United States or countries in Europe.

\section{Linkages between Water Scarcity Issues and Agricultural Policies}

There is value in a study of water scarcity in Canada with a focus on the synergy between water policy and agricultural policies. This study has brought to light the importance of the link between fresh water use in Canada and agriculture. Detailed 
study of how to improve agricultural policies to increase water conservation has the potential for great benefit in all three selected jurisdictions.

\section{Building on Policy Evaluation to Undertake Comparative Policy Analysis}

Comparative policy analysis, a method introduced in Section 3.1.2, would be a valuable "next-step" method that could be used to build upon this study. A comparative policy analysis would compare and contrast two or more jurisdictions policy approaches and create recommendations based on the results. For this type of study, it would be prudent to consider just two jurisdictions in order to simplify the comparison, given that policy contexts are already inherently complex.

\section{Exploration and Examination of the Potential for Voluntary Initiatives and Corporate Social Responsibility (CSR)}

Corporate social responsibility and voluntary initiatives are currently underexplored as they relate to water scarcity issues. Businesses are expected to play an even more important role in water issues in the future (Institute for Human Rights and Business, 2009; the CEO Water Mandate, 2015). CSR and Voluntary Initiatives are tools used by companies to demonstrate that they conduct business in a socially and environmentally responsible way. These initiatives, as they relate to the water scarcity issues, would be a valuable and rich topic for future study.

\subsection{Closing Statement}

Canada's freshwater resources are of paramount importance for Canada, including the economy, the environment and Canadians. Will Canada's relative abundance of freshwater spare the crisis level situations that have plagued other jurisdictions? Or will wasteful water use, economic costs and environmental impacts remain unchecked? Will climate change and population growth continue to put pressure on this resource while Canadian governments fail to act? Or will Canada learn from abroad and create policy to minimize these issues before a disaster occurs? It is strongly recommended 
that Canadian provinces would be wise to create policies that will protect our freshwater resources now and for future generations. 


\section{REFERENCE LIST}

Alberta Water, 2014. Work: ENGOs - Elbow River Watershed Partnership. Accessed July 29, 2013 from http://albertawater.com/work/alberta-watercommunity/engos

Alberta Water, 2015. Learn: Water Licenses, Transfers and Allocation. Accessed January 30,2015 from http://albertawater.com/how-is-water-governed/water-licencestransfers-and-allocation

Allan, D. and Flecker, A., 1993. Biodiversity Conservation in Running Waters. Bioscience. 43(1). Pg. 32-43.

Allen, D., Mackie, D. and Wei, M. 2004. Groundwater and Climate Change: a Sensitivity Analysis for the Grand Forks Aquifer, Southern British Columbia, Canada. Hydrogeology Journal. 12. Pg. 270-290.

An, H. and Eheart, J.W., 2006. Evaluation of Programs from Regulating Withdrawal of Surface Water Under the Riparian Legal System. Journal of Water Resource Planning and Management. 132. Pg. 385-394.

Andrews, M., 2010. Good Governance Means Different Things in Different Countries. Governance. 23(1). Pg. 7-35.

Asian Development Bank, 2013. Thinking about Water Differently - Managing the Water-Food-Energy-Nexus.

Ashford, D., 1993. History and Context in Comparative Public Policy. University of Pittsburgh Press. Pittsburgh, Pennsylvania, USA.

Australian Government, 2014. State of the Climate 2014. Australian Government - Bureau of Meteorology. Accessed May 1, 2015 from: http://www.bom.gov.au/state-ofthe-climate/

Bakker, K., 2003. Good Governance in Restructuring Water Supply: a Handbook. Federation of Canadian Municipalities.

Bakker, K. ed., 2007. Eau Canada: the Future of Canada's Water. Vancouver, BC. UBC Press.

Bakker, K. and Cook, C., 2011. Water Governance in Canada: Innovation and Fragmentation. Water Resources Development. 27(2). Pg. 275-289.

Barnett, T., Adam, J. and Lettenmaier, D., 2005. Potential Impacts of a Warming Climate on Water Availability in Snow-dominated Regions. Nature. 438. Pg. 303-309. 
Bastmeijer, K and Koivurova, T., 2008. Theory and practice of transboundary environmental impact assessment. Eds. Vol. 1. Martinus Nijhoff Publishers.

Bennett, C. 1991., What is Policy Convergence and What Causes It? British Journal of Political Science. 21:215-233.

Bennett, C. and Howlett, M., 1992. The Lessons of Learning: Reconciling Theories of Policy Learning and Policy Change. Policy Sciences. 25. Pg. 275-294.

Bjornland, H., Nicol, L. and Klien, K., 2007. Challenges in Implementing Economic Instruments to Manage Irrigation Water on Farms in Southern Alberta. Agricultural Water Management. 92(3). Pg. 131-141.

Black, D., Wallbrink, P. and Jordan., P., 2014. Towards Best Practices Implementation and Application Models for Analysis of Water Resource Management Scenarios. Environmental Modeling and Software. 52. Pg. 136-148.

Block, R. and Forrest, J., 2005. A Gathering Storm: Water Conflict in Alberta. Alberta Law Review. 43(1). Pg. 31-50.

Boardley, A. and Kinkhead M., 2006. An Analysis of Canada and Other Water Conservation Practices and Initiatives: Issues, Opportunities and Suggested Directions. Canadian Council of Ministers of the Environment. Accessed July 12, 2014 from http://www.ccme.ca/assets/pdf/kinkead_fnl_rpt_2005_04_2.1_web.pdf

Booth, L. and Quinn, F., 1995. Twenty-five Years of the Canada Water Act. Canadian Water Resources Journal. 20(2). Pg. 65-90.

Boyd, D., 2011. Unnatural law: Rethinking Canadian Environmental Law and Policy. UBC Press.

Brabec, E., Schulte, S. and Richards, P., 2002. Impervious Surfaces and Water Quality: a Review of Current Literature and its Implications for Watershed Planning. Journal of Planning Literature. 16(4). Pg. 499-514.

Brandes, O., Ferguson, K., M'Gonigle, M., Sandborn, C., 2005. At a Watershed: Ecological and Sustainable Water Management in Canada. University of Victoria. From: http://www.elc.uvic.ca/press/AtaWatershed.pdf

Brandes, O. and Curran, D., 2009. Setting a New Course in British Columbia: Water Governance Reform Options and Opportunities. Polis Project on Ecological Governance. Victoria, British Columbia. 
Belliveau, S., Smit, B., and Bradshaw, B. 2006. Multiple Exposures and Dynamic Vulnerability: Evidence from the Grape Industry in the Okanagan Valley, Canada. Global. Environmental Change. 16. Pg. 364-378.

Brooymans, H., 2011. Water in Canada: a Resource in Crisis. Edmonton, Alberta. Lone Pine Publishing.

Brownsey, K., 2008. Enough for Everyone: Policy Fragmentation and Institutions in Alberta in Sproule-Jones, M., Johns, C. and Heinmiller, B.T. Canadian Water Politics Conflicts and Institutions.

Brynes, J., Crase, L. and Dollery, B. 2006. Regulation Versus Pricing in Urban Water Policy: the Case of the Australian National Water Initiative. The Australian Journal of Agriculture and Resource Economics. 50(3). Pg. 437-449.

Buttle, J., Dillon, P. and Eerkes, G., 2004. Hydrologic Coupling of Slopes, Riparian Zones and Streams: an Example from the Canadian Shield. Journal of Hydrology. 287. Pg. 161-177.

Canadian Association of Petroleum Producers, 2015. Water Use - Quick Facts. Accessed July 18, 2015 from: http://www.oilsandstoday.ca/topics/WaterUse/Pages/default.aspx

Canadian Council of Ministers of the Environment (CCME), 2014. Accessed November 23, 2014 from: http://www.ccme.ca/en/about/index.html

Canadian Environmental Assessment Agency (CEAA), 1994. A Reference Guide for the Canadian Environmental Assessment Act - Determining Whether a Project is Likely to Cause Significant Effects. Federal Environmental Assessment Review Office.

Canadian Geographic, 2014a. Glossary: definition of watershed. Accessed December 12, 2014 from:

http:// www.canadiangeographic.ca/glossary/definition.asp? word=watershed $\underline{\& i d=149}$

Canadian Geographic, 2014b. Pacific Ocean. Accessed December 10, 2014 from http://www.canadiangeographic.ca/watersheds/map/?path=english/watersheds/pac ific-ocean

Canada West Foundation, No Date Listed. The Evolution of Water Policy in Alberta Canada West Foundation Backgrounder: Water Information Sheet \#7. Accessed June 28, 2014 from http://cwf.ca/pdf-docs/publications/the-evolution-of-waterpolicy-in-alberta.pdf. 
Canadian Legal Information Institute (Canlii), 2014. Accessed November 24, 2014 from http://www.canlii.org/en/ca/laws/stat/sc-1999-c-33/latest/sc-1999-c-33.html

Canadian Legal Information Institute (Canlii), 2015: Accessed March 13, 2015 from https://www.canlii.org/en/bc/laws/stat/sbc-2003-c-53/latest/part-11/sbc2003-c-53-part-11.html

Carroll, A., Taylor, S., Regniere, J. and Safranyik, 2003. Effect of Climate Change on Range Expansion by the Mountain Pine Beetle in British Columbia. Accessed May 2, 2015 from:

http://digitalcommons.usu.edu/cgi/viewcontent.cgi?article=1190\&context=bar kbeetles

Castro, J., 2007. Water Governance in the Twenty-First Century. Ambiente and Sociedade. 10(2). Pg. 97-118.

CBC News, 2014. The National - California Drought. Accessed July 30, 2014 from: http://www.cbc.ca/player/News/TV\%20Shows/The\%20National/ID/2437233 $\underline{505}$

CEO Water Mandate, 2015. Mission and Governance. Accessed August 23, 2015 from http://ceowatermandate.org/what-we-do/mission-governance/

Chiti, M., 1995. Are There Universal Principles of Good Governance? European Public Law. 1(2). Pg. 241-258.

Christensen, R., 2015. BC Water Act Reform. Ecojustice. Accessed March 30, 2015 from: http://www.ecojustice.ca/backgrounder-statement-on-bc-water-act-reform/

Christensen, R. and Brandes, O., 2015. California's Oranges and B.C.'s Apples? Lessons for B.C. from California's Groundwater Reform. POLIS Project on Ecological Governance, University of Victoria/Ecojustice.

Christensen, R. and Droitsch, D., 2008. Fight to the Last Drop - A Glimpse Into Alberta's Water Future. Accessed July 2, 2014 from: http:// www.ecojustice.ca/publications/reports/fight-to-the-last-drop-aglimpse-into-alberta2019s-water-future/attachment.

Clarke, C., 2014. If California's Drought Weren't Scary Enough, Now it May Trigger Earthquakes. Accessed August 6, 2014 from: http:// www.takepart.com/article/2014/08/04/california-drought-may-causeearthquakes 
Climate Adaptation, 2015. Droughts - Spain. Accessed May 2, 2015 from http://www.climateadaptation.eu/spain/droughts/

Cline, H., 2008. Making the California Water Crisis a People Issues. Western Farm Press. 30(24). Pg. 1-10.

Cohen , S., Neilsen, D., Smith, S., Neale, T., Taylor, B., Barton, M., Merritt, W., Alila, Y., Shephard, P., McNeill, R., Tansey, J., Carmichael, J. and Langsdale, S., 2006. Learning with Local Help: Expanding the Dialogue on Climate Charge and Water Management in the Okanagan Region, British Columbia, Canada. Climate Change. 75. Pg. 331-358.

Cohen, S., Miller, K., Hamlet, A. and Avis, W., 2000. Climate Change and Resource Management in the Columbia River Basin. Water International. Pg.253-272.

Cohn, D. 2007. Academics and Public Policy: Informing Policy Analysis and Policy Making in Dobuzinskis, L, Howlett, M., and Laycock, D., editors., 2007. Policy Analysis in Canada: the State of the Art.

Cook, C. and Bakker, K., 2012. Water Security: Debating an Emerging Paradigm. Global Environmental Change. 22(1). Pg. 94-102.

Council of Canadians, 2014. Action Alert: Protect B.C's Water from Corporate Freeloaders. Accessed December 12, 2014 from http://www.canadians.org/protect-bc-water

Crabbe, P. and Robin, M., 2006. Institutional Adaptation of Water Resource Infrastructures to Climate Change in Eastern Ontario. Climatic Change. 78(1). Pg. 103-133.

Crabbe, A. and Leroy, P., 2008. The Handbook of Environmental Policy Evaluation. Earthscan Publishing. Sterling, VA.

Cummings, R. and Nercissiantz, V., 1992. Use of Water Pricing as a Means for Enhancing Water Use Efficiency in Irrigation: Case Studies in Mexico and the United States. Natural Resources Journal. 32. Pg. 731-755.

Dale, V., Efroymson, R. and Kline, K., 2011. The Land-use-Climate Change-Energy Nexus. Landscape Ecology. 26. Pg. 755-773.

Dani, S., Harding, J., Case, K., Young, R., Cochrane, S., Gao, J. and Baxter, D., 2006. A Methodology for Best Practice Knowledge Management. Proceedings of the Institution of Mechanical Engineers, Part B: Journal of Engineering Manufacture. 220(10) Pg. 1717-1728. 
Davies, J. and Allen, C., 1973. Equilibrium, Potential and Actual Evapotranspiration from Cropped Surfaces in Southern Ontario. Journal of Applied Meteorology. 12(4). Pg. 649-657.

Davis, D., 2014. Comparing Environmental Policies in 16 Countries. CRC Press. Boca Raton, Florida, USA.

Deason, J., Schad, T. and Sherk, G., 2001. Water Policy in the United States: A Perspective. Water Policy. 3. Pg. 175-192.

Deaton, J., Lintner, A. and Harrington, D., 2008. Evaluating an Environmental Right: Information Disclosure, Public Comment, and Government Decision Making in Ontario. Canadian Journal of Agricultural Economics. 56(3). Pg. 277-294.

Dellapenna, J., 2004. Special Challenges to Water Markets in Riparian States. Georgia State University Law Review. 21(2). Pg. 305-333.

DeLeon, P. and Resnick-Terry, P., 1998. Comparative Policy Analysis: Deja vu All Over Again? Journal of Comparative Policy Analysis: Research and Practice. 1: 9-22.

de Loë, R., 2008. Canadian Water Resources Association (CWRA). Toward a Canadian National Water Strategy. Final Report. May 13, 2008. http://www.cwra.org/Resource/assets/CNWS_Report_Final_2008_06_18.pdf

de Loë, R, Kreutzwider, R. and Neufeld, D., 2005. Local Groundwater Source Protection in Ontario and the Provincial Water Protection Fund. Canadian Water Resources Journal. 30(2). Pg. 129-144.

de Loë, R. and Swainson, R., 2010. Exploring the Role of Policy Transfer in Water Governance: a Discussion Paper. Water Policy and Governance Group. Waterloo, ON.

Di Maria, C., Smulders, S. and Werf, E., 2012. Absolute Abundance and Relative Scarcity: Environmental Policy with Implementation Gaps. Ecological Economics. 74. Pg. 104-119.

Doeveren, V., 2011. Rethinking Good Governance: Identifying Common Principles. Public Integrity. 13(4). Pg. 301-318.

Dolbeare, K., 1975. Public Policy Evaluation. Sage. United States.

Dolan, A., Kreutzwiser, R. \& de Loë, R., 2000. Rural Water Use and Conservation in Southwestern Ontario. Journal of Soil and Water Conservation. 55(2). Pg. 161-171.

Dolowitz, D. and Marsh, D., 1996. Who Learns What from Whom: A Review of the Policy Transfer Literature. Political Studies. XLIV. Pg. 343-357. 
Dolowitz, D. and Marsh, D., 2000. Learning from Abroad: The Role of Policy Transfer in Contemporary Policy-Making. Governance. 13(1). Pg. 5-23.

Dolowitz, D., 2006. A Policy-Maker's Guide to Policy Transfer. Political Quarterly. 74(1). Pg. 101-108.

Dovers, S., 1997. Sustainability: Demands on Policy. Journal of Public Policy. 16. Pg. 303318.

Durley, J.L, de Loë, R., Kreutzwiser, R., 2003. Drought Contingency Planning and Implementation at the Local Level in Ontario. Canadian Water Resources Journal. 28(1). Pg. 21-52.

Ecojustice, 2010a. Ontario's Water Opportunities and Conservation Act. Accessed April 20, 2013 from http://www.ecojustice.ca/cases/ontario-water-act

Ecojustice, 2010b. Water Opportunities Act Must Set Targets for Ontario's Wasteful Water Use. Accessed December 16, 2014 from https:/ / www.ecojustice.ca/mediacentre/press-releases/water-opportunities-act-must-set-targets-for-ontario2019swasteful-water-use

Ecojustice, 2013. Ontario's Water Opportunities and Conservation Act. Accessed April 20, 2013 From: http:// www.ecojustice.ca/cases/ontario-water-act

Ecojustice, 2015. Ontario's Water Opportunities and Conservation Act-Backgrounder. Accessed March 28, 2015 from: http://www.ecojustice.ca/case/ontarios-wateropportunities-and-conservation-act//

Ecojustice, 2015b. Forcing Environmental Assessments for All Major Projects. Accessed July 18, 2015 from: http:/ / www.ecojustice.ca/case/forcing-environmentalassessments-for-all-major-projects/

Eggertson, L., 2008. Investigative Report: 1766 Boil Water Advisories Now in Place in Canada. Canadian Medical Association Journal. 178(10). pg. 1261-1263.

Ehsan, R., MacLeod, S. and Fillion, Y., 2011. Evaluating the Impact of Climate Change Mitigation Strategies on the Optimal Design and Expansion of the Amhurstview, Ontario Water Network: a Canadian Case Study. Journal of Water Resources and Planning and Management. 138(2). Pg. 100-110.

Elfer, M. McDowell, A. and Robin, J., 2004. Water Conservation in Georgia: Bringing Efficiency into Mainstream Thinking. American Water Works Association Journal. 96(4). Pg. 136-142. 
Environment Canada, 2015. Administrative Monetary Penalty System - Consultation Document. Accessed March 8, 2015 from https:// www.ec.gc.ca/alefewe $/$ default.asp?lang $=$ En\&n $=465314 E 0-1 \&$ offset $=2 \&$ toc $=$ show

Environmental Commissioner of Ontario, 2001. Ontario's Permit to Take Water Program and the Protection of Ontario's Water Resources. Accessed January 15, 2015 from http:/ / www.eco.on.ca/uploads/Reports-Staff\%20Reports-andPublications / 2001\%20brief\%20to\%20the\%20walkerton\%20inquiry.pdf

Environmental Commissioner of Ontario, 2008. Water Takings Charges for Industrial and Commercial Water Users under OWRA. Accessed March 8, 2015 from http://www.ecoissues.ca/index.php/Water_Taking_Charges_for_Industrial_an d_Commercial_Water_Users_under_the_OWRA

Environmental Commissioner of Ontario, 2012a. Discovering Ontario's Water Footprint. Accessed March 8, 2015 from: http://www.eco.on.ca/blog/tag/permit-to-takewater/

Environmental Commissioner of Ontario, 2012b. Losing Our Touch - Annual Report 2011/2012 Part 2. Accessed March 28, 2015 from: http://www.eco.on.ca/uploads/ReportsAnnual/2011_12/Losing\%20Our\%20Touch.pdf

Environmental Reporting BC, 2014. Long Term Trends in Groundwater Levels in BC. Accessed December 10, 2014 from: http://www.env.gov.bc.ca/soe/indicators/water/wells/index.html

Falkenmark, M., 1994. Landscape as Life Support Provider: Water-related Limitations. In Graham-Smith, F. (editor), Population: the Complex Reality. The Royal Society. London, UK.

Falkenmark, M. and Lundqvist, J., 1996. Towards Water Security: Political Determination and Human Adaptation Crucial. Natural Resources Forum. 21(1). Pg. 37-51.

Falkenmark, M. and Rockstrom, J., 2004. Balancing Water for Humans and Nature: the New Approach to Ecohydrology. Earthscan.

Falkenmark, M. and Rockstrom, J., 2006. The New Blue and Green Water Paradigm: Breaking New Ground for Water Resource Planning and Management. Journal of Water Resource Planning and Management. 132(3). Pg. 129-132. 
Farahbakhsh, K. and McCullough, J., 2012. Square Peg, Round Hole: First Nations Drinking Water Infrastructure and Federal Policies, Programs and Processes. International Indigenous Policy Journal. 3(1). Pg. 3-22.

Farley, K., Tague, C. and Grant, G., 2011. Vulnerability of Water Supplies from the Oregon Cascades to Changing Climate: Linking Science to Users and Policy. Global Environmental Change. 21. Pg. 110-122.

Farthing, S., 1997. Evaluating Local Environmental Policy. Averybury. Great Britain.

Federal Department of Environmental Protection (FDEP), 2014. The Laws of Water - A Primer of Florida Water Law. Accessed August 8, 2014 from http://www.protectingourwater.org/florida_water_story/waterlaw/

Field, and Olewiler. 2011. Environmental Economics. Third Edition. McGraw-Hill. Ryerson.

Flemming, W. and Hall, E. 2000. Water Conservation Incentives for New Mexico: Policy and Legislative Alternatives. Natural Resources Journal. 40. Pg. 69-96.

Flyvberg, B., 2006. Five Misunderstandings about Case Study Research. Qualitative Inquiry. 12: 219-245.

Folke, C., 2006. Resilience: the Immergence of Perspective for Social-Ecological Systems Analysis. Global Environmental Change. 16(3). Pg. 253-267.

Fountain, H., 2015. California Drought is Worsened by Global Warming, Scientists Say. New York Times. Accessed May 1, 2015 from http://www.nytimes.com/2015/04/02/science/california-drought-isworsened-by-global-warming-scientists-say.html?_r=2

Frind, E. and Middleton, T., 2014. Toward Water Sustainability for Waterloo Region. Canadian Water Resources Journal. 39(2). Pg. 88-94.

Fumano, D., 2013. Nestle Bottles Millions of Liters of Canadian Water - and Pays Nothing. Canada.com. Accessed December 12, 2014 from http://o.canada.com/news/nestle-bottled-water-cost

Funk, A., 2007. Suggestions for Urban Water Conservation Planning. Bulletin of Science, Technology and Society. 27(2). Pg.170-181.

Gage, A., 2014. The Strengths and Weaknesses of the New Water Sustainability Act. West Coast Environmental Law. Accessed March 17, 2015 from: http://wcel.org/resources/environmental-law-alert/strengths-and-weaknessesnew-water-sustainability-act 
Gaviria, G., 2011. Columbian Environmental Policy Analysis. Semestre Economico. 14(30). Pg. 121-134.

Georgia State's Water Plan, 2015. Accessed July 4, 2015 from http://www.georgiawaterplanning.org/

Gibson, R., 2001. Specification of Sustainability-based Environmental Assessment Decision Criteria and Implications for Determining "Significance" in Environmental Assessment. Doctoral dissertation, University of British Columbia.

Gleick, P., 1993. Water in Crisis: a Guide to the World's Freshwater Resources. Oxford University Press Inc. New York, New York.

Gleick, P., 1998. The Human Right to Water. Water Policy. (1) Pg. 487-503.

Gleick, P., 1998. Water Crisis: Paths to Sustainable Water Use. Ecological Applications. 8(3). Pg. 571-579.

Gleick, P., 2002. Soft Water Paths. Nature. 418. Pg. 373.

Gleick, P., Codey, H., Katz, D., Lee, E., 2009. Understanding Reducing the Risks of Climate Change for Transboundary Waters. Pacific Institute.

Glennon, R., 2004. Water Scarcity, Marketing, Privatization. Texas Law Review. 83. Pg. 1873-1902.

Glennon, R., 2009. Unquenchable: America's Water Crisis and What to do About It. Island Press. Washington, DC.

Godfrey, J. 2011. Australia Leads Water Reporting Initiative. Charter. 82(1). pg. 24.

Gosselin, P., Hrudey, S., Naeth, M., Plourde, A., Therrien, R., Van Der Kraak, G. and Xu, Z., 2010. Environmental and Health Impacts of Canada's Oil Sands Industry. Accessed May 1, 2015 from: http://rscsrc.ca/sites/default/files/pdf/RSC\%20Oil\%20Sands\%20Panel\%20Main\%20Rep ort $\% 20$ Oct $\% 202012$.pdf

Government of Alberta (AB Gov), 2003. Water for Life: Alberta's Strategy for Sustainability. Accessed July 2, 2014 from http://environment.gov.ab.ca/info/library/6190.pdf.

Government of Alberta, 2009. Compliance Assurance Program. Accessed March 13, 2015 from: http://esrd.alberta.ca/focus/compliance-assuranceprogram/documents/ComplianceAssuranceProgram-2009.pdf 
Government of Alberta, 2012. Water for Life: Progress Report - December 1, 2008 March 31, 2011. Accessed January 9, 2015 from http://environment.gov.ab.ca/info/library/8437.pdf

Government of Alberta, 2014a. Our Water, Our Future: A Plan for Action. Accessed January 10, 2015 from: http://esrd.alberta.ca/ water/waterconversation/documents/WaterFuture-PlanAction-Nov2014.pdf

Government of Alberta, 2014b. Water for Life. Accessed December 9, 2014 from http://esrd.alberta.ca/water/water-conversation/documents/6364.pdf

Government of Alberta, 2015. The Strategy: Achievements. Accessed January 5, 2015 from: http://www.waterforlife.alberta.ca/0890.html

Government of British Columbia (BC Gov), 2008. Living Water Smart: British Columbia's Water Plan. Accessed July 15, 2014 from: http://www.env.gov.bc.ca/wsd/water_rights/surface_water/

Government of British Columbia, 2010a. British Columbia's Water Act Modernization Policy Proposal on British Columbia's New Water Sustainability Act. From: http://www.livingwatersmart.ca/water-act/docs/wam_wsa-policyproposal.pdf

Government of British Columbia, 2011. Schedule 1 - Water Application Fees. Accessed May 6, 2013 from http://www.env.gov.bc.ca/wsd/water_rights/cabinet/schedule_1_fees_water_ Oct-2011.pdf

Government of British Columbia, 2013a. Water Conservation Strategy. Accessed June 23, 2013 From:

http://www.env.gov.bc.ca/wsd/plan_protect_sustain/water_conservation/wtr _cons_strategy/strategy.html\#12

Government of British Columbia, 2013b. Background on Water Act Modernization. Accessed March 30, 2013 from: http://www.livingwatersmart.ca/water-act/

Government of British Columbia, 2013c. Water Sustainability Act from BC - Technical Briefing. Accessed January 12, 2015 from http://engage.gov.bc.ca/watersustainabilityact/files/2013/10/WSA_technical briefing_final.pdf

Government of British Columbia, 2014a. Provincial Legislation Associated with Water. Accessed July 12, 2014 from: http://www.env.gov.bc.ca/wsd/water_rights/overview_legislation/index.html 
Government of British Columbia, 2014b. Living Water Smart: British Columbia's Water Plan. Accessed July 15, 2014 from http://livingwatersmart.ca/

Government of British Columbia, 2014c. BC's Historical New Water Sustainability Act. Accessed July 19, 2014 from: http://www.newsroom.gov.bc.ca/2014/03/bcshistoric-new-water-sustainability-act.html

Government of British Columbia, 2014d. Water Conservation Strategy. Accessed July 19, 2014 from:

http://www.env.gov.bc.ca/wsd/plan_protect_sustain/water_conservation/wtr cons_strategy/strategy.html\#12

Government of British Columbia, 2014e. Living Water Smart Book. Accessed July 15, 2014 from http://livingwatersmart.ca/book/

Government of British Columbia, 2014f. The Evaluation of BC's Water Laws. Accessed July 15, 2014 from: http://engage.gov.bc.ca/watersustainabilityact/water-lawframework

Government of British Columbia, 2015. Living Water Smart Progress. Accessed January 5, 2015 from http://www.livingwatersmart.ca/progress.html

Government of Ontario (ON Gov), 2005. "Permits to Take Water". Accessed July 12, 2014 from: https://www.ontario.ca/environment-and-energy/permits-takewater

Government of Ontario, 2010. Water Opportunities and Water Conservation Act 2010: from: http://www.elaws.gov.on.ca/html/statutes/english/elaws_statutes_10w19_e.htm

Government of Ontario, 2012a. Fact Sheet: What is the Provincial Legal Structure around Water in Ontario. Accessed from June 24, 2014 from: http://s.cela.ca/files/FactSheet-DrinkingWaterLegislation2012.pdf

Government of Ontario, 2012b. Ontario's Great Lakes Strategy. Accessed January 30, 2015 from https:// dr6j45jk9xcmk.cloudfront.net/documents/896/5-1-5-great-lakesstrategy-en.pdf

Government of Ontario, 2013a. Administrative Monetary Penalties. Accessed March 13, 2015 from: http:/ / www.ontariocanada.com/registry/showAttachment.do?postingId=14402 \&attachmentId $=22331$ 
Government of Ontario, 2013b. Permits to Take Water Overview and Guidelines Partnership Educational Services. Accessed Sept. 27. 2104 from:

https:// www.nchca.ca/resources/content/MOEPTTW_Presentation_Feb_2013.pdf

Government of Ontario, 2014a. Ontario Key Facts. Accessed December 10, 2014 from https://www.ontario.ca/government/about-ontario

Government of Ontario, 2014b. 2014 Mandate Letter: Environment and Climate Change - Premiers Instructions to the Minister on Priorities for the Year 2014. Accessed February 17,2015 from https://www.ontario.ca/government/2014-mandateletter-environment-and-climate-change\#section-1

Government of Ontario, 2015a. Commission on the Reform of Ontario's Public Services. Chapter 13: Environment and Natural Resources. Accessed March 8, 2015 from: http://www.fin.gov.on.ca/en/reformcommission/chapters/ch13.html\#ch13-a

Government of Ontario, 2015b. Ontario Low Water Response - Working Together to Manage Low Water. Accessed April 12, 2015 from: http://www.omafra.gov.on.ca/english/environment/facts/low_waterbr.htm

Grafton, R.Q. and Kompas, T., 2007. Pricing Sydney Water. The Australian Journal of Agriculture and Resources Economics. 51. pg. 227-241.

Grant, J., Angen, E. and Dyer, S., 2013. Forecasting the Impacts of Oilsands Expansion. Pembina Institute.

Grant., J. Huot, M., Lomphers, N., Dyers, S. and Dow, M., 2013. Below the Surface: a Review of Key Facts in the Oilsands Debate. The Pembina Institute.

Green, T., Taniguchi, M., Kooi, H., Gurdak, J., Allen, D., Hiscock, K., Treidel, H. and Aureli, A., 2011. Beneath the Surface of Global Climate Change: Impacts of Climate Change on Groundwater. Journal of Hydrology. 405. Pg. 532-560.

Greenbaum, A. and Wellington, A., 2010. Environmental Law and Policy in the Canadian Context. Concord, Ontario. Captus Press.

Gregory, R. and Keeney, R., 2002. Making Smarter Environmental Management Decisions. Journal of the American Water Resources Association. 38(6). Pg. 16011612.

Grey, D. and Sadoff, C., 2007. Sink or Swim? Water Security for Growth and Development. Water Policy. 9. Pg. 545-571. 
Griffiths, M. and Woynillowicz, D., 2003. Oil and Troubled Waters - Reducing the Impact of the Oil and Gas Industry on Alberta's Water Resources. The Pembina Institute for Appropriate Development.

Guess, G. and Farnham, P., 1989. Cases in Public Policy Analysis. New York. Longman.

Guglyuvatyy, E., 2010. Climate Change Policy Evaluation - Method and Criteria. Environmental Law and Policy. 40(6). Pg. 355-362.

Gupta, S., 2012. Population Growth and Its Impacts on Environmental Situation - Policy Recommendations for a Sustainable Energy Future. Journal of International Environmental Application and Science. 7(2). Pg. 432-445.

Hajkowicz, S. and Collins, K., 2007. A Review of Multiple Criteria Analysis for Water Resource Planning and Management. Water Resource Management. 21. Pg. 15531566.

Hamlet, A., 2003. Chapter 11-the Role of Transboundary Agreements in the Columbia River Basin: an Integrated Assessment in the Context of Historic Development, Climate, and Evolving Water Policy. Accessed March 22, 2015 from: http://www.hydro.washington.edu/pub/hamleaf/IJC_meeting_apr_2006/ham let_kluwer.pdf

Harrison, K., 1995. Is Cooperation the Answer? Canadian Environmental Enforcement in Comparative Context. Canadian Environmental Enforcement. 14(2). Pg. 211-244.

Hatch, M., 2005. Environmental Policymaking. Assessing the Use of Alternative Policy Instruments, Los Angeles.

Heidenheimer, A.J., Helco, H., Adams, C., 1990. Comparative Public Policy: the Politics of Social Choice in America, Europe, and Japan (3 ${ }^{\text {rd }}$ ed.). St. Martin's Press. New York.

Helco, H., 1972. Policy Analysis. British Journal of Political Science. 2(1). 83-108.

Hickey, G., Brunet, N. and Allan, N., 2010. A Constant Comparison of the Environmental Assessment Criteria in Canada. Journal of Environmental Policy and Planning. 12(3). Pg. 315-329.

Hienmiller, B., 2013. Advocacy Coalitions and the Alberta Water Act. Canadian Journal of Political Science. 46(3). Pg. 525-547.

Hildebrand, M., Gaur, S. and Kelly, J., 2009. Water Conservation Made Legal: Water Budgets and California Law. American Water Works Association Journal. 101(4). Pg. 85-89. 
Hill, C., Furlong, K., Bakker, K. and Cohen, A., 2008. Harmonization Versus Subsidiarity in Water Governance: a Review of Water Governance and Legislation in Canadian Provinces and Territories. Canadian Water Resources Journal. 33(4). Pg. 315-322.

Hipel, K., Obeidi, A., Fang, L. and Kilgour, D., 2008. Adaptive Systems Thinking in Integrated Water Resources Management with Insights into Conflicts Over Water Exports. INFOR: Information Systems and Operational Research. 46(1). Pg. 5170.

Hofmann, N. and B. Mitchell., 1995. “Evolving Toward Participatory Water Management: The Permit to Take Water Program and Commercial Water Bottling in Ontario." Canadian Water Resources Journal. 20(2). Pg. 91-100.

Hood, C., Dixon, R. and Beeston, C., 2008. Rating the Rankings: Assessing International Ranking of Public Service Performance. International Public Management Journal. 11(3). Pg. 298-328.

Howard, B., 2014. Aral Sea's Eastern Basin is Dry for the First Time in 600 Years. National Geographic. Accessed March 14, 2015 from: http://news.nationalgeographic.com/news/2014/10/141001-aral-sea-shrinkingdrought-water-environment/

Howlett, M., Ramesh, M. and Perl, A., 2009. Studying Public Policy: Policy Cycles and Policy Subsystems ( $3^{\text {rd }}$ ed.). Oxford University Press. Don Mills, Ontario.

Hunter, J., 2014. Critics Condem BC's New Watered Down Act. The Globe and Mail. Accessed December 12, 2014 from http://www.theglobeandmail.com/news/british-columbia/critics-condemnbcs-new-watered-down-water-act/article17448655/

Huntington, T., 2005. Evidence of Intensification of the Global Water Cycle: Review and Synthesis. Journal of Hydrology. 319. Pg. 83-96.

Hussey, K. and Dovers, S., 2006. Trajectories in Australian Water Policy. Journal of Contemporary Water Research and Education. 135. Pg. 36-50.

Illical, M. and Harrison, K., 2007. Protecting Endangered Species in the US and Canada: The Role of Negative Lesson Drawing. Canadian Journal of Political Science. 40(2). pg. 367-394.

Innes, J. and Booher, D., 2010. Planning with Complexity: An Introduction to Collaborative Rationality for Public Policy. Routledge. 
Institute for Human Rights and Business, 2009. Draft Business, Human Rights and the Right to Water: Challenges, Dilemmas and Opportunities - Roundtable Consultative Report. Accessed August 23, 2015 from http://www.ihrb.org/pdf/More_than_a_resource_Water_business_and_human rights.pdf

Ivey, J. de Loë, R. and Kreutzwiser, R., 2006. Planning for Source Water Protection in Ontario. Applied Geography. 26(3). Pg. 192-209.

Jefferson, B., Palmer, A., Jeffrey, P., Stuetz, R. and Judd, S., 2004. Grey Water Characterization and its Impact on the Selection and Operation of Technologies for Urban Use. Water Science and Technology. 50(2). Pg. 157-164.

Johansen, D., 2002. Bulk Water Removals, Water Exports and the NAFTA. Accessed April 11, 2015 from: http://publications.gc.ca/Collection-R/LoPBdP/BP/prb0041e.htm

Johns, C., and Raasmussen, K. 2007. Institutions for Water Resource Management in Canada in Sproule-Jones, Mark, Carolyn Johns and B. Timothy Heinmiller, editors. Canadian Water Politics: Conflicts and Institutions. McGill-Queen's University Press.

Jong, W., 2002.The theory and practice of institutional transplantation: experiences with the transfer of policy institutions. Eds. M. Jong, Konstantinos Lalenis, and Virginie Mamadouh. 74. Springer.

Jorns, C., 2007. Water Wars: The Need for a National Water Policy. UWA Strategy Research Project. Pg. 1-22.

Jury, W. and Vaux. H., 2005. The Role of Science in Solving the World's Emerging Water Problems. Proceedings of the National Academy of Science. 102(44). Pg. 1571515720.

Jyrkama, M. and Sykes, J., 2007. The Impact of Climate Change on Spatially Varying Groundwater Recharge in the Grand River Watershed (Ontario). Journal of Hydrology. 338. Pg. 237-250.

Kay, P., Hendricks, E. and Rahman, N., 2007. Sustainable Water Policy: The Soft Path for Water - Ontario Case Study. Friends of the Earth Canada. Ottawa , ON.

Kelly, E., Short, J., Schindler, D., Hodson, P., Ma, M., Kwan, A. and Fortin, B., 2009. Oil Sands Development Contributes Polycyclic Aromatic Compounds to the Athabasca River and its Tributaries. Proceedings of the National Academy of Sciences of the United States of America. 106(52). Pg. 1-6.

Konisky, D. and Woods, N., 2012. Measuring State Environmental Policy. Review of Policy Research. 29(4). Pg. 544-569. 
Kreutzwiser, R.D., de Loë, R.C., Durley, J. and Priddle, C., 2004. Water Allocation and Permit to Take Water Program in Ontario: Challenges and Opportunities. Canadian Water Resources Journal. 29(2). Pg. 135-146.

Kurek, J. Kirk, J., Muir, D., Wang, X., Evans, M. and Smol, J., 2012. Legacy of Half Century of Athabasca Oil Sands Development Recorded by Lake Ecosystems. Proceedings of the National Academy of Sciences of the United States of America.

Lafleur, P., Hember, R., Admiral, S. and Roulet, N., 2005. Annual and Seasonal Variability in Evapotranspiration at a Shrub-covered Bog in Southern Ontario, Canada. Hydrologic Processes. 19. Pg. 3522-3555.

Lansford, R., Shaul, B.-D., Gebhard, T., Brutsaert, W. and Creel, B. 1975., A SocioEconomic Evaluation of Alternative Water Management Policies on the Rio Grande in New Mexico. Natural Resources Journal. 15. Pg. 307-325.

Law Commission of Ontario, 2015. Administrative Monetary Penalties as an Alternative to the Court Process. Accessed March 17, 2015 from http:// www.lcocdo.org/en/provincial-offences-interim-report-sectionV

Leadlay, H.J. and Kreutwiser, R., 1999. Rural Water Supply Allocation in Ontario: an Evaluation of Current Policy and Practice. Canadian Water Resources Journal. 24(1). Pg. 1-14.

Leary, N. Conde, C. and Kulkarni, J., 2007. Climate Change and Vulnerability. Earthscan.

LeRoy, P., 1995. Troubled Waters: Population and Water Scarcity. Colorado International Journal of Environmental Law and Policy. 6(2). Pg. 299-326.

LeRoy, P., Allan, D., Palmer, M., Hart, D., Richter, B., 2003. River Flows and Water Wars: Emerging Science for Environmental Decision Making. Biological Sciences Faculty Publications. Paper 233.

Levintanus, A., 1994. Saving the Aral Sea. Journal of Environmental Management. 36(3). Pg. 193-199.

Lewis, A., Hilton, J. and Vocke, R., 2005. Water Supply Options in New Mexico Water Planning Region. Journal of the American Water Resources Association. 41(3). Pg. 635.

Li, F., Wichmann, K. and Otterpohl, R., 2009. Review of the Technological Approaches for Grey Water Treatment and Reuses. Science of the Total Environment. 407(11). Pg. 3439-3449. 
Liberal Party, 2012. Just the Facts: Conservative Hypocrisy on Environmental Protection. Accessed May 1, 2015 from: https:// www.liberal.ca/facts-conservativehypocrisy-environmental-protection/

Lightfoot, E., 2003. The Policy Transfer Model. The Social Policy Journal. 2. Pg. 21-34.

Lindblom, C., 1958. Policy Analysis. The American Economic Review. 48(3). pg. 298-312.

Loomis, J. and Helfand, G., 2001. Environmental Policy Analysis for Decision Making. Kluwer Academic Publisherse. Secaucus, New Jersey.

Lovins, A., 1976. Energy Strategy: the Road Not Taken? Foreign Affairs. Accessed May 26, 2015 from https://www.foreignaffairs.com/articles/united-states/1976-1001/energy-strategy-road-not-taken

MacDonald, G., 2007. Severe and Sustained Drought in Southern California and the West: Present Conditions and Insights from the Past on Causes and Impacts. Quaternary International. 173/174. Pg. 87-100.

Mahmoud, M., Liu, Y., Hartmann, H., Stewart, S., Wagener, T., Semmens, D., Stuart, R., Gupta, H., Dominguez, D., Dominguez, F., Hulse, D., Letcher, R., Rashleigh, B., Smith, C., Street, R., Ticehurst, J., Twery, M., Delden, H., Waldick, R., White, D. and Winter, L., 2009. A Formal Framework for Scenario Development in Support of Environmental Decision-Making. Environmental Modelling and Software. 24. Pg. 798-808.

Manuel, J., 2008. Drought in the Southeast: Lessons for Water Management. Environmental Health Perspectives. 116(4). Pg. 168-171.

Marchildon, G., Kulshreshtha, S., Wheaton, E. and Sauchyn, D., 2006. Drought and Institutional Adaptation in Alberta and Saskatchewan, 1914-1939. Graduate School of Public Policy, University of Regina.

Martin-Downs, D., 2010. One Water: Supporting Watershed Management and Green Infrastructure in Ontario Policy. Ontario Water Conservation Alliance. Ontario, Canada.

Martinez, S. Verhines, S. and Lopez, E., 2013. Working Towards Solutions: Integrating Our Water and Our Economy - 2013 Review of the State Water Plan.

Marsh, D. and Sharman, J., 2009. Policy Diffusion and Policy Transfer. Policy Studies. 30:269-288.

Maas, C., McClenaghan, T. and Pleasance, G., 2010. The Water-Energy Nexus - Linking Water and Energy in Ontario Policy. Ontario Water Conservation Alliance Policy Report. 
Mascarenhas, M., 2012. Where the Waters Divide: First Nations, Tainted Water and Environmental Justice in Canada. Local Environment. 12(6). Pg. 565-577.

Matsui, K., 2012. Water Ethics for First Nations and Biodiversity in Western Canada. International Indigenous Policy Journal. 3(3). Pg. 1-26.

McDonald, A., and Brown, S., 2003. Water in Canada: Resources and Issues. British Journal of Canadian Studies. 16(2). pg. 259-282.

McKay, J., 2005. Water Institutional Reforms in Australia. Water Policy. 7. Pg. 35-52.

Merritt, W., Alila, Y., Barton, M, Taylor, B., Cohen, S. and Neilson, D., 2006. Hydrologic Response to Scenarios of Climate Change in Sub Watersheds of the Okanagan Basin, British Columbia. Journal of Hydrology. 326(1-4). Pg. 79-108.

Michaels, S. and de Loë, R., 2010. Importing Notions of Governance: Two Examples from the History of Canadian Water Policy. American Review of Canadian Studies. 40(4). Pg. 495-507.

Mickwitz, P., 2003. A Framework for Evaluating Environmental Policy Instruments Context and Key Concepts. Evaluation. 9(4). Pg. 415-436.

Moore, D., 2013. BC Water Act to Regulate Groundwater to Regulate, Force Nestle to Pay. Huffpost British Columbia. Accessed July 30, 2014 from: http:/ / www.huffingtonpost.ca/2013/10/18/bc-water-act-climate-changenestle_n_4124163.html

Morris, P. and Therivel R. editors. 2001. Methods of Environmental Impact Assessments. Vol. 2. Taylor and Francis.

Morrison, J., Quick, M. and Foreman, M., 2002. Climate Change in the Fraser River Watershed: Flow and Temperature Projections. Journal of Hydrology. 263. Pg. 230244.

Muldoon, P. and McClenaghan, T., 2007. A Tangled Web: Reworking Canada's Water in Bakker, K., ed. Eau Canada: The Future of Canada's Water. Vancouver, BC. UBC Press.

Murray, C., 2000. Concern Mounts Over Shrinking, Dirty Great Lakes. South China Morning Post. Accessed on July 5, 2014 from http:/ / ezproxy.lib.ryerson.ca/login?url=http:// search.proquest.com.ezproxy.lib .ryerson.ca/ docview / 265572909?accountid $=13631$

Nagourney, A., 2015. As California Drought Enters $4^{\text {th }}$ Year, Conservation Efforts and Worries Increase. New York Times. Accessed May 1, 2015 from: http:/ / www.nytimes.com/2015/03/18/us/as-california-drought-enters-4th- 
year-conservation-efforts-and-worries-

increase. html?action $=$ click\&contentCollection $=$ Science $\&$ module $=$ RelatedCovera ge\&region=Marginalia\&pgtype $=$ article

NDP, 2012. Conservative Environmental Plan on the Wrong Track. Accessed May 1, 2015 from: http://www.ndp.ca/news/conservative-environmental-plan-wrong-track

Nelitz, M., Douglas T., and Rutherford, M., 2009. Freshwater for Fish and People: Moving Towards "Living Water Smart". Pacific Fisheries Resource Conservation Council. Vancouver, British Columbia.

Neuman, J., 2004. The Good, the Bad, and the Ugly: the First Ten Years of the Oregon Water Trust. Nebraska Law Review. 83(2). Pg. 432-457.

Nobel, B., 2009. Promise and Dismay: the State of Environmental Assessment and Practices in Canada. Environmental Impact Assessment Review. 29(2). Pg. 66-75.

Nowlan, L., 2005. Buried Treasure: Groundwater Permitting and Pricing in Canada. Walter and Duncan Gordon Foundation.

Nowlan, N. and Bakker, K., 2007. Delegating Water Governance: Issues and Challenges in the BC Context. Program on Water Governance. University of British Columbia.

OECD, 2015. Environmental Policy Tools and Evaluation. Accessed May 26, 2015 from http://www.oecd.org/env/tools-evaluation/

O'Hara, S., 2000. Lessons from the Past: Water Management in Central Asia. Water Policy. 2(4-5). Pg. 365-384.

Oki, T. and Kanae, S., 2006. Global Hydrologic Cycles and World Water Resources. Science. 313. Pg. 1068-1072.

Ontario Power Generation, 2014. Hydroelectric Power. Accessed December 13, 2014 from: http://www.opg.com/generating-power/hydro/Pages/hydro.aspx

Pal, L., 1992. Public Policy Analysis - an Introduction (2nd Edition). Nelson Canada. Scarborough, Ontario, Canada.

Pederson, N., Bell, A., Knight, T., Leland, C., Malcomb, N., Anchukaitis, K., Tackett, K., Scheff, J., Brice, A., Catron, B., Blozan, W. and Riddle, J., 2012. A Long-Term Perspective on a Modern Drought in the American Southeast. Environmental Research Letters. 7(1). Pg. 1-19. 
Pembina Institute, 2015. Oilsands - Key Facts in Context. Accessed July 18, 2015 from: http://www.pembina.org/oil-sands/key-facts

Percy, D., 1986. Water Rights Law and Water Shortages in Western Canada. Canadian Water Resources Journal. 11(2). Pg. 14-23.

Percy, D., 1996. Seventy-five Years of Alberta Water Law: Maturity, Demise and Rebirth. Alberta Law Review. 35(1). Pg. 221-241.

Percy, D., 2004. Responding to Water Scarcity in Western Canada. Texas Law Review. 83. Pg. 2091-2107.

Perramond, E., 2013. Water Governance in New Mexico: Adjudication, Law and Geography. Geoforum. 45. Pg. 83-93.

Phyper, J. and Ibbotson, B., 2003. The Handbook of Environmental Compliance in Ontario ( ${ }^{\text {rd }}$ edition). McGraw-Hill Ryerson. Toronto, Canada.

Pike, R., Spittlehouse, D., Bennett, K. Egginton, P., Tschaplinski, Murdock, T. and Werner, A., 2008. Streamline Watershed Management Bulletin. 11(2).

Plummer, R., De Grosbois, D., Armitage, D. and de Loë, R., 2013. An Integrative Assessment of Water Vulnerability in First Nations Communities in Southern Ontario, Canada. Global Environmental Change. 239(4). Pg. 749-763.

Ponrajah, R., Witherspoon, J. and Galiana, F., 1998. Systems to Optimize Conversion Efficiencies on Ontario Hydroelectric Plants. Power Systems - IEEE Transactions. 13(3). Pg. 1044-1050.

Pollock, M., 2011. Balzac Water Treatment Plant Boost for Big Mall. Accessed December 13,2014: http://www.airdrieecho.com/2011/09/14/balzac-water-treatmentplant-boost-for-big-mall

Ragin, C., 1987. The Comparative Method: Moving Beyond Qualitative and Quantitative Strategies. University of California Press. Berkeley.

Richter, B., Mathews, R., Harrison, D. and Wigington, R., 2003. Ecologically Sustainable Water Management: Managing River Flows for Ecological Integrity. Ecological Applications. 13(1). Pg. 206-224.

Rihoux, B. and Grimm, H., 2006. Innovative Comparative Methods for Policy Analysis: Beyond the Quantitative-Qualitative Divide. Boston, MA. Kluwer Academic Publishers. 
Reid, M., and Brooks, J., 2000. Detected Effects of Environmental Water Allocations in Wetlands of the Murray-Darling Basin, Australia. Regulated Rivers: Research and Management. 16. Pg. 479-496.

Renzetti, S., 1999. Municipal Water Supply and Sewage Treatment: Costs, Prices, Distortions. Canadian Journal of Economics. Pg. 688-704.

Rijsberman, F., 2006. Water Scarcity - Fact or Fiction? Agricultural Water Management. 80(1). Pg. 5-22.

Rittel, H. and Webber, M., 1973. Dilemmas in General Theory of Planning. Policy Sciences. 4. Pg. 155-169.

Rogers, P. and Hall, A., 2003. Effective Water Governance - TEC Background Paper No. 7. Elanders Novum, Sweden.

Rolfe, C., 1997. Administrative Monetary Penalties: a Tool for Ensuring Compliance - Paper Canadian Council of Ministers of the Environment Workshop on Economic Instruments. 24. Pg. 1-9.

Rose, R., 1991. What is Lesson drawing? Journal of Public Policy. 11(1). Pg. 3-30.

Rose, R., 1993. Lesson-Drawing in Public Policy. Chatham House Publishers Inc. Chatham, New Jersey.

Rose, R., 2005. Learning from Comparative Public Policy - A Practical Guide. Routledge. New York.

Rost, S., Gerten, D., Bondeau, A., Lucht, W., Rohwer, J. and Schaphoff, S., 2008. Agricultural Green and Blue Water Consumption and its Influence on the Global Water System. Water Resources Research. 44(9) Pg. 1-17.

Rudra, R., 2007. Investigation of Season Hydrology and Variable Source Areas within Regions of Ontario. Accessed March 21, 2015 from: http://www.omafra.gov.on.ca/english/research/nmjrp/projects/2007/moe002 $\underline{\mathrm{htm}}$

Sandford, R., 2009. Restoring the Flow: Confronting the World's Water Woes. Rocky Mountain Books. Surrey, BC.

Saunders, O., 2010. Institutional Relationships and Alberta's Water for Life Strategy. Canadian Institute of Resources Law.

Saunders, O. and Vlavianos, N., 2010. Alberta's Water for Life and Recent Trends in International Law. Canadian Institute of Resources Law, University of Calgary. 
Saunders, J. and Wenig, M., 2007. Whose Water? Canadian Water Management and the Challenged of Jurisdictional Fragmentation in Bakker, K., editor. Eau Canada: The Future of Canada's Water. Vancouver, BC. UBC Press.

Saxe, D., 2000. Walkerton - Investigations and Outlook. Hazardous Materials Management. 12(3). Pg. 1-38.

Schmidt, J., 2011. Alternative Water Futures in Alberta. Parkland Institute.

Schmidt, J., 2014. Water Management and the Procedural Turn: Norms and Transitions in Alberta. Water Resource Management. 28. Pg. 1127-1141.

Service Ontario E-Laws, 2010. An Act to Enact the Water Opportunities Act, 2010 and to Amend Other Acts in Respect of Water Conservation and Other Matters. Accessed March 31, 2015 from: http://www.elaws.gov.on.ca/html/source/statutes/english/2010/elaws_src_s10019_e.htm

Shrybman, S., 2000. The Accord to Prohibit Bulk Water Removal - Will it Actually Hold Water? BC Freshwater Workshop Paper. Access March 12, 2015 from: http://www.wcel.org/sites/default/files/publications/The $\% 20$ Accord $\% 20$ to $\%$ 20Prohibit $\% 20$ Bulk\%20Water\%20Removal.pdf

Solecki, W. and Michaels, S., 1994. Looking for Postdisaster Policy Wonder. Environmental Management. 18(4). Pg. 587-595.

Soroka, S., 2002. Issue Attributes and Agenda-Setting by Media, the Public, and Policymakers in Canada. International Journal of Public Opinion Research. 14(3). Pg. 264-285.

Sprague, J., 2007. Great Wet North? Canada's Myth of Water Abundance in Bakker, K., editor. Eau Canada: The Future of Canada's Water. Vancouver, BC. UBC Press.

Sproule-Jones, M, Johns C., Heinmiller T., editors. 2008. Canadian Water Politics: Conflicts and Institutions. McGill-Queen's University Press.

Stake, R., 1995. The art of case study research. Thousand Oakes, CA. Sage.

Statistics Canada, 2015. Population, Urban and Rural by Province and Territory. Accessed April 4, 2015 from http://www.statcan.gc.ca/tables-tableaux/sumsom/101/cst01/demo62a-eng.htm

Steeves, J., 2012. Water Management Plan Recommended for Okanagan. Kelowna Capital News. Accessed March 22, 2015 from http://www.kelownacapnews.com/news/178951251.html 
Steurer, R., 2013. Disentangling Governance: a Synoptic view of Regulation by Government, Business and Civil Society. Policy Science. 46. Pg. 387-410.

Stone, D., 1999. Learning Lessons and Transferring Policy across Time, Space and Disciplines. Politics. 19:51-59.

Surendran, S. and Wheatley, A., 1998. Grey-water Reclamation for Non-Potable Re-Use. Water and Environment Journal. 12(6). Pg. 406-413.

Swainson, R. and de Loë, R. 2011. The Importance of Context in Relation to Policy Transfer: a Case Study of Environmental Water Allocation in Australia. Environmental Policy and Governance. 21. Pg. 58-69.

Taiken, O. 2010. Global Water Issues Today and Future Perspectives. Asia-Pacific Review. 10(2). Pg. 60-77.

Targeted News Service, 2014. New Mexico Dems: Senator Tom Udall Introduces Bill to Help New Mexico Farmers, Communities Address Drought, Water Scarcity.

Tauxe, L., 2015. Lecture 22 - Fresh Waters of the Earth. Accessed March 21, 2015 from: http:/ / topex.ucsd.edu/es10/lectures/lecture22/lecture22.html

Taylor, D., 2000. Facts, Myths and Monsters: Understanding the Principles of Good Governance. The International Journal of Public Sector Management. 13(2). Pg. 108124.

Taylor, L., 2009. Water Challenges in Oil Sands Country: Alberta's Water for Life Strategy. Policy Options. Pg. 44-47.

Thirlwell, G., Madramootoo, C. and Heathcote, I., 2007. Energy-water Nexus: Energy Use in the Municipal, Industrial, and Agricultural Water Sectors. Presentation to the Canada-US Water Conference.

Thoms, M. and Sheldon, F., 2002. An Ecosystem Approach from Determining Environmental Water Allocations in Australian Dryland River Systems: the Role of Geomorphology. Geomorphology. 47(2-4). Pg. 153-168.

Troy, P., 2008. Troubled Waters: Confronting the Water Crisis in Australia's Cities. Canberra, Australia. ANU E Press.

United Nations Environment Programme (UNEP), 2014. Rio Declaration on Environment and Development. Accessed November 24, 2014 from: http://www.unep.org/Documents.Multilingual/Default.asp?DocumentID=78\& $\underline{\text { ArticleID }=1163}$ 
United States (US) Drought Monitor, 2015. April 28, 2015 Drought Monitor Data. Accessed May 2, 2015 from: http://droughtmonitor.unl.edu/

United States Environmental Protection Agency (US EPA), 2013. Saving Water in Oregon. Accessed August 8, 2014: http://www.epa.gov/watersense/docs/oregon_state_fact_sheet_508.pdf

Vancouver Island Water Resource Vulnerability Mapping Project, 2014. Project Charter. Accessed December 13, 2014 from http://web.viu.ca/groundwater/Library/Project\%20Charter1.htm

Vander Ploeg, C., 2010. From H2O - Turning Alberta's Water Headache Into Opportunity. Canada West Foundation. Accessed July 30, 2014 from: http://cwf.ca/pdfdocs/publications/h20-report-vdp-2010.pdf

Vander Ploeg, C., 2011. Water Pricing: Seizing a Public Policy Dilemma by the Horns. Canada West Foundation Backgrounder. Accessed August 2, 2014 from: http://cwf.ca/publications-1/Canadian_Water_Pricing_Backgrounder_9

Vorosmarty, C., Green, P., Salisbury, J. and Lammer, R., 2000. Global Water Resources: Vulnerability from Climate Change and Population Growth. Science. 289. Pg. 284-288.

Vorosmarty, C. and Sahagian, D., 2000. Anthropogenic Disturbance of the Terrestrial Water Cycle. BioScience. 50(9). Pg. 753-765.

Vorosmarty, C., McIntyre, P., Gessner, M., Dudgeon, D., Prusevich, A., Green, P., Glidden, S., Bunn, S., Sullivan, C., Liermann, C. and Davies, P., 2010. Global Threats to Human Water Security and River Biodiversity. Nature. 467. Pg. 555561.

Walker, J., 1969. The Diffusion of Innovations Among the American States. The American Political Science Review. 63(3). Pg. 880-899.

Walter and Duncan Gordon Foundation, 2007. Groundwater Extraction and Ecosystem Protection in Canada: Permitting, Planning and Collaboration - Workshop Report.

Webb, K. and Morrison, A., 1999. Voluntary Approaches, the Environment and the Law: A Canadian Perspective in Carraro, C., and Leveque, F. 1999. Editors. Voluntary Approaches in Environmental Policy. Kluwer Academic Publishing. Great Britain.

Weimer, D and Vining, A., 2011. Policy Analysis: Concepts and Practice (5 $5^{\text {th }}$ ed.). Longman. United States.

White, C., 2012. Understanding Water Scarcity: Definitions and Measurements. Water Security. Accessed December 6, 2014 from 
http://www.iwmi.cgiar.org/News_Room/pdf/Understanding_water_scarcity. $\underline{\mathrm{pdf}}$

White, J., Murphy, L. and Spence, N., 2012. Water and Indigenous Peoples: Canada Paradox. 3(3). Pg. 1-25.

Winfield, M., 2009. Policy Instruments in Canadian Environmental Policy in VanNijnatten, D. and Boardman, R., editors in Canadian Environmental Policy and Politics ( ${ }^{\text {rd }} \mathrm{ed}$ ). Oxford University Press. Don Mills, Ontario.

Wolfe, S. and Brooks, D., 2003. Water Scarcity: an Alternative View and its Implications for Policy and Capacity Building. Natural Resources Forum. 27. Pg. 99-107.

Wolff, G. and Glieck, P., 2002-2003. The Soft Path for Water. Accessed 23, 2015 from http://www.colorado.edu/geography/class_homepages/geog_4501_s12/readi ngs/PacInst \%20SoftPath\%2002.pdf

Woo, M., 2008. Water in Canada, Water for Canada. The Canadian Geographer. 45(1). Pg. 85-92.

Woodhouse C. and Lukas, J., 2006. Drought, Tree Rings and Water Resource Management in Colorado. Canadian Water Resources Journal. 31(4). Pg. 297-310.

Xu, J., Grumbine, R., Shrestha, A., Erickson, M., Yang, X, Wang, Y., Wilkes, A., 2009. The Melting Himalayas: Cascading Effects of Climate Change on Water, Biodiversity and Livelihoods. Conservation Biology. 23(3). Pg. 520-530.

Young, D., 2010. David Suzuki Foundation. Water is Life. Accessed April 20, 2013 From http://www.davidsuzuki.org/blogs/healthy-oceans-blog/2010/05/water-islife/

Zhang, X., Vincent, L., and Hogg, W. and Niitsoo, A., 2000. Temperature and Precipitation Trends in Canada during the 20th Century. Atmosphere-Ocean. 38(3). Pg. 395-429.

Zhe, L., Boyle,F. and Reynolds, A., 2010. Rainwater Harvesting and Greywater Treatment Systems for Domestic Application in Ireland. Desalination. 260(1). Pg. $1-8$.

Zubrycki, K., Roy, D., Venema, H.D., Brooks, D., 2011. Water Security in Canada: Responsibilities of the Federal Government. International Institute for Sustainable Development. Accessed July 22, 2014 from: http://www.iisd.org/pdf/2011/water_security_canada.pdf 